\title{
Synchrotron diffraction studies of spontaneous magnetostriction in rare earth transition metal compounds
}

\author{
by \\ Ning Yang \\ A dissertation submitted to the graduate faculty \\ in partial fulfillment of the requirements for the degree of \\ DOCTOR OF PHILOSOPHY \\ Major: Materials Science and Engineering \\ Program of Study Committee: \\ Matthew J. Kramer, Major Professor \\ R. William McCallum \\ Steve W. Martin \\ Alan I. Goldman \\ Gordon J. Miller
}

Iowa State University

Ames, Iowa

2004

Copyright $\odot$ Ning Yang, 2004. All rights reserved. 
Graduate College Lowa State University

This is to certify that the doctoral dissertation of

Ning Yang

has met the dissertation requirements of Iowa State University

Major Professor

For the Major Program 


\section{TABLE OF CONTENTS}

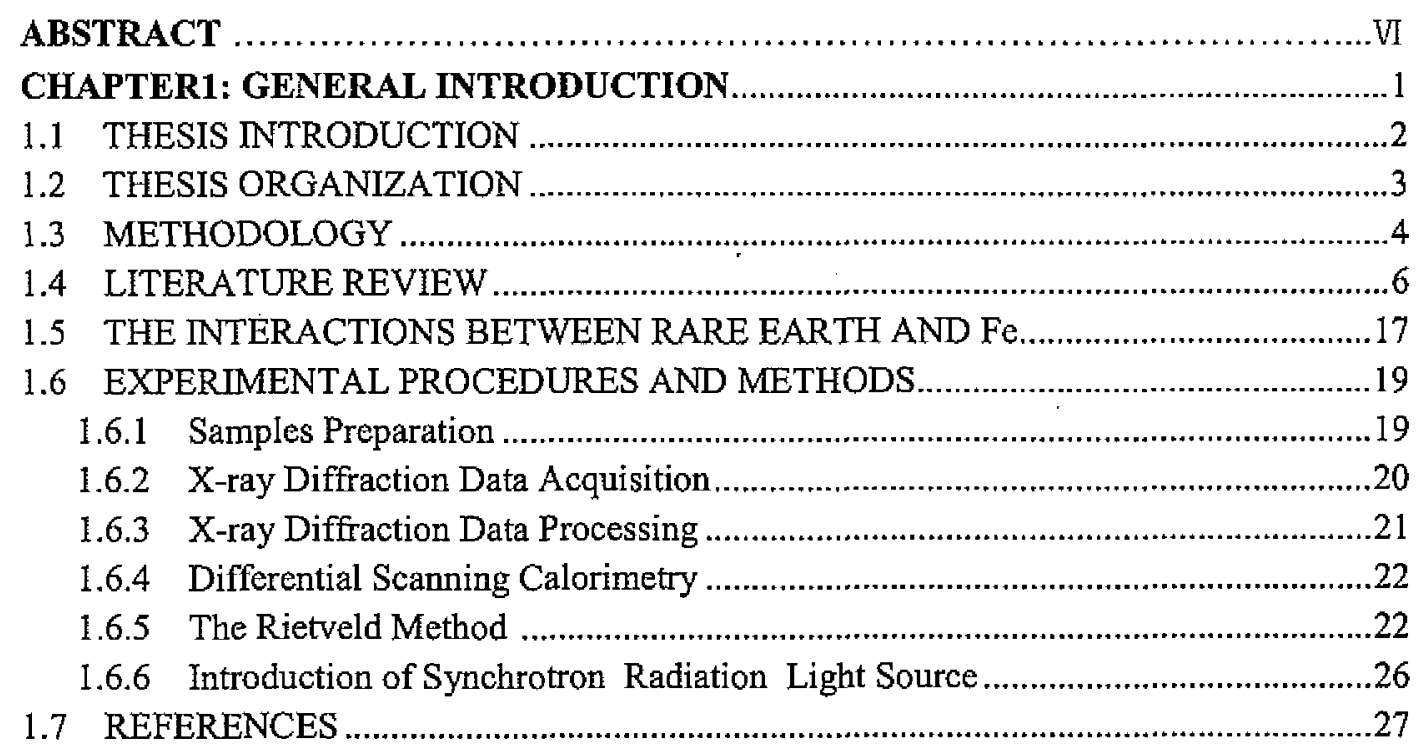

\section{CHAPTER 2: SPONTANEOUS MAGNETOSTRICTION IN $\mathbf{R}_{2} \mathbf{F e}_{14} \mathbf{B}$}

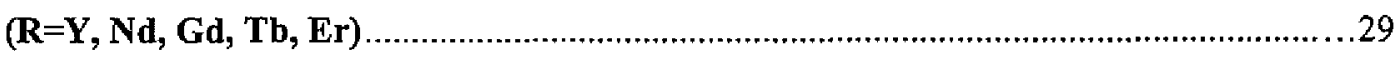

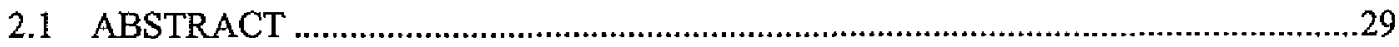

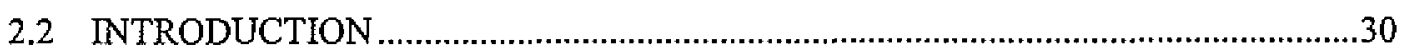

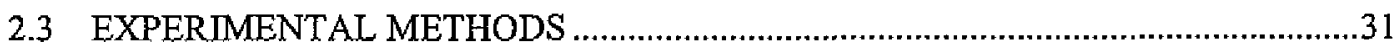

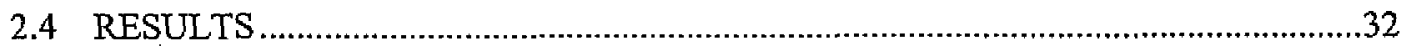

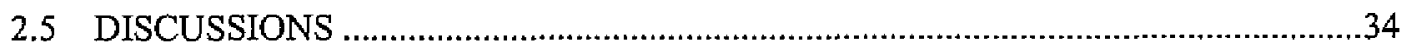

2.5.1 The Thermal Expansion Anomalies ................................................................34

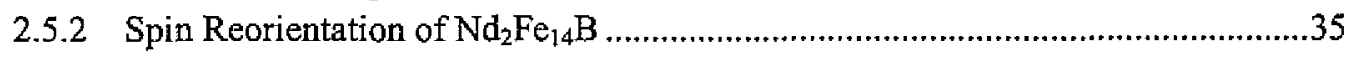

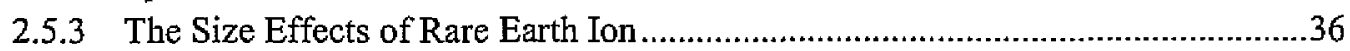

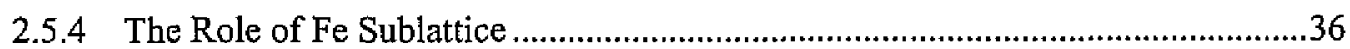

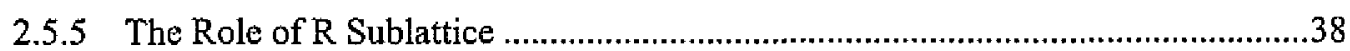

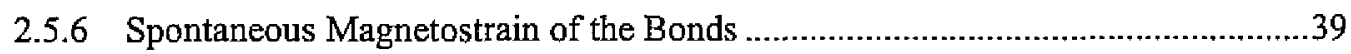

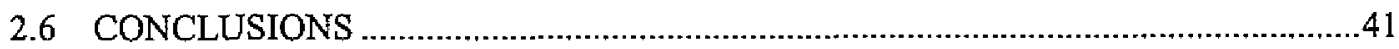

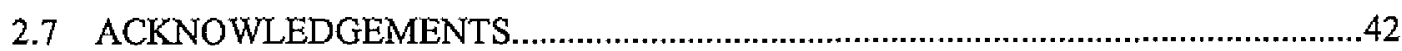

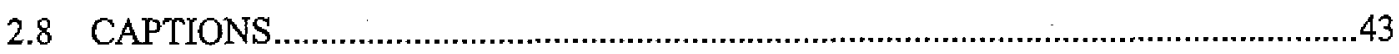

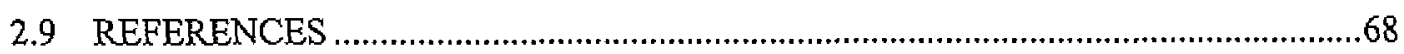


CHAPTER 3:SPONTANEOUS MAGNETOSTRICTION OF $\mathbf{R}_{2} \mathrm{Fe}_{17}$

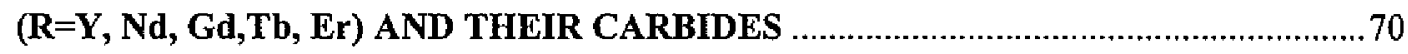

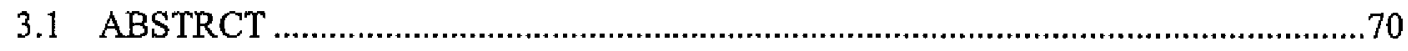

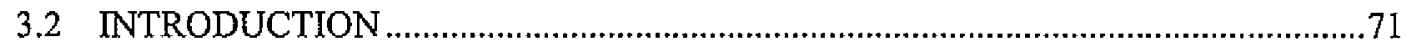

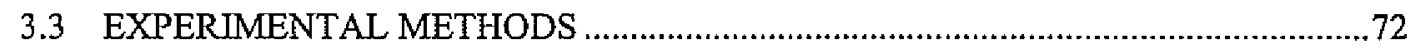

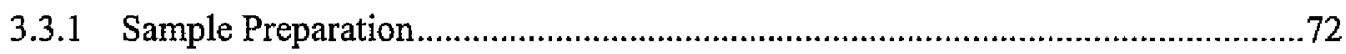

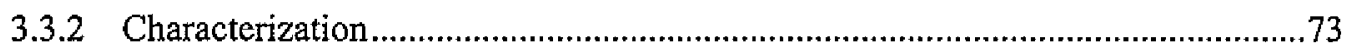

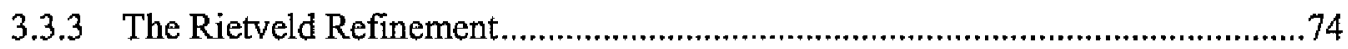

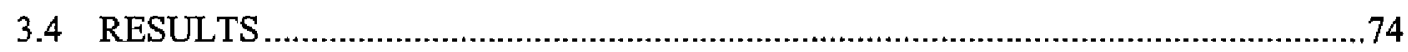

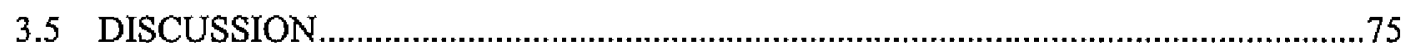

3.5.1 The Thermal Expansion of $\mathrm{R}_{2} \mathrm{Fe}_{17}$ and their Carbides .........................................75

3.5.2 The Role of the Fe Sublattice ...........................................................................77

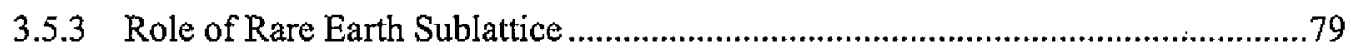

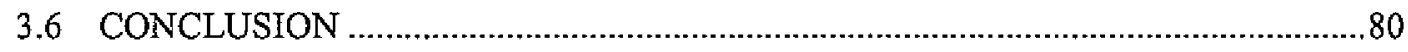

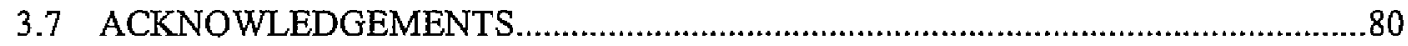

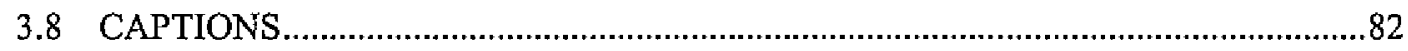

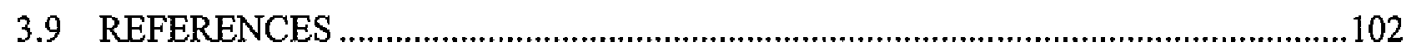

CHAPTER 4:CRITICAL BOND LENGTHS AND THE ROLE IN SPONTANEOUS MAGNETOSTRICTION OF $\mathbf{R}_{2} \mathrm{Fe}_{17} \mathrm{C}_{\mathrm{X}}(\mathbf{R}=\mathrm{Y}$, Nd, Gd,

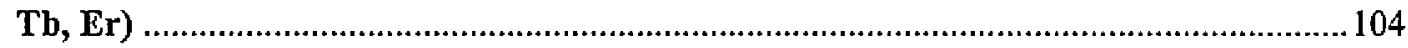

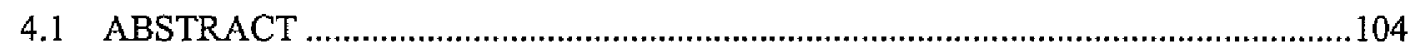

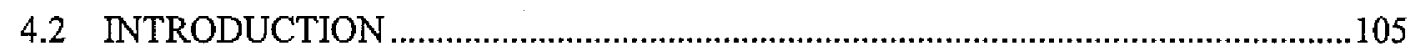

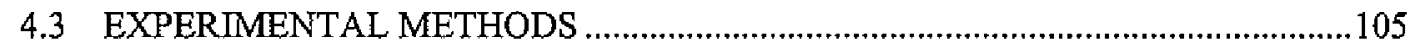

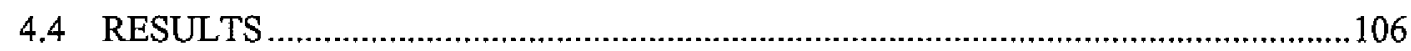

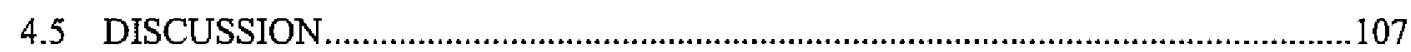

4.5.1 The Bond Length Change with Interstitial Carbon ...........................................107

4.5.2 The Spontaneous Magnetostriction of the Bonds.............................................109

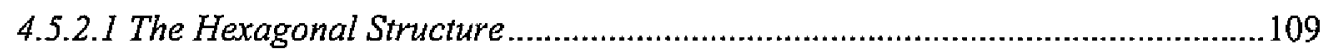

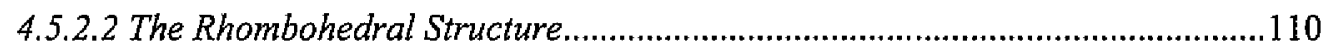

4.5.3 The Contribution of Different $R$ and Fe Sites ............................................112

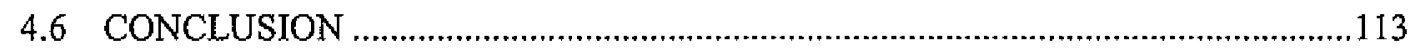

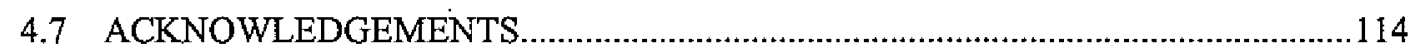

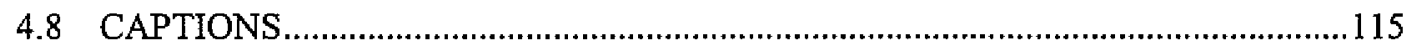

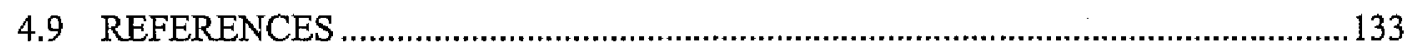


CHAPTER 5: AN EVALUATION OF THEORETICAL MODELS ON SPONTANEOUS MAGNETOSTRICTION ......................................... 134

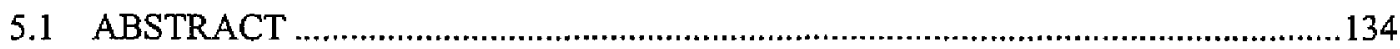

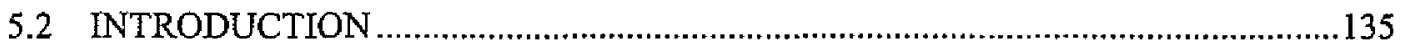

5.3 THE LOCAL AND ITINERANT MOMENT MODELS .......................................136

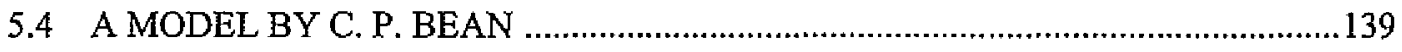

5.5 A LANDAU MODEL OF SPONTANEOUS MAGNETOSTRICTION .....................141

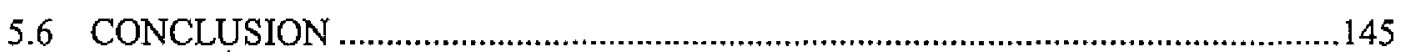

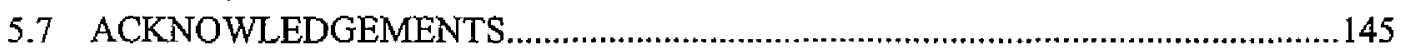

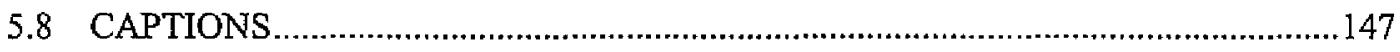

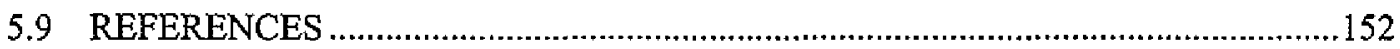

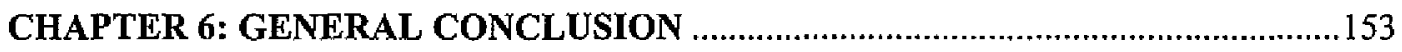

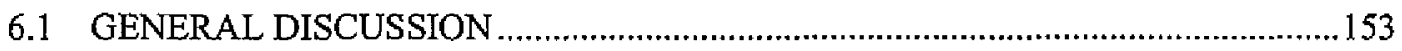

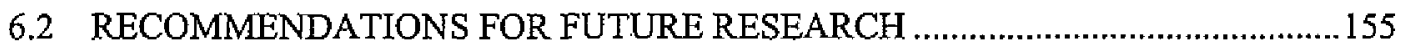

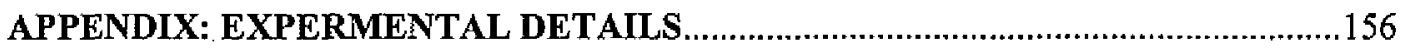

1. THE RIETVELD REFINEMENT OF X-RAY PATTERNS....................................156

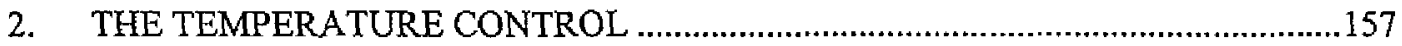

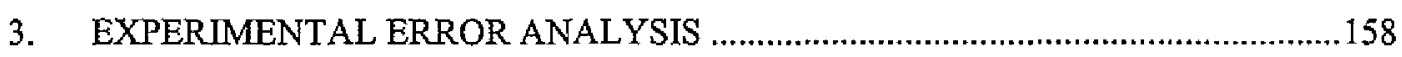

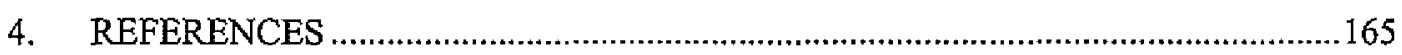

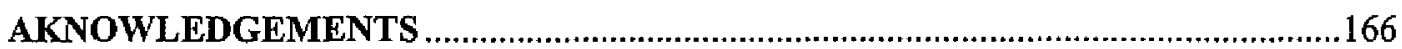




\begin{abstract}
Thermal expansion anomalies of $\mathrm{R}_{2} \mathrm{Fe}_{14} \mathrm{~B}$ and $\mathrm{R}_{2} \mathrm{Fe}_{17} \mathrm{C}_{\mathrm{x}}(\mathrm{x}=0,2)(\mathrm{R}=\mathrm{Y}, \mathrm{Nd}, \mathrm{Gd}, \mathrm{Tb}$, Er) stoichiometric compounds are studied with high-energy synchrotron X-ray powder diffraction using Debye-Scherrer geometry in temperature range $10 \mathrm{~K}$ to $1000 \mathrm{~K}$. Large spontaneous magnetostriction up to their Curie temperatures $\left(T_{c}\right)$ is observed. The a-axes show relatively larger invar effects than c-axes in the $\mathrm{R}_{2} \mathrm{Fe}_{14} \mathrm{~B}$ compounds whereas the $\mathrm{R}_{2} \mathrm{Fe}_{17} \mathrm{C}_{\mathrm{x}}$ show the contrary anisotropies. The iron sub-lattice is shown to dominate the spontaneous magnetostriction of the compounds. The contribution of the rare earth sublattice is roughly proportional to the spin magnetic moment of the rare earth in the $\mathrm{R}_{2} \mathrm{Fe}_{14} \mathrm{~B}$ compounds but in $\mathrm{R}_{2} \mathrm{Fe}_{17} \mathrm{C}_{\mathrm{x}}$, the rare earth sub-lattice contribution appears more likely to be dominated by the local bonding. The calculation of spontaneous magnetostrain of bonds shows that the bonds associated with $\mathrm{Fe}(\mathrm{j} 2)$ sites in $\mathrm{R}_{2} \mathrm{Fe}_{14} \mathrm{~B}$ and the dumbbell sites in $\mathrm{R}_{2} \mathrm{Fe}_{17} \mathrm{C}_{\mathrm{x}}$ have larger values, which is strongly related to their largest magnetic moment and Wigner-Seitz atomic cell volume. The roles of the carbon atoms in increasing the Curie temperatures of the $\mathrm{R}_{2} \mathrm{Fe}_{17}$ compounds are attributed to the increased separation of $\mathrm{Fe}$ hexagons. The $\mathrm{R}_{2} \mathrm{Fe}_{17}$ and $\mathrm{R}_{2} \mathrm{Fe}_{14} \mathrm{~B}$ phases with magnetic rare earth ions also show anisotropies of thermal expansion above $T_{c}$. For $R_{2} \mathrm{Fe}_{17}$ and $\mathrm{R}_{2} \mathrm{Fe}_{14} \mathrm{~B}$ the $\alpha_{a} / \alpha_{c}>1$ whereas the anisotropy is reversed with the interstitial carbon in $\mathrm{R}_{2} \mathrm{Fe}_{17}$. The average bond magnetostrain is shown to be a possible predictor of the magnetic moment of $\mathrm{Fe}$ sites in the compounds. Both of the theoretical and phenomenological models on spontaneous magnetostriction are discussed and a Landau model on the spontaneous magnetostriction is proposed.
\end{abstract}




\section{CHAPTER 1}

\section{GENERAL INTRODUCTION}

\subsection{THESIS INTRODUCTION}

Magnetostriction is the change of a sample's shape and dimension due to the change of its magnetic state. Magnetostriction results from the dependence of magnetic and electronic exchange interactions on interatomic distances. Magnetostriction can be observed in two ways; magnetostriction induced by an external magnetic field and the spontaneous magnetostriction which appears when the magnetic state changes with temperature.

The classical invar alloys are $3 \mathrm{~d}$ transition metal-based alloys, whose major components are $\mathrm{Fe}$ and $\mathrm{Ni}$. The Fe alloys with 35 atomic percent of $\mathrm{Ni}$ has very low thermal expansion coefficient $\left(10^{-6}\right)$, an order of magnitude smaller than that of $\mathrm{Fe}$ or $\mathrm{Ni}$. The classical invar anomalies and alloys based on 3d metals have been extensively studied for a long time and been discussed in great details by Wasserman [1]. The 3d based alloys have only a single type of electrons responsible for the magnetic properties and have a highly symmetrical structure.

The rare earth and $3 \mathrm{~d}$ transition metals intermetallic compounds can form a wide range of magnetic materials. The localized magnetism of rare-earth sublattice, combined with an itinerant magnetism of $3 \mathrm{~d}$ sublattice makes the intermetallics very attractive subjects from a scientific point of view. On the other hand, large magnetic anisotropy, originating from the rare-earth sublattice, in combination with high magnetic moment and Curie temperature, originating from the $3 \mathrm{~d}$ sublattice, have led to the discovery of several excellent materials for application as permanent magnets and magnetostrictors $[2,3,4]$. For the above reasons, the 
rare earth transition intermetallics have been extensively studied and a large amount of information has been collected on the magnetic moments, magnetocrystalline anisotropy, temperature dependence of the magnetic ordering and spin-reorientation.

However, on the other hand, the R-T intermetallics are much more complicated than the $3 \mathrm{~d}$ metals and alloys since they have at least two different types of magnetic atoms and form more complicated anisotropic lattices. Although research has shown that many R-T intermetallics show a large spontaneous magnetostriction, the magnetostriction of R-T compounds is far from being understood $[5,6,7,8,9,10,11,12,13,14,15,16,17,18]$. Part of the reason is that the experimental results of magnetovolume effect of most $R-T$ compounds have become available only relatively recent. Another reason may come from the 'big gap' between the results of different groups. In addition, the experimental techniques used in the previous studies had difficulties and limitations, which reduced the accuracy of lattice dimensions.

Synchrotron radiation has been proved to be a powerful tool to probe on the structure of materials $[19,20,21,22]$. The high brilliance make the taking of data in short time to be possible and the high quality of data taken at large reciprocal distances allows for tracking changes in lattice parameters and bond lengths as a function of temperature using Rietveld analysis.

The objective of the thesis work is to utilize high-energy high-flux synchrotron $x$-ray, the powder diffraction techniques and the full pattern Rietveld refinement to study the spontaneous magnetostriction of a variety of related rare earth transition metal compounds. The invar effects of $\mathrm{R}_{2} \mathrm{Fe}_{14} \mathrm{~B}, \mathrm{R}_{2} \mathrm{Fe}_{17}$ and $\mathrm{R}_{2} \mathrm{Fe}_{17}$ carbides with $\mathrm{R}=\mathrm{Y}, \mathrm{Nd}, \mathrm{Gd}, \mathrm{Tb}, \mathrm{Er}$ were investigated. The samples selection covered different rare earth magnetic moment and ion 
size, which will give a good account of the roles of rare earth sublattices on thermal expansion behaviors of the compounds. The comparison of $\mathrm{R}_{2} \mathrm{Fe}_{14} \mathrm{~B}$ and $\mathrm{R}_{2} \mathrm{Fe}_{17}$ will provide

a general idea of the roles of $\mathrm{Fe}$ sublattice and the $\mathrm{R}_{2} \mathrm{Fe}_{17}$ carbides will explain the roles of interstitials in modifying the local environment and mediating the exchange interactions between sites.

By this research, we expect to further the study on this topic by more accurate measurement and much more structural information extracted during the spontaneous magnetostriction.

\subsection{THESIS ORGANIZATION}

The thesis is divided into six sections and an appendix. The first chapter is the general introduction, including the literature review, introduction of the experimental methods and a brief discussion on the exchange interaction between the rare earth and transition atoms.

The second chapter focuses on the study of $\mathrm{R}_{2} \mathrm{Fe}_{14} \mathrm{~B}$ compounds. In this chapter, the thermal expansion anomaly of $\mathrm{R}_{2} \mathrm{Fe}_{14} \mathrm{~B}$ will be described and discussed. The spontaneous magnetostrain of the lattice dimensions as well as the bond length are calculated and the contributions to the invar effects from both Fe sublattice and rare earth sublattice will be discussed. Finally, the temperature dependences of bond lengths and the thermal expansion behaviors of the Fe sublattice will be summarized and discussed.

The third chapter discusses the spontaneous magnetostriction of $\mathrm{R}_{2} \mathrm{Fe}_{17}$ and their carbides. In this chapter, the magnetostriction associated to a related series of compounds to the 2-14-1 compounds will be discussed. The role of the carbon insertion on the Curie temperature and 
magnetic anisotropy will be described and the roles of the Fe sublattice and rare earth sublattice on spontaneous magnetostriction will be presented.

The fourth chapter details the roles of crystal chemistry in altering bond lengths in $\mathrm{R}_{2} \mathrm{Fe}_{17}$ and their carbides. This chapter focuses particularly on the role of carbon insertion into the $\mathrm{R}_{2} \mathrm{Fe}_{17}$ compounds and how this interstitial atom alters the temperature dependence of the interaction of both the Fe and rare earth sublattices. The length of the similar bonds in two polymorphic structures with and without carbon are calculated and compared.

The fifth chapter discusses both physical and phenomenological modeling of spontaneous magnetostriction in rare earth transition metal compounds. Both molecular field and band models will be discussed and a phenomenological model on the first and second order magnetic phase transition model will be introduced. Finally, a phenomenological model based on the Landau phase transitions will be proposed.

A general conclusion is also presented to show the similarities and differences between magnetostricition in these crystallograpically related rare earth transition metal compounds.

An appendix is also included to provide more detailed information about the experimental setup, which is too lengthy to include in the chapters of this alternate thesis format. This includes the temperature calibrations and further details of refinements and their uncertainties.

\subsection{METHODOLOGY}

The spontaneous magnetostriction of the rare earth transition metal compounds is moderately significant effect in this important family of permanent magnetic materials. Although some research has been preformed on this topic, understanding and quantifying the 
magnetostriction is beneficial to the understanding of the basic magnetic properties and can provide clues to tailored structures which may have more promising properties. For instance, the exchange interactions between transition metal atoms and the rare earth and transition metals can be studied indirectly by careful measurements of the bond length changes as a function of temperature.

The previous studies had limitations. Single crystals combined with x-ray diffraction were used to determine the change in lattice parameters with temperatures [5,7]. Although the lattice parameters can be tracked by measuring two perpendicular reflections, the standard diffraction geometry used with the lab x-ray source have large systematic errors, especially under changing temperatures conditions. Polycrystalline samples combined with contact dilatometry may give much higher accuracy for measuring the bulk thermal expansion coefficients, but only the average volumetric expansion can be obtained using this method $[13,14,15]$. As we all know, rare earth and transition metal always form highly anisotropic compounds, which results in very different thermal expansion properties along different directions.

The third generation synchrotron source features high-energy high-brilliance $\mathrm{x}$-rays and allows for various in-situ studies (time resolved or temperature dependent). The high energy $x$-ray beam allows for full sample penetration in the transmission geometry even with the sample containing heavy elements. In addition, the transmission geometry reduces the error induced by sample shifts that typically occur during heating and cooling. Powder samples allow for a larger range of sample chemistries than single crystals. Whole pattern structural refinement, in particular Rietveld refinement, provides all the crystallographic information about the samples. The lattice parameters were determined by fitting the 2 theta positions of 
all the peaks instead of a few specific reflections, which greatly improves the precision of the measurement. Due to the very short wavelength of the synchrotron $x$-ray used in this study, the number of the reflections is sufficient to refine the atomic position and thermal parameters with a high degree of confidence. It has been proposed that for a reliable refinement of the structure, the number of the reflection should be at least three times of the number of the refined structural parameters [23]. In our studies, the number of the reflection in the 2-14-1 phases are about 50 whereas the number of refined structural parameters are about 16 , which is at the low limit end of the rule. For the $2-17$ samples, there are only 10 or 12 structural parameters refined but more than 30 reflections available, which also fulfills the requirement. The high-flux at the APS provides the reasonable data sampling rate of only a few minutes per pattern with sufficient signal:noise to obtain a large data base of structural parameters on a large number of composition to fully study the role crystal chemistry on influencing spontaneous magnetostriction in rare earth transition metal permanent magnets.

\subsection{LITERATURE REVIEW}

The research on the spontaneous magnetostriction (invar anomalies or invar effects) of rare earth and transition compounds began in 1970's, as a result of the intensive research on the new permanent magnets composed of rare earth and $3 \mathrm{~d}$ transition metals. The first compounds being studied were the $\mathrm{RFe}_{2}$ and $\mathrm{RCO}_{2}$ laves phases [24]. The Laves phases having the $\mathrm{AB}_{2}$ stoichiometry are the largest class of binary intermetallics. In the R-T alloy systems, this type of compounds exists with $\mathrm{T}=\mathrm{Mn}, \mathrm{Fe}, \mathrm{Co}$ and $\mathrm{Ni}$. The $\mathrm{RT}_{2}$ compounds crystallize in a relatively simple cubic structure of the $\mathrm{MgCu}_{2}$ type ( $\mathrm{Fd} 3 \mathrm{~m}$ space group). The unit cell of this structure contains 8 formula units and the lattice parameter is about $7 \AA$. The 
$\mathrm{R}$ atoms occupy the $8 \mathrm{a}$ sites and the $\mathrm{R}$ sublattice has a diamond structure. The $3 \mathrm{~d}$ atoms occupy $16 \mathrm{~d}$ sites and form 4 tetrahedrons around $[3 / 4,3 / 4,3 / 4]$ and its equivalent sites. The $R_{2}$ compounds are ferromagnetic (with nonmagnetic or light $\mathrm{R}$ elements) or ferrimagnetic (with heavy $R$ elements). The easy axes of $\mathrm{RT}_{2}$ phases are [111] or [100] directions.

The anisotropic magnetostriction can be observed in most of the $\mathrm{RT}_{2}$ phases. But the magnetostrictive strain along the easy axes can be both positive and negative. The highest known room-temperature magnetostriction was observed in $\mathrm{TbFe}_{2}[25]$ with $\lambda_{111}=4.5 \times 10^{-3}$ and resulted in considerable interest in $\mathrm{RFe}_{2}$ as magnetostrictive materials.

It has been noted that the rare earth sublattice makes the major contribution to the total anisotropic magnetostriction of $\mathrm{RFe}_{2}$, which follows from the fact that the magnetostriction in the compounds with nonmagnetic $R=Y$ and $L u$ does not exceed $8 \times 10^{-5}$, which is two orders lower than those $\mathrm{R}$ ions having nonzero orbital moment [24]. The rare-earth contribution to the anisotropic magnetostriction in $\mathrm{RFe}_{2}$ has been well explained with the framework of the single ion model, where the giant magnetostriction as well as the magnetocrystalline anisotropy originates from the electrostatic interaction between the anisotropic $4 f$ electron shell of the $R$ ion and the crystal field.

The $\mathrm{RCO}_{2}$ compounds are very different from $\mathrm{RFe}_{2}$. They have much lower Curie Temperatures $\left(T_{c}\right)$, which make them unattractive for applications. Also, the Co sublattice has no intrinsic magnetic moments. The main difference in anisotropic magnetostriction between $\mathrm{RCO}_{2}$ and $\mathrm{RFe}_{2}$ is that the Co contribution is not negligible compared to the $\mathrm{R}$ contribution.

In addition to lave phases, rare earth elements and transition metals can form kinds of intermetallics compounds. The R-Co system can form compounds like $\mathrm{RCO}_{2}, \mathrm{R}_{3} \mathrm{Co}, \mathrm{RCO}_{3}$, 
$\mathrm{RCo}_{5}, \mathrm{R}_{2} \mathrm{Co}_{7}, \mathrm{R}_{5} \mathrm{Co}_{19}, \mathrm{R}_{2} \mathrm{Co}_{17}$, where only $\mathrm{RCO}_{2}$ has cubic crystal structure. For the noncubic structures, the error in the determination of spontaneous magnetostrictive strains is much higher than that of cubic compounds. Quantitative data with reasonable accuracy usually could not be obtained on polycrystalline samples. Therefore, only data for some compounds obtained from single crystals is available.

The binary R-Fe phase diagram contains a much lower number of intermetallic compounds than the R-Co systems, especially in R-Fe systems with light R elements, which contain only $\mathrm{RFe}_{2}$ and $\mathrm{R}_{2} \mathrm{Fe}_{17}$ phases. But, several classes of ternary compounds based mainly on $\mathrm{Fe}$ and $\mathrm{R}$, with low content of a third elements, were discovered in 1980 s during a search for Co-free permanent-magnetic materials. The most important one is the $\mathrm{R}_{2} \mathrm{Fe}_{14} \mathrm{M}(\mathrm{M}$ $=\mathrm{B}, \mathrm{C})$ phase $[2,3,4]$.

The crystal structures of $\mathrm{R}_{2} \mathrm{Fe}_{17}$ are strongly related to the $\mathrm{CaCu}_{5}$ type. The $\mathrm{R}_{2} \mathrm{Fe}_{17}$ can be generated from three $\mathrm{CaCu}_{5}$ structural units by replacement of one $\mathrm{R}$ atom with two $3 \mathrm{~d}$ atoms $\left(3 \mathrm{RFe}_{5}-\mathrm{R}+2 \mathrm{Fe}=\mathrm{R}_{2} \mathrm{Fe}_{17}\right)$. The structural block of $\mathrm{R}_{2} \mathrm{Fe}_{17}$ has about the same dimension along $\mathrm{c}$ axis as that of the 1:5 lattice, whereas the unit cell should have 3 times larger area in the basal plane than in the 1:5 lattice. As a result, the lattice is almost doubled. The double layer stacking of these structural blocks corresponds to the hexagonal structure modification, i.e. the $\mathrm{Th}_{2} \mathrm{Ni}_{17}$ type $\left(\mathrm{P} 6_{3} / \mathrm{mmc}\right)$ and the unit cell contains two formula units (Figure 1-1a). This structure is observed for the heavy $R$ and $Y$. In the case of light $R$, a three-layer stacking leads to the rhombohedra structure modification, i.e. to the $\mathrm{Th}_{2} \mathrm{Zn}_{17}$ type $(\mathrm{R}-3 \mathrm{~m})$ and each unit cell contains three formula units (Figure 1-1b).

The special feature of $\mathrm{R}_{2} \mathrm{Fe}_{17}$ is the very short Fe-Fe distances. In the dumbbell structure, $\mathrm{d}_{\mathrm{FcFe}} \approx 2.39 \AA$ and there are several other distances with $\mathrm{d}_{\mathrm{FeFe}} \approx 2.44 \AA$, which are also shorter 


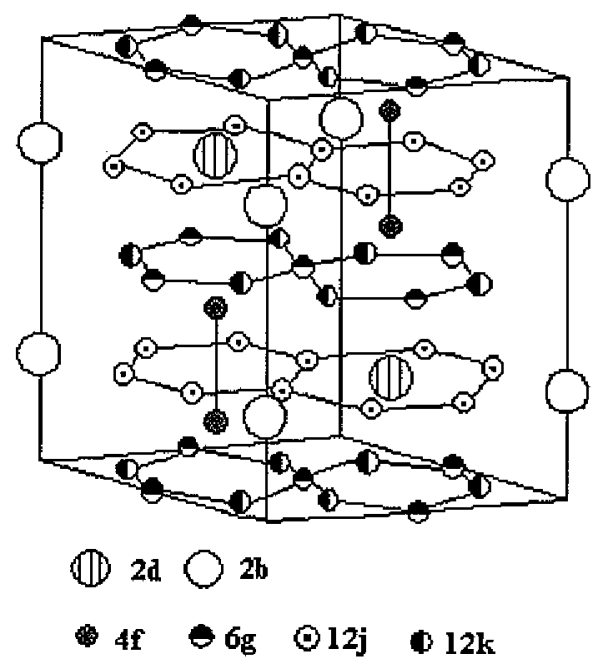

a

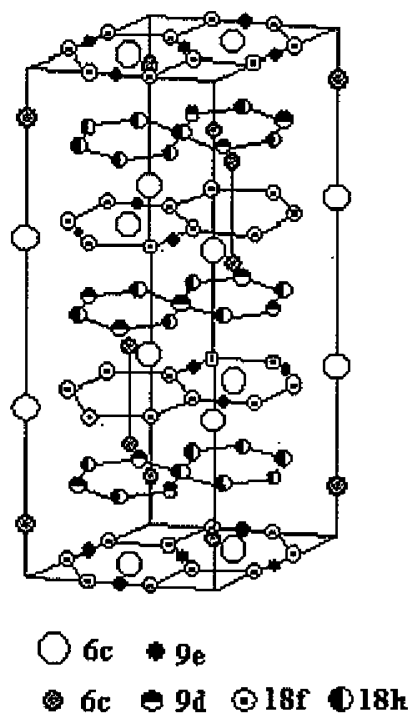

b

Figure 1-1. Crystal structure of $\mathrm{R}_{2} \mathrm{Fe}_{17}$. $\bigcirc \mathrm{R}$ atoms $\mathrm{Fe}$ atoms
a. Hexagonal modification, $\mathrm{Th}_{2} \mathrm{Ni}_{17}$ type
b. Rhombohedral modification, $\mathrm{Th}_{2} \mathrm{Zn}_{17}$ type 
than $\mathrm{d}_{\mathrm{FeFe}} \approx 2.50 \AA$ in the bec $\mathrm{Fe}[11,26]$. For this reason, a negative exchange interaction between the $\mathrm{Fe}$ atoms separated by such distances is considered to exist with positive interactions in the case of larger iron distances. The total $\mathrm{Fe}-\mathrm{Fe}$ exchange interactions are positive so that the Fe sublattice is ferromagnetic in most $\mathrm{R}_{2} \mathrm{Fe}_{17}$. However, the existence of these competitive interactions leads to low Curie temperatures, which is true for most of these compounds

The rare-earth carbides $\mathrm{R}_{2} \mathrm{Fe}_{17} \mathrm{C}_{\mathrm{x}}$ are interstitial solutions in $\mathrm{R}_{2} \mathrm{Fe}_{17}$ [27], in which the atomic sites for $\mathrm{C}$ (as well as for $\mathrm{N}$ in the case of the isostructural nitrides) are $9 \mathrm{e}$ in the thombohedral modification and $6 \mathrm{~h}$ in the hexagonal structure. The maximum carbon content, when all the sites are occupied, is 3 per formula unit. However, single-phase compounds with only $x \approx 2$ were obtained [28]. Carbides of high $C$ content have the rhombohedral structure even though their parent compounds have the hexagonal structure.

One of the most important features of these carbides is the increase of $T_{c}$ by a factor of about $2[29,30]$. This was attributed to the decrease of negative exchange-interaction due to the considerable increase of the unit cell volume caused by carbon addition.

The spontaneous magnetostriction of the $\mathrm{R}_{2} \mathrm{Fe}_{17}$ and their carbides has been studied intensively by groups. Givord et al [10] found that only in the $\mathrm{R}_{2} \mathrm{Fe}_{17}$ compounds can the large spontaneous magnetostriction accompanied by Invar-like thermal expansion be observed. The very short Fe-Fe distances present in the 'dumbbells' was believed to be responsible. The exchange interactions between the $\mathrm{Fe}$ atoms in the dumbbells are assumed to be negative. However, due to the domination of the positive exchange interactions with the other Fe atoms, the magnetic moments of the Fe atoms in dumbbells adopt a parallel orientation and the negative interaction is not satisfied. Since the negative interaction 
decreases with increasing distance, the lattice expends and the observed spontaneous magnetostriction appears as a result of the competition between magnetic and elastic energy.

D. Gignoux [12] studied spontaneous magnetostriction of the $\mathrm{Y}_{2} \mathrm{Fe}_{17}$ and $\mathrm{Lu}_{2} \mathrm{Fe}_{17}$ and a very large magnetostriction was observed for these samples. In his results, the c-axes showed a much stronger invar anomaly than a-axes. The other $\mathrm{R}_{2} \mathrm{Fe}_{17}$ compounds have similar spontaneous magnetostriction. He concluded that in the $\mathrm{R}_{2} \mathrm{Fe}_{17}$ alloys, the thermal expansion anomaly observed below the ordering temperature is a result of the strong dependence of the magnetic interactions with interatomic distances associated with a competition of interactions of opposite signs. The positive spontaneous volume magnetostriction leads to an increase of the positive interactions and a decrease of the negative interactions.

Forced magnetostriction of several $\mathrm{R}_{2} \mathrm{Fe}_{17}$ compounds have been measured on single crystals by A.V. Andreev et al [31]. From these measurements, Andreev concluded that only the exchange magnetostriction influences the thermal expansion in $\mathrm{R}_{2} \mathrm{Fe}_{17}$. This magnetostriction consists mainly of the Fe sublattice contribution and the contribution from the R-Fe interaction is found to be lower than $15-25 \%$ of the total volume effect. He also concluded that for all the compounds studied, the temperature dependence of spontaneous volume magnetostriction $\omega_{s}$ follows the square of magnetic moment of the Fe sublattice and the value of $\omega_{\mathrm{s}}$ only slightly depends on $\mathrm{R}$.

However, there is a contradiction if one compares the lattice expansion of $\mathrm{R}_{2} \mathrm{Fe}_{17}$ and the compounds with interstitial carbon atoms. The latter leads to an increase of $\omega_{\mathrm{s}}$ instead of strong decrease which would be expected from the above consideration. The interstitial atoms should increase the $\mathrm{Fe}-\mathrm{Fe}$ bond lengths and reduce the negative interaction, which decreases with the increasing distance, resulting in lowering the magnetostriction. Yet in fact, 
the carbides of high $\mathrm{C}$ contents, $\omega_{s}$ becomes close to that in $\mathrm{R}_{2} \mathrm{Fe}_{14} \mathrm{~B}$, which have largest invar volume effect.

Another attractive point with $\mathrm{R}_{2} \mathrm{Fe}_{17}$ compounds is the research on how to improve the Curie temperature of the parents' compounds in order to make them more suitable for permanent magnets. As we mentioned before, the interstitial $\mathrm{N}, \mathrm{C}$, or $\mathrm{H}$ atoms in the compounds elevates the $\mathrm{T}_{\mathrm{c}}$. On the other hand, the substitutions of $\mathrm{Al}$ or $\mathrm{Ga}$ for $\mathrm{Fe}$ also elevate the $T_{c}$ of the compounds $[32,33]$. These elevations of $T_{c}$ of the compound have been explained by the expansion of the lattice caused by the interstitial atoms or a substitution of elements with a larger ionic radius. However, the substitution of Si for Fe elevates $T_{c}$ even with the contraction of the lattice. T. Kamimori studied this problem and concluded that the elevations of $T_{c}$ can be explained by both positive volume effect of $T_{c}$ and the reduction of invar properties of the parent compounds [34].

As a conclusion of the discussions above, the large positive volume magnetostriction is found to be a common feature of the rare-earth intermetallics with high Fe content. The $\mathrm{R}_{2} \mathrm{Fe}_{17}$ is only one group of such materials, and their spontaneous magnetostriction is not the largest. The invar like behavior of $\mathrm{R}_{2} \mathrm{Fe}_{17}$ is a result of the anomalously low Curie temperature, which is actually connected with the presence of negative exchange interaction. The rare earth ternary compounds $\mathrm{R}_{2} \mathrm{Fe}_{14} \mathrm{~B}$ have been extensively studied after the discovery of their unique permanent magnetic properties $[35,36]$. The crystal structure of $\mathrm{R}_{2} \mathrm{Fe}_{14} \mathrm{~B}$ is a novel type. The lattice is tetragonal and belongs to the $\mathrm{P} 4_{2} / \mathrm{mnm}$ space group [37]. The unit cell contains 4 formula units of $\mathrm{R}_{2} \mathrm{Fe}_{14} \mathrm{~B}$ and schematic is shown in Figure 1-2a. There are six crystallographically distinct iron sites, two different rare earth sites and one boron site. From Figure 1-2a, it can be seen that each $\mathrm{R}_{2} \mathrm{Fe}_{14} \mathrm{~B}$ unit cell consists of an eight layers 
repeated along the $\mathrm{c}$ axis. All the $\mathrm{R}$ and $\mathrm{B}$ atoms, but only four $\mathrm{Fe}(\mathrm{c})$ atoms out of the total iron number of 56 , reside on the $\mathrm{z}=0$ and $\mathrm{z}^{\mathrm{m}} 1 / 2$ mirror planes. Between these planes, the
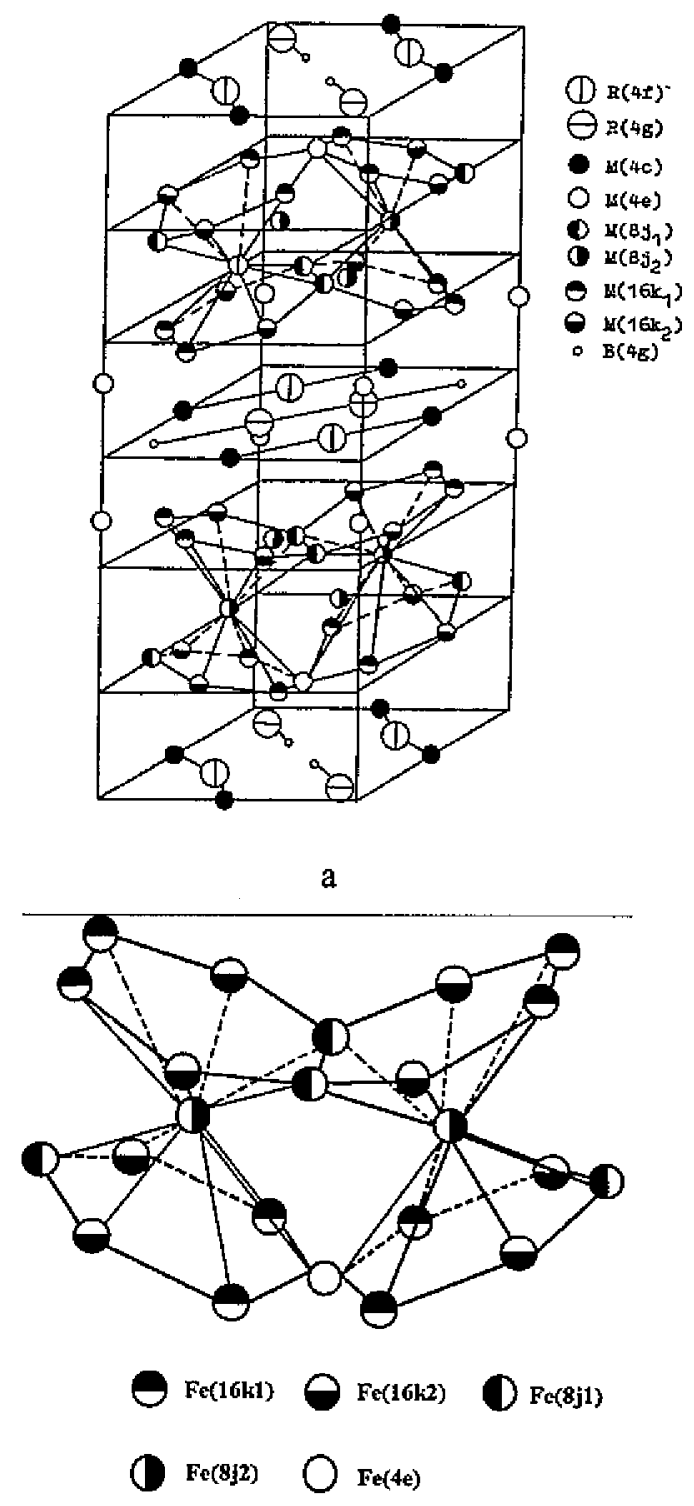

b

Figure 1-2 a: Unit cell of $\mathrm{R}_{2} \mathrm{Fe}_{14} \mathrm{~B}$ phase

$\mathrm{b}$ : Fe sublattice between basal plane and $\mathrm{z}=1 / 2$ mirror plane in $2-14-1$ phase 
other Fe atoms form three puckered nets. The Fe(k1), Fe(k2), Fe(j1) and $\mathrm{Fe}(\mathrm{e})$ sites comprise two slightly distorted hexagonal arrays rotated by $\sim 30^{\circ}$ with respect to one another. They enclose a net located above or below the centers of the hexagons in the neighboring layers (Figure 1-2b).

Though the structure of $\mathrm{R}_{2} \mathrm{Fe}_{14} \mathrm{~B}$ is more complicated than the structure of $\mathrm{R}_{2} \mathrm{Fe}_{17}$, the shortest $\mathrm{Fe}-\mathrm{Fe}$ interatomic distance is practically the same as in $\mathrm{R}_{2} \mathrm{Fe}_{17}, \sim 2.39 \AA$, which occurs between the Fe atoms on the $\mathrm{j} 1$ and $\mathrm{k} 2$ positions [37]. However, these pairs are found in the basal plane instead of along the $\mathrm{c}$-axis in $\mathrm{R}_{2} \mathrm{Fe}_{17}$. There are also several distances 2.44-

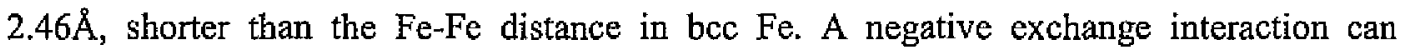
therefore be expected for such pairs.

The magnetic properties of $\mathrm{R}_{2} \mathrm{Fe}_{14} \mathrm{~B}$ depend on the nature of the $\mathrm{R}$ components, as found in all other types of R-3d metal intermetallics. The compounds with nonmagnetic and light $R$ elements are ferromagnetic and those with heavy $\mathrm{R}$ elements are ferrimagnetic. The main feature of the magnetism in $\mathrm{R}_{2} \mathrm{Fe}_{14} \mathrm{~B}$, which does not exist in other $\mathrm{R}-\mathrm{Fe}$ compounds, is the uniaxial anisotropy of the Fe sublattice.

The thermal expansion of $\mathrm{R}_{2} \mathrm{Fe}_{14} \mathrm{~B}$ compounds in the magnetically ordered range is found to be very anisotropic $[5,38]$. Although the thermal expansion has been studied for all of the $\mathrm{R}_{2} \mathrm{Fe}_{14} \mathrm{~B}$ compounds, only half of the studies were carried out on single crystals or wellaligned polycrystalline samples.

A.V. Andreev et al have studied the thermal expansion and spontaneous magnetostriction of $\mathrm{R}_{2} \mathrm{Fe}_{14} \mathrm{~B}$ compounds $(\mathrm{R}=\mathrm{Y}, \mathrm{Nd}, \mathrm{Sm})$ in 1985 [5]. In their study, the temperature dependences of the lattice parameters were measured at $4.2-800 \mathrm{~K}$ for single crystals of the rare-earth compounds. A huge (2\%) spontaneous bulk magnetostriction was observed in 
$\mathrm{R}_{2} \mathrm{Fe}_{14} \mathrm{~B}$. Studies of various $\mathrm{R}-\mathrm{Co}$ and $\mathrm{R}-\mathrm{Fe}$ compounds have shown that the magnetic property of compounds where $\mathrm{R}$ is replaced by nonmagnetic $\mathrm{Y}$ is a means of determining the behavior of the $3 \mathrm{~d}$ sublattice. By comparing the temperature dependence of the relative volume magnetostriction of three samples, Andreev found that dependence curves agree well with the square of the iron magnetic moments and surmised that the volume magnetostriction of $\mathrm{R}_{2} \mathrm{Fe}_{14} \mathrm{~B}$ was entirely due to the iron sublattice.

K.H.J. Buschow et al. measured the thermal expansion of the $\mathrm{R}_{2} \mathrm{Fe}_{14} \mathrm{~B}$ compounds with more than ten different types of $\mathrm{R}$ in the temperature range of 4-1000K [10]. In his studies, he used the polycrystalline unmagnetized samples and the thermal expansion above room temperature was measured by means of a standard dilatometer. The low-temperature measurements were made using a strain gauge. In his studies, he concluded that substantial magnetovolume effects persist at temperatures considerably higher than the corresponding Curie temperature and the spontaneous magnetostriction is composed of two contributions that originate from the iron sublattice and the rare earth sublattice respectively. He thought the contribution due to the rare earth sublattice is roughly proportional to the total $4 \mathrm{f}$ moments, but he was not able to support this hypothesis.

In the preliminary studies completed so far, all of the thermal expansion in $\mathrm{R}_{2} \mathrm{Fe}_{14} \mathrm{~B}$ shows a huge spontaneous volume magnetostriction. But there are quantitative differences between the various results. For instance, the $\omega_{\mathrm{s}}$ for $\mathrm{Nd}_{2} \mathrm{Fe}_{14} \mathrm{~B}$ varies from $20 \times 10^{-3}$ to $28 \times 10^{-3}$. A.V. Andreev gave the reasons for the differences first to the different values of the volume thermal expansion coefficients in the paramagnetic region and second to the different extrapolations of paramagnetic dependences to the ordered range [32]. Another contradiction 
concerns the contribution to $\omega_{\mathrm{s}}$ from the $\mathrm{R}$ sublattice. This contribution varies from negligible or about $10 \%$ of total $\omega_{\mathrm{s}}$ to rather than the substantial value of $25 \%$.

Several experimental methods have been employed in measuring of the thermal expansion of rare earth and transition metal compounds. But every method so far has some intrinsic problems or systematic errors to contend with. For instance, in Andreev's studies, the lattice parameters were determined only by two crystal reflections [5]. However, using only two orthogonal reflections is problematic since this fails to account for shifts due to lattice strains or intercalations. In addition, the Bragg- Brentano geometry used in heating and cooling stages is subjected to systematic errors due to shifting of the sample away from focal point of the x-rays. In K.H.J. Buschow's research, the lattice changes were determined by the dilatometers on polycrystalline samples $[13,14]$. But using dilatometer on polycrystalline samples one is not able to separate the thermal behavior contributions from different crystallographic directions and only the volumetric information can be obtained. The systematic errors of different methods may contribute to the differences between the results of different groups. Another shortcoming for all the methods is that no method can give account for the invar effect of the specific bonds. All the given results have only the thermal expansion data for the unit cell dimensions.

Our research on the spontaneous magnetostriction of R-T alloys by using the synchrotron diffraction will have much better Iattice parameter accuracy and the abilities to probe the invar effect "inside" the unit cell. It will greatly further the study on this topic and help the theoreticians to develop models to explain the phenomenon. 


\subsection{THE INTERACTIONS BETWEEN RARE EARTH AND Fe}

The alloys and intermetallic compounds obtained by combining rare earth metals with $3 \mathrm{~d}$ metals form an important class of materials that find applications in permanent magnets, magnetostrictive devices and magneto-optical recordings. In general, it can be said that the $3 \mathrm{~d}$ sublattice is responsible for a sufficiently high magnetization and magnetic ordering temperature while the $4 \mathrm{f}$ sublattice provides a sufficiently high magnetic anisotropy. The best properties can be expected only when there is a sufficiently strong magnetic coupling between the two sublattice.

In the R-T compounds with $\mathrm{T}=\mathrm{Fe}, \mathrm{Co}$, the strongest interaction is the $3 \mathrm{~d}-3 \mathrm{~d}$ interaction which primarily determines the Curie temperature. The $4 \mathrm{f}-4 \mathrm{f}$ interaction is very weak and can be neglected. The $4 \mathrm{f}-3 \mathrm{~d}$ interaction, although much weaker than the $3 \mathrm{~d}-3 \mathrm{~d}$ interaction, is of special importance since by this interaction the strongly anisotropic R-sublattice magnetization is coupled to the more isotropic T-sublattice magnetization.

The rare earth and iron moments are coupled ferromagnetically for the light rare earth and antiferromagnetically for the heavy rare earths. This applies to a large number of crystalline as well as amorphous R-TM systems spanning a broad range of structures and compositions. The rare earth moments can be solely derived from the $4 \mathrm{f}$ electrons and that the ground state of the $4 \mathrm{f}$ shell is specified by Hund's rules. The total angular momentum $J$ of the $4 \mathrm{f}$ shell in the Hund's-rule state is $\mathrm{J}=\mathrm{L}-\mathrm{S}$ for the light lanthanides and $\mathrm{J}=\mathrm{L}+\mathrm{S}$ for the heavy lanthanides. So the total $\mathrm{R}$ moment and $\mathrm{R}$-spin moment are antiparallel for the light rare earth ions and parallel for the heavy rare earth ions. Regarding the R-Fe moment coupling, the statement is equivalent to that the rare earth $4 \mathrm{f}$ spin moments are always 
antiparallel to the iron $3 \mathrm{~d}$ spin moments. In other words, the $3 \mathrm{~d}-4 \mathrm{f}$ exchange interaction is invariably antiferromagnetic.

There are several theories about why the $3 \mathrm{~d}-4 \mathrm{f}$ coupling occurs. Wallace and Buschow suggested that the $3 \mathrm{~d}-4 \mathrm{f}$ coupling occurs indirectly through polarization of the $s$ conduction electrons by an interaction of the Ruderman-Kittel-Kasuya-Yosida (RKKY) type interaction $[39,40]$. However, this mechanism is incapable of explaining all the extensive experimental results. A more realistic coupling scheme has been proposed by Campbell and expounded by Buschow $[41,42]$. The theory suggests that the $4 \mathrm{f}$ spins induce a positive local $5 \mathrm{~d}$ moment and the $3 \mathrm{~d}-4 \mathrm{f}$ interaction is mediated by the intra-atomic $4 \mathrm{f}-5 \mathrm{~d}$ exchange interaction and inter-atomic $3 \mathrm{~d}-5 \mathrm{~d}$ exchange. Campbell also argues that the $3 \mathrm{~d}-5 \mathrm{~d}$ exchange interaction can be expected to be negative too, resulting in an antiferromagnetic $3 \mathrm{~d}-4 \mathrm{f}$ coupling. This model is very appealing and is supported by quantitative theoretical work $[43,44,45]$.

The $4 \mathrm{f}-3 \mathrm{~d}$ exchange interaction in intermetallic compounds can be determined by several different methods experimentally. Analysis of the magnetic scattering of specific atomic sites using neutron scattering is well suited but not very commonly used. With the availabilities of single crystal, the low temperature magnetic isotherms measurement along the main crystallographic directions can be used to determine the inter-sublattice coupling strength. This method has been used primarily for compounds of types $\mathrm{R}_{2} \mathrm{Co}_{17}, \mathrm{R}_{2} \mathrm{Fe}_{17}$ and $\mathrm{R}_{2} \mathrm{Fe}_{14} \mathrm{~B}$. The Mössbauer spectroscopy can also be used to determine the magnetic-coupling constants in the compounds with suitable Mössbauer nucleus [46,47].

The high field free-powder method (HFFP) has been used to determine the intersublattice coupling strength in a fairly large number of different compounds. By the HFFP method, J.P. Liu et al studied the $4 \mathrm{f}-3 \mathrm{~d}$ exchange interaction in quite a large number of 
intermetallic compounds and an empirical relationship was found between the inter-sublattice coupling constant and the reciprocal normalized molar volumes of the various R-T compounds. In this relationship, the smaller the unit cell, the larger the $\mathrm{J}_{\mathrm{RT}}$. This may reflect the strong volume dependence of the $5 \mathrm{~d}-3 \mathrm{~d}$ hybridization [48].

For most of the series of R-T compounds, the inter-sublattice coupling constant decrease with the increasing atomic number $\mathrm{Z}$ of the $\mathrm{R}$ ion. Belorizky gave an explanation for this observation; besides the lanthanide contraction, the reduction of the atomic radius of $\mathrm{R}$ ions with increasing $Z$, an even stronger decrease of the radius of the $4 f$-shell occurs with increasing $Z$. This leads to a smaller overlap of the $4 f$ and $5 d$ shells. The $4 f-5 d$ exchange interaction is determined by the $4 \mathrm{f}-5 \mathrm{~d}$ overlap and since the $4 \mathrm{f}-3 \mathrm{~d}$ inter-atomic exchange interactions are mediated by the intra-atomic $4 \mathrm{f}-5 \mathrm{~d}$ interaction, this larger spatial separation of $4 \mathrm{f}$ and $5 \mathrm{~d}$ shells results in a reduction of the $\mathrm{R}-\mathrm{T}$ interaction.

There is yet another mechanism which affects the R-T interaction when substituting through the lanthanide series. Band-structure calculation show that the decreasing lattice constants alone would lead to an increase in the R-T interaction due to enhanced $5 \mathrm{~d}-3 \mathrm{~d}$ hybridization. Therefore, whether the R-T interaction may decrease or increase with increasing atomic number of the $\mathrm{R}$ component depends on which of the two counteracting effects prevails.

\subsection{EXPERIMENTAL PROCEDURES AND METHODS}

\subsubsection{Samples Preparation}

The ingots of R-T intermetallics and ternary compounds are prepared by means of arc melting high purity raw materials under an atmosphere of purified argon. The ribbon is 
obtained by ejecting the melt onto a copper chill wheel with high tangential wheel speed; depending on the requirement of the as-spun state. A portion of the ribbon samples are wrapped in tantalum foil sealed in a quartz tube and annealed at $900^{\circ} \mathrm{C}$ for 12 hours. The annealed ribbon were ground into powder in an inert atmosphere and loaded into thin walled amorphous silica tubes, which were the standard sample holders for $\mathrm{x}$-ray experiments and normally gave very low background diffuse scattering.

The samples for high temperature study were backfilled with Ar inside the capillaries. For low temperature studies using a Displex a slightly different setup was used because the thermal diffusion through the sample was very critical for the accurate lattice measurements with respect to temperature. To improve the thermal diffusivity of the powder samples, copper rods instead of the quartz rod were used to seal the samples. One end of the copper rods was flat and fully contacted with the powder inside the capillaries. The samples were also sealed within He glove bag to improve the thermal exchange between the particles at low temperature range.

\subsubsection{X-ray Diffraction Data Acquisition}

The synchrotron $x$-ray diffraction experiments were carried out at Advanced Photon Source, Argonne National Laboratory. The data may be obtained on different beam line stations. Because of the transmission geometry of the experiments, the $x$-ray with energy around $80 \mathrm{KeV}(\lambda \approx 0.155 \AA)$ was employed. The highest $Q$ value was kept fairly constant to make the data sets to be comparable. The detectors of x-ray were either a Mar345 or a Bruker6500 CCD system, which can give very good time and spatial resolution of the diffraction patterns with high signal noise ratio. 
For the data in the temperature range above room temperature, the samples were heated up to $1000 \mathrm{~K}$ in the specially designed high temperature synchrotron diffractions furnace [22]. To cool the sample down to $10 \mathrm{~K}$, a specially designed cryostat was used. Both of the furnace and the cryostat have conical exits, which allow the measurement of the whole Debye rings. During the exposures, the beam was centered near the middle of the capillary tube for the high temperature experiments and right above the copper rod for the low temperature experiments. The distance between the samples to the detectors was calibrated by the NIST (640c) silicon standard.

\subsubsection{X-ray Diffraction Data Processing}

The images of the diffraction patterns are processed by the Fit2d software [49] and were converted to two theta versus intensity spectra. The whole group of images obtained in one experiment for a certain sample was processed by a macro, which guaranteed that the processing parameters for the whole group were constant. The spectrums were then fitted by Rietveld refinement using GSAS software [50], by which the lattice parameters and the interatomic distances are obtained. The atomic positions of rare earth and $\mathrm{Fe}$ atoms in $\mathrm{R}_{2} \mathrm{Fe}_{14} \mathrm{~B}$ phase, as well as the thermal factors for all atoms and peak profiles were also refined. The peak shape was refined with a pseudo-Voigt function. The experimental pattern shows very good signal-noise ratio and the calculated patterns fits it very well. The wRp of the refinement is less than $5 \%$ normally. 


\subsubsection{Differential Scanning Calorimetry}

Differential Scanning Calorimetry (DSC) measures the temperature and heat flow associated with transitions in materials as a function of time and temperature in controlled atmosphere. The measurements provide quantitative and qualitative information about physical and chemical changes that involve endothermic or exothermic processes.

With DSC, the Curie temperatures of samples were determined. During the measurements, the samples were heated up with $20^{\circ} \mathrm{C} / \mathrm{min}$ and cooled down at the same rate and heated up again. The measurements were carried out using powder samples in a hermetically sealed aluminum pan.

\subsubsection{The Rietveld Method [51]}

The Rietveld Method is a full diffraction pattern analysis, in which the least -squares refinement are carried out until the best fit is obtained between the entire observed powder diffraction pattern and the entire calculated pattern based on the simultaneously refined models for the crystal structure, diffraction optics effects, instrumental factors, and other specimen characteristics as may be desired and can be modeled. The key feature of the method is that a crystal structure model is needed and all the rest work is to refine the structure by minimizing the difference between the calculated and observed patterns. The quantity minimized in the least-squares refinement is the residual $S_{y}$,

$$
S_{y}=\sum_{i} W_{i}\left(y_{i}-y_{c i}\right)^{2}
$$

where

$$
W_{i}=1 / y_{i}
$$




$$
\begin{aligned}
& y_{i}=\text { observed (gross) intensity at the } i^{\text {th }} \text { step, } \\
& y_{c i}=\text { calculated intensity at the } i^{\text {th }} \text { step }
\end{aligned}
$$

and the sum is over all data points.

The powder diffraction pattern of crystalline materials maybe thought of as a collection of individual reflection profiles, each of which has a peak height, a peak position, tails decay gradually with distance from the peak maximum position, and an integrated area which is proportional to the Bragg intensity, $I_{k}$, where $K$ stands for the Miller indices, $H, K, L . I_{k}$ is proportional to the square of the absolute value of the structure factor $F_{k}$.

It is a crucial feature of the Rietveld method that no effort is made in advance to allocate observed intensity to particular Bragg reflections nor to resolve overlapped reflections. The method is a structure refinement method instead of a structure solution method. As a result, a reasonably good starting model is needed.

At any arbitrarily chosen point, the intensity $y_{j}$ consists of contribution from many Bragg reflections. The calculated intensities $\mathrm{y}_{\mathrm{ci}}$ are determined from the $\mathrm{F}_{\mathrm{k}}{ }^{2}$ values calculated from the structural model by summing of the calculated contributions from neighboring Bragg reflections plus the background:

$$
y_{c i}=s \sum_{K} L_{K}\left|F_{K}\right|^{2} \Phi\left(2 \theta_{i}-2 \theta_{K}\right) P_{K} A S_{r} E+y_{b i}
$$

where

$s$ is the scale factor

$\mathrm{K}$ is the Miller indices, $\mathrm{h}, \mathrm{k}, \mathrm{l}$ for a Bragg reflection

$\mathrm{L}_{\mathrm{K}}$ contains the Lorentz, polarization and multiplicity factors

$\Phi$ is the reflection profile function 
$P_{k}$ is the preferred orientation function

$A$ is the absorption factor

$\mathrm{S}_{\mathrm{r}}$ is the surface roughness factor

$\mathrm{E}$ is an extinction factor

$F_{K}$ is the structure factor for the $K^{\text {th }}$ Bragg reflection and $y_{b i}$ is the background intensity at the $i^{\text {th }}$ step.

The structure factor, $\mathrm{F}_{\mathrm{K}}$, is given by

$$
F_{K}=\sum_{j} N_{j} f_{j} \exp \left[2 \pi i\left(h x_{j}+k y_{j}+l z_{j}\right)\right] \exp \left[-M_{j}\right]
$$

where

$\mathrm{h}, \mathrm{k}, \mathrm{l}$ are the Miller indices,

$x_{j}, y_{j}$ and $z_{j}$ are the position parameters of the $\mathrm{j}^{\text {th }}$ atom in the unit cell,

$$
M_{j}=8 \pi^{2} \overline{\mu_{s}^{2}} \sin ^{2} \theta / \lambda^{2}
$$

$\overline{\mu_{s}^{2}}$ is the root-mean-square thermal (and random static) displacement of the $\mathrm{j}^{\text {th }}$ atom parallel to the diffraction vector, and $\mathrm{N}_{\mathrm{j}}$ is the site occupancy multiplier for the $\mathrm{j}^{\text {th }}$ atom site.

The reflection profile function approximates the effects of both instrumental features and possibly, specimen features, specimen displacement, and specimen caused broadening. The dependence of the breadth $\mathrm{H}$ of the reflection profiles measured as full-width-at-halfmaximum(FWHM) has typically been modeled as

$$
H^{2}=U \tan ^{2} \theta+V \tan \theta+W
$$

where $U, V, W$ are the refinable parameters. The most useful analytical profile functions are Gaussian(G) and Lorentzian (L) functions. The Gaussian function is, 


$$
\frac{C_{0}^{1 / 2}}{H_{K} \pi^{1 / 2}} \exp \left(-C_{0}\left(2 \theta_{i}-2 \theta_{K}\right)^{2} / H_{K}^{2}\right)
$$

the Lorentzian function is,

$$
\frac{C_{1}^{1 / 2}}{\pi H_{K}} 1 /\left[1+C_{1} \frac{\left(2 \theta_{i}-2 \theta_{K}\right)^{2}}{H_{K}^{2}}\right]
$$

where $\mathrm{H}_{\mathrm{k}}$ is the full-width-at-half-maximum (FWHM) of the $\mathrm{K}^{\text {th }}$ Bragg reflection. $\mathrm{C}_{0}$ $=4 \ln 2$ and $C_{1}=4$.

The least squares minimization procedures lead to a set of normal equations involving derivatives of all the calculated intensities, $\mathrm{y}_{\mathrm{ci}}$, with respect to each adjustable parameter and are soluble by inversion of the normal matrix with elements $M_{j k}$ formally given by

$$
M_{j k}=-\sum_{i} 2 w_{j}\left[\left(y_{i}-y_{c i}\right) \frac{\partial^{2} y_{c i}}{\partial x_{j} \partial x_{k}}-\left(\frac{\partial y_{c i}}{\partial x_{j}}\right)\left(\frac{\partial y_{c i}}{\partial x_{k}}\right)\right]
$$

where $x_{j}, x_{k}$ are the adjustable parameters. The least square procedure provides the value of parameters constituting the local minimum closest to the starting value. Because the relationships between the adjustable parameters and the intensities are non-linear, the starting model must be close to the correct model or the non-linear least squares procedure will not lead to the global minimum. Rather, the procedure will either diverge or lead to a false minimum if the starting point is in its domain.

The model parameters that may be refined include atom positional, thermal and siteoccupancy parameters and parameters for the background, lattice, instrumental geometricaloptical features, specimen aberrations and specimen reflection-profile broadening agents such as crystallite size and microstrain. The parameters can be refined separately or simultaneously. Multiple phases can be also refined simultaneously and the comparative 
analysis of the separate overall scale factors for the phases offers what is probably the most reliable method for doing quantitative phase analysis.

The quality of the refinement can be given numerically in terms of agreement indices or $R$ values. The weighted profile $R$ value, $R_{w p}$ is defined as

$$
R_{w p}=\left\{\sum_{i} w_{i}\left[y_{i}(o b s)-y_{i}(c a l c)\right]^{2} / \sum_{i} w_{i}\left[y_{i}(o b s)\right]^{2}\right\}^{1 / 2} \quad \text { eq. } 1-10
$$

where $y_{i}(o b s)$ is the observed intensity at step I, $y_{i}(c a l c)$ is the calculated intensity and $w_{i}$ is the weight. The expression in the numerator is the value that is minimized during a Rietveld refinement.

\subsubsection{Introduction of Synchrotron Radiation Light Source}

The synchrotron radiation is generated when the speed or trajectory of high speed charged particle is changed. The particles (electrons) in the beam that orbits the APS storage ring are accelerated when their trajectory is altered by the bending magnets that make the beam travel in a circle. The x-rays emitted at each of these bends go off in a direction tangential to the arc of the particle beam.

The insertion device (ID) is an earmark of the third generation synchrotron light sources. The ID is a linear array of north-south permanent magnets with alternating polarity are inserted into the straight sections of the path of changed particles. Depends on the magnetic fields and distance between the individual magnets, the ID can be wiggler or undulator. The beamlines used in this thesis were all undulator beamlines (6ID and 1ID), which is characterized as high-energy high-brilliance beams. 


\subsection{REFERENCES}

${ }^{1}$ E. F. Wasserman, Ferromagnetic Materials, 5 (1990) 237.

${ }^{2}$ J. J. Croat, J. F. Herbst, R. W. Lee and F. E. Pinkerton, Appl. Phys. Lett., 44 (1984) 148.

${ }^{3}$ N. C. Koon and B. N. Das, J. Appl. Phys., 55 (1984) 2063.

${ }^{4}$ G. C. Hadjipanayis, R. C. Hazelton and K. R. Lawless, Appl. Phys. Lett., 43 (1983) 797.

${ }^{5}$ A. V. Andreev, A.V. Deryagin, S.M. Zadvorkin and S.V. Terent'ev, Sov. Phys. Solid State. 27(6) (1985) 987.

${ }^{6}$ A. V. Andreev and M.I Bartashevich, J. Less-Common Metals, 162 (1990) 33.

${ }^{7}$ A. V. Andreev, F.R. de Boer, T.H. Jacobs and K.H.J. Buschow. J. Magn. Magn. Mater., 104-107 (1992) 1305-1307.

${ }^{8}$ A.V. Andreev, J. Magn. Magn. Mater., 140-144 (1995) 961-964.

${ }^{9}$ H. Fujii, H. Nagata, Y. Uwatoko, T. Okamoto, H. Yamamoto and M. Sagawa, J. Magn. Magn. Mater., 70 (1987) 331.

${ }^{10}$ D. Givord and R. Lemaire, W. J. James, J.M. Moreau and J.S. Shah, IEEE Trans. Magn., MAG-7 (1971) 657.

"D. Givord and R. Lemaire, IEEE Trans. Magn., 10 (1974) 109.

${ }^{12}$ D. Gignoux, D. Givord, F. Givord and R. Lemaire, J. Magn. Magn. Mater., 10 (1979) 288.

${ }^{13}$ K. H. J. Buschow, R. Grossinger, J. of the Less-Common Met, 135 (1987) 39.

${ }^{14}$ K. H. J. Buschow, J. Less-Common Met., 144 (1988) 65.

${ }^{15}$ T. H. Jacobs, K.H.J. Buschow, H.Muller and R. Grossinger. J. Magn. Magn. Mater., 115 (1992) 260.

${ }^{16}$ P. C. Ezekwenna, M. Shumsky, W.J. James and Ph. l' Heritier. J. Magn. Magn. Mater., 168 (1997) 149-153

${ }^{17}$ S. A. Nikitin, E.A. Ovtchenkov, I.S. Tereshina, A.A. Salamova and V.N. Verbetsky, J. Magn. Magn. Mater., 195 (1999) 464.

${ }^{18}$ J. L. Wang, M.R. Ibarra, C. Marquina and B. Garcia-landa, J. Appl. Phys., 91 (2002) 8216.

${ }^{19}$ M. J. Kramer, N. Yang, L.H. Lewis, R.W. McCallum and K.W. Dennis, J. Appl. Phys., 91 (2002) 8156.

${ }^{20}$ N. Yang, Dennis KW, McCallum RW, Kramer M J, Zhang YG and Lee P L., J. Appl. Phys., 93 (10) (2003) 7990-7992.

${ }^{21} \mathrm{YW}$, Xu, Yang N, Dennis KW, McCallum RW, Kramer MJ, Zhang YG and Lee PL., J. Appl. Phys., 93 (10) (2003) 7993.

${ }^{22}$ Margulies, L., M. J. Kramer, R. W. McCallum, S. Cycia, D. R. Haeffner, J. C. Lang and A. I. Goldman, Review of Scientific Instruments, 70, No. 9 (1999) 3554.

${ }^{23}$ L. B. McCusker, R.B. Von Dreele, D.E. Cox, D. Louër and P. Scardi, J. Appl. Cryst., 32 (1999) 36-50.

${ }^{24}$ A. E. Clark, Ferromagnetic Materials, 1 (1980) 531.

${ }^{25}$ A. E. Clark and H.Belson, Phys. Rev. B, 5 (1972) 3642.

${ }^{26}$ D. Givord et al, J. Less-Common Metal, 29 (1972) P361.

${ }^{27}$ M. Gueramian, A. Belings, K Yvon and J. Muller, Solid State Commun., 64 (1987) 39.

${ }^{28}$ H-S. Li and J.M.D Coey, Magnetic materials, Vol, 6 (1991).

${ }^{29}$ D. B. de Mooij and K.H.J. Buschow, J. Less-Common Met., 142 (1998) 349.

${ }^{30}$ J. M. D. Coey and H.Sun, J. Magn. Magn. Mater., 87 (1990) L251.

${ }^{31}$ A. V. Andreev, Handbook of Magnetic Materials, 8 (1995) 59. 
${ }^{32}$ K. S. V.L Narasimhan, W.E. Wallace, R.D. Hutchens and J.E. Greedan, AIP Conf. Proc, 18,2 (1974) 1212 .

${ }^{33}$ R. van Mens, J. Magn. Magn. Mater., 61 (1986) 24.

${ }^{34}$ T. Kamimori, K.Kinoshita, J. Mochimaru, K. Konishi, H.Tange, J. Magn. Magn. Mater., 226-230 (2001) 993-995.

${ }^{35}$ M. Sagawa, S. Fujimura, N. Togawa, H. Yamamoto and Y. Matsuura., J. Appl. Phys., 55 (1984) 2083.

${ }^{36}$ J. J. Croat, J. F. Herbst, R.W.Lee and F.E Pinkerton, J. Appl. Phys., 55 (1984) 2078.

${ }^{37}$ J. F. Herbst, Rev. Mod. Phys., 63 (1991) 819.

${ }^{38}$ D. Givord, H. S. Li, J. M. Moreau and R. Perrier, Physica B, 130 (1985) 323.

${ }^{39}$ W. E. Wallace, Prog. Rare Earth Sci. and Tech., Vol. 3 (1968) p.1.

${ }^{40}$ K. H. J. Buschow, Phys. Status Solidi. A, 7 (1971) 199.

${ }^{41}$ I. A. Campbell, J. Phys., F 2 (1972) L47.

${ }^{42}$ K. H. J. Buschow, Rep. Prog. Phys., 40 (1977) 1179.

${ }^{43}$ B. Szpunar and B. Kozarzewski, Phys. Status Solidi. B, 82 (1977) 205.

${ }^{44}$ S. S. Jaswal, Phys. Rev. B., 41 (1990) 9697.

${ }^{45}$ Z-Q. Gu and W. Y. Ching, Phys. Rev. B, 36 (1987) 8530.

${ }^{46}$ J. M. Friedt, A. Vasquez, J. P. Sanchez, P. L'Héritier and R. Fruchart, J. Phys. F, 16 (1986) 651.

${ }^{47}$ F. Grandjean, G. J. Long, D. E. Tharp, O. A. Pringle and W. J. James, J. Phys. (Paris) 49 (1988) C8-581.

${ }^{48}$ J. P. Liu, F.R. de Boer, P.F.de Chatel, R. Coehoorn and K.H.J. Buschow, J. Magn. Magn. Mater., 132(1994) 159-179.

${ }^{49}$ A. P. Hammersley, S. O. Svensson, M. Hanfland, A. N. Fitch and D. Häusermann, "TwoDimensional Detector Software: From Real Detector to Idealized Image or Two-Theta Scan", High Pressure Research, 14 (1996) pp235-248.

${ }^{50}$ A.C. Larson and R.B. Von Dreele, "General Structure Analysis System (GSAS)", Los Alamos National Laboratory Report LAUR 86-748 (2000).

${ }^{51}$ R. A. Young, "Using the Rietveld Method", 1995. 


\title{
CHAPTER 2
}

\section{SPONTANEOUS MAGNETOSTRICTION IN $\mathrm{R}_{2} \mathrm{Fe}_{14} B$}

\author{
$(\mathbf{R}=\mathbf{Y}, \mathrm{Nd}, \mathrm{Gd}, \mathrm{Tb}, \mathrm{Er})$ \\ Ning Yang ${ }^{1}{ }^{2}$, K. W. Dennis ${ }^{1}$, R. W. McCallum ${ }^{1}$ and M. J. Kramer ${ }^{1}$ \\ Yuegang Zhang ${ }^{2}$, Peter L. Lee ${ }^{2}$ \\ A paper prepared for the Journal of Applied Physics
}

\subsection{ABSTRACT}

Thermal expansion anomalies of $\mathrm{R}_{2} \mathrm{Fe}_{14} \mathrm{~B}(\mathrm{R}=\mathrm{Y}, \mathrm{Nd}, \mathrm{Gd}, \mathrm{Tb}, \mathrm{Er}$ ) stoichiometric compounds were studied by $\mathrm{X}$-ray diffraction with high-energy synchrotron radiation using a Debye-Scherrer geometry in temperature range of $\sim 10 \mathrm{~K}$ to $1000 \mathrm{~K}$. A large invar effect with a corresponding large temperature dependence of lattice parameters $\sim 10 \mathrm{~K}$ to $15 \mathrm{~K}$ above their Curie temperatures $\left(T_{\mathrm{c}}\right)$ were observed. The a-axes showed a larger invar effect than the c-axes in all compounds. The spontaneous magnetostrain of the lattices and bonds were calculated. The linear thermal expansion above $T_{c}$ is isotropic for $\mathrm{Y}_{2} \mathrm{Fe}_{14} \mathrm{~B}$ but anisotropic for all the other compounds studied. The iron sub-lattice was shown to dominate the volumetric spontaneous magnetostriction of the compounds and the contribution from the rare earth sublattice is roughly proportional to the spin magnetic moment of the rare earth. The bondlength changes are consistent with the theoretical spin density calculation. The average bond magnetostrains around Fe sites are approximately proportional to their magnetic moments.

\footnotetext{
${ }^{1}$ Ames Laboratory and the Department of Materials Science and Engineering, Iowa State University, Ames IA 50010.

${ }^{2}$ Advanced Photon Source, Argonne National Laboratory, Argonne, IL 60439.
} 


\subsection{INTRODUCTION}

The $\mathrm{R}_{2} \mathrm{Fe}_{14} \mathrm{~B}$ were found as excellent permanent magnetic materials in middle 80 's and propelled permanent magnet research and technology into a new and exciting era ${ }^{1,2,3,4}$. The prototypical compound $\mathrm{Nd}_{2} \mathrm{Fe}_{14} \mathrm{~B}$ sustains the record of energy product and it is the most commonly used material in the family. In addition to the economic advantage and technological interest, the new system also created an extraordinarily fertile area for basic scientific investigation.

The spontaneous magnetostriction of rare earth transition metal compounds has been studied extensively by several groups. ${ }^{5,6,7}$ A.V.Andreev et al. studied the invar anomalies of $\mathrm{R}_{2} \mathrm{Fe}_{14} \mathrm{~B}(\mathrm{R}=\mathrm{Y}, \mathrm{Nd}, \mathrm{Sm})$ using single crystal samples and $\mathrm{x}$-ray diffraction. ${ }^{5}$ Even though his work covered the temperature range from $4 \mathrm{~K}$ to $1000 \mathrm{~K}$, he used only two reflections to determine the lattice parameters. K.H.J. Buschow et al. investigated the volumetric spontaneous magnetostriction of $\mathrm{R}_{2} \mathrm{Fe}_{14} \mathrm{~B}$ with polycrystalline samples by contact dilatometry, providing the information only on average volumetric effects. ${ }^{6}$

The $R_{2} T M_{14} M(R=$ rare earth, $T M=$ transition metals and $M=B, C, N)$ compounds are all isostructural with space group $\mathrm{P} 42 / \mathrm{mnm}$ and form stoichiometric compounds of $2: 14: 1$ of rare earths, transition metals and metalloids respectively. ${ }^{8}$ This allows for various substitutions of magnetic and non-magnetic atoms to probe the magnetic coupling between R-R and R-TM sites. For instance, the magnetic moments of rare earth and Fe in these compounds are coupled ferromagnetically for light rare earths $(\operatorname{Pr}, \mathrm{Nd}, \mathrm{Sm})$, antiferromagnetically for heavy rare earths (Gd, Tb, Dy, Ho, Er, Tm, Yb) or nonmagnetically ( $\mathrm{La}, \mathrm{Ce}, \mathrm{Lu}, \mathrm{Y})$. 
Synchrotron radiation has been proved to be a powerful tool to investigate the structural problems of materials., ${ }^{9,10}$ The high-energy high-flux synchrotron $\mathrm{x}$-ray, combined with two dimensional area detector allows for the collection of data in very short time and the full pattem structural analysis (Rietveld refinement) makes the tracking of the lattice parameters and the atomic coordinates with high accuracy.

In this paper, we have studied the thermal expansion behaviors and spontaneous magnetostriction of a series of $\mathrm{R}_{2} \mathrm{Fe}_{\mathrm{I} 4} \mathrm{~B}$ compounds( $\left.\mathrm{R}=\mathrm{Y}, \mathrm{Nd}, \mathrm{Gd}, \mathrm{Tb}, \mathrm{Er}\right)$ from $10 \mathrm{~K}$ to $1000 \mathrm{~K}$ using high-energy synchrotron $\mathrm{x}$-ray powder diffraction. The samples were selected to cover different magnetic moments rare earth, which will give a good account of the roles of Fe and rare earth sublattices on thermal expansion behaviors of the compounds.

\subsection{EXPERIMENTAL METHODS}

The ingots of samples were prepared by means of arc melting high purity rare earths (99.95\%), Fe (99.99\%) and B (99.5\%) under purified Ar. The arc-melted ingots were melt spun by ejecting the melt through a $0.8 \mathrm{~mm}$ quartz glass orifice onto a copper chill wheel with tangential wheel speed is $25 \mathrm{~m} / \mathrm{s}$ under 250 torr of high purity He. A portion of the resulting ribbon was wrapped in tantalum foil, sealed in silica tube under high purity Argon and annealed at $900^{\circ} \mathrm{C}$ for 12 hours, which guaranteed the complete devitrification of amorphous phase and the formation of the thermodynamically stable phases. The annealed ribbons were ground into powder in an Argon glove box and sealed under Ar in $2 \mathrm{~mm}$ ID thin walled amorphous silica tubes. The Curie temperature of samples was measured by differential scanning calorimeter (DSC) and determined by averaging the peaks position of differential 
heating and cooling curves. The spin reorientation temperature was determined by the differential curve of DC measurement with SQUID.

The synchrotron $\mathrm{x}$-ray diffraction experiments were carried out at two beam lines (1-ID and 6-ID) at the Advanced Photon Source, Argonne National Laboratory. The data were collected with incident energy around $80 \mathrm{KeV}(\lambda \approx 0.155 \AA)$, employing Mar345 image plate detector systems with $0.1 \times 0.1 \mathrm{~mm}$ pixel size. The samples were heated from room temperature to $1000 \mathrm{~K}$ in a specially designed high temperature synchrotron $\mathrm{x}$-ray diffraction furnace with the temperature accuracy of $\pm 1 \mathrm{~K}^{9}$ For the low temperature regime, a cryostat was employed with a specially designed $\mathrm{x}$-ray window for collection of the full Debye rings and an improved sample mount for recording temperatures accurately. The samples were cooled down to $10 \mathrm{~K}$ first and then gradually heated up to $300 \mathrm{~K}$. The data were collected every $20 \mathrm{~K}$ for both of the configurations.

The images collected were processed and reduced to intensity versus $2 \theta$ spectra using Fit2D software. ${ }^{11}$ The patterns were then refined by Rietveld method using GSAS software package. ${ }^{12,13}$ The lattice parameters, peak shape profiles, atomic coordinates and thermal parameters for all atoms were refined simultaneously. The peak shape was refined with a pseudo-voigt profile function.

\subsection{RESULTS}

At different beamlines, the experimental setups were different, but $\mathrm{Q}$ was kept around $8 \AA^{-}$ ${ }^{1}$ for all the patterns, which gave sufficient number of reflections allowing for a reliable refinement of the variables. The experimental diffraction patterns show excellent signal-tonoise ratio and the calculated patterns fit the experimental patterns very well. The refined 
thermal factors of rare earth and Fe atoms increase linearly with temperature, as expected. The background and the peak shape profile parameters vary less than $10 \%$ and the wRp of the refinements is below $5 \%$.

Strong spontaneous magnetostriction was observed in all of the samples (Figure 2-1, Figure 2-2 and Figure 2-3). The lattice parameters of the samples determined (Table 2-1) at room temperature are very close to the published values, ${ }^{8}$ which confirms the structural and chemical reliabilities of the samples and the accuracy of the experimental configuration. The minima of the curves are observed to occur at about $10 \mathrm{~K}$ to $15 \mathrm{~K}$ higher than their measured Curie temperatures (Table 2-1), as shown in Figure 2-3. This effect was also observed in several other families of related R-T intermetallics and has been attributed to the existence of

short-range magnetic order above $T_{c}{ }^{14,15,16,17}$ In the low temperature regime measurements, a sharp dimensional change of the unit cell (Figure 2-4, Figure 2-5, Figure 2-6) around the spin reorientation temperature was observed for the $\mathrm{Nd}_{2} \mathrm{Fe}_{14} \mathrm{~B}$ sample.

From the full pattern Rietveld refinement, the atomic coordinates as a function of temperature can be obtained. Combined with the precise determination of the lattice parameters, the temperature dependences of the bond-length can be determined. The temperature dependence of the bond length between $\mathrm{Fe}(\mathrm{k} 1)$ and $\mathrm{Fe}(\mathrm{k} 1)$ sites and between $\mathrm{Fe}(\mathrm{kl})$ and $\mathrm{Fe}(\mathrm{k} 2)$ sites in the $\mathrm{Fe}$ sublattice are shown in Figure 2-7 and Figure 2-8.

\subsection{DISCUSSIONS}

\subsubsection{The Thermal Expansion Anomalies}

From Figure 2-1 and Figure 2-2, it can be seen that a-axes have stronger spontaneous magnetostriction than c-axes, which is strongly related to their axial magnetic anisotropy. In 
$\mathrm{R}_{2} \mathrm{Fe}_{14} \mathrm{~B}$, the magnetic moments are aligned parallel to the easy axis (c-axis) and induce more lattice contraction in the basal plane as temperature increased.

The thermal expansion of the compounds depends on two contributions, the phononic lattice expansion and the magnetic ordering. The change of lattice parameters for different temperatures normalized to the values expected in the absence of magnetic moments is its magnetostrain, defined as:

$$
\begin{aligned}
& \lambda_{a}=\left(a-a_{0}\right) / a_{0} \\
& \lambda_{c}=\left(c-c_{0}\right) / c_{0} \\
& \omega_{s}=\left(V-V_{0}\right) / V_{0}
\end{aligned}
$$

where $a_{0}, c_{0}$ and $V_{0}$ are values extrapolated from the paramagnetic state. The extrapolations were based on Debye theory,

$$
a_{r}=a_{0}+A T F(\theta / T)
$$

where $a_{0}$ and $A$ are constants. $F(\theta / T)=\frac{1}{T} \int_{0}^{r} C_{V} d T$ is a tabulated function. The a-axes have stronger magnetostrain than c-axes, as listed in Table 2-1. Among the samples, $\mathrm{Tb}_{2} \mathrm{Fe}_{14} \mathrm{~B}$ undergoes the largest volumetric spontaneous magnetostrain, whereas the values for $\mathrm{Y}_{2} \mathrm{Fe}_{14} \mathrm{~B}, \mathrm{Nd}_{2} \mathrm{Fe}_{14} \mathrm{~B}$ and $\mathrm{Er}_{2} \mathrm{Fe}_{14} \mathrm{~B}$ are quite close to each other (Figure 2-9).

Above the Curie temperature, the thermal expansion has only the contribution from phononic lattice expansion and is linear. The temperature dependences of c-axes over a-axes are shown in Figure 2-10. It can be seen that in $\mathrm{Nd}_{2} \mathrm{Fe}_{14} \mathrm{~B}, \mathrm{Gd}_{2} \mathrm{Fe}_{14} \mathrm{~B}, \mathrm{~Tb}_{2} \mathrm{Fe}_{14} \mathrm{~B}$ and $\mathrm{Er}_{2} \mathrm{Fe}_{14} \mathrm{~B}$, a-axes expand faster than c-axes. The thermal expansion coefficients of a-axes are bigger than that of the c-axes (Table 2-1). The result is in good agreement with previous work., 
The anisotropic thermal expansion was thought to be due to the magnetocrystalline anisotropy, which is dominated by the rare earth contribution produced by the crystal-field splitting of the $4 \mathrm{f}$ shell. ${ }^{8,18}$ The thermal expansion of $\mathrm{Y}_{2} \mathrm{Fe}_{14} \mathrm{~B}$ was determined to be isotropic in the paramagnetic temperature range and can be related to the non-magnetic state of $Y$ sublattice. The thermal expansion behaviors in the paramagnetic temperature range confirm the conclusion that the rare earth sublattice dominates the magnetocrystalline anisotropy of the $\mathrm{R}_{2} \mathrm{Fe}_{14} \mathrm{~B}$ structures. ${ }^{8}$

\subsubsection{Spin Reorientation of $\mathrm{Nd}_{2} \mathrm{Fe}_{14} \mathrm{~B}$}

The spin reorientation or the change of the direction of easy axis, occurs at $135 \mathrm{~K}$ in $\mathrm{Nd}_{2} \mathrm{Fe}_{14} \mathrm{~B} .{ }^{19,20,21}$ Below $135 \mathrm{~K}$, the net magnetization rotates away from c-axis to [110] direction and reaches $30^{\circ}$ at $4 \mathrm{~K}^{8}$ From Figure 2-4, Figure 2-5 and Figure 2-6, we can see that there is a quite sharp volumetric change corresponding to the spin reorientation temperature $\left(\mathrm{T}_{\mathrm{s}}\right)$. Assuming the spin reorientation is responsible for the anomalous thermal expansion below $135 \mathrm{~K}$, it appears that the spin reorientation has stronger effect on thermal expansion of a-axis than that of c-axis. Below $\mathrm{T}_{\mathrm{s}}$, the a-axis undergoes a low rate of thermal expansion then increases suddenly to a plateau around $T_{s}$. This effect can be explained as the rotation of easy direction back to $\mathrm{c}$-axis enhances the magnetization along $\mathrm{c}$-axis and expands the a-axis due to the higher magnetic ordering.

The volumetric change associated with the $T_{s}$ is smaller in our study, $-0.05 \%$, compared with previous result, $-0.1 \%{ }^{5}$ The difference may be due to the different sample preparation; single crystal versus annealed melt spun ribbons, or due to experimental bias; extrapolation of two reflections versus full pattern refinement. 


\subsubsection{The Size Effects of Rare Earth Ion}

The lattice parameters and unit cell volumes (Figure 2-11) of $\mathrm{R}_{2} \mathrm{Fe}_{14} \mathrm{~B}$ decrease through the sample series (Nd, Gd, Tb, Er) due to the lanthanide contraction (Table 2-1). The $c$-axis decreases more than the $a$-axis suggesting that the basal plane dimension is controlled more by the stable trigonal Fe-B prisms than by the size of $\mathrm{R}$ ions. ${ }^{8}$ Figure $2-12$ shows the magnetostrain of $c$-axes of $\mathrm{Nd}_{2} \mathrm{Fe}_{14} \mathrm{~B}, \mathrm{Gd}_{2} \mathrm{Fe}_{14} \mathrm{~B}$ and $\mathrm{Tb}_{2} \mathrm{Fe}_{14} \mathrm{~B}$ versus the length of $c$-axes. For these three samples, the shorter the $c$-axis, the higher the magnetostrain along $c$-axis becomes, consistent with negative interaction theory. ${ }^{22}$ In this theory, the magnetostriction is caused by the negative interaction between specific Fe sites with very short bond length. Since the differences in the $c$-axes are mainly due to the ionic radii of the rare earth ions, the smaller the rare earth, the larger the negative interaction between the rare earth and $\mathrm{Fe}$ becomes. The observation of a larger magnetostrain with decreasing ionic radii of the rare earth supports the negative interaction theory.

\subsubsection{The Role of Fe Sublattice}

The reduced volumetric magnetostriction curves (Figure $2-13),\left(\omega(\mathrm{T}) / \omega(10 \mathrm{~K}) \mathrm{vs} . \mathrm{T} / \mathrm{T}_{\mathrm{c}}\right)$, allows for a quantitative cross comparison of the various compounds. In general, all the curves overlapped each other. In $\mathrm{Y}_{2} \mathrm{Fe}_{14} \mathrm{~B}$, the $\mathrm{Y}$ ion is non-magnetic; therefore, studying $\mathrm{Y}$ Fe compounds gives a good account of the properties of Fe sublattice. ${ }^{5}$ With the consideration of the isotypical structure of $\mathrm{R}_{2} \mathrm{Fe}_{14} \mathrm{~B}$, this similarity can only be attributed to the Fe sublattice.

It has been shown that volumetric spontaneous magnetostriction of the Fe sublattice is proportional to the squared Fe sublattice magnetization with temperature, following a 
parabolic curve. ${ }^{5,23}$ The reduced volumetric magnetostrictive curves show a good fit with parabolic shaped curve, which suggests the spontaneous magnetostriction of $R_{2} \mathrm{Fe}_{14} \mathrm{~B}$ phases is dominated by the Fe sublattice as previously reported. ${ }^{5}$

Figure 2-14 shows the Fe sublattice composed of 5 independent Fe sites, Fe(k1), Fe(k2), $\mathrm{Fe}(\mathrm{j} 1), \mathrm{Fe}(\mathrm{j} 2)$ and $\mathrm{Fe}(\mathrm{e})$. The $\mathrm{Fe}(\mathrm{j} 2)$ sites are located in the center of the subalttice. The shape and dimension change of the sublattice can be determined by the refinement of lattice and atomic coordinates. Comparing the shape of the sublattice with temperature shows that the sublattice shrinks in the basal plane and collapses around the $\mathrm{Fe}(\mathrm{j} 2)$ site as the temperature increases. This result is fully consistent with the theoretical work of $\mathrm{Gu}$ and Ching, using the orthogonalized linear combination of atomic orbital (OLCAO) method, showed that the spin density distribution corresponded only to the Fe sublattice. ${ }^{24}$ Their theoretical work shows the spin moments are more distributed along the basal plane than c-axis within the $\mathrm{Fe}$ sublattice. Figure 2-15 is the contour map of spin density distribution on (110) plane of the $\mathrm{Nd}_{2} \mathrm{Fe}_{14} \mathrm{~B} .{ }^{24}$ Since orbital magnetic moment of $\mathrm{Fe}$ is "quenched", only the spin moment contributes to the exchange interaction. The higher the spin moment density, the stronger the interaction is between neighboring sites and therefore the larger the spontaneous magnetostriction. The stronger spontaneous magnetostrain along a-axis is consistent with the higher spin moment density calculated in the basal plane. Along c-axis, only the interaction between $\mathrm{Fe}(\mathrm{e})$ sites on the edge induce the relative position movement of two iron subnets mirrored at $\mathrm{z}=1 / 2$. As a result, the lower spin moment density distribution induces a subtle change of the $\mathrm{Fe}(\mathrm{j} 2)$ sites position. 


\subsubsection{The Role of R Sublattice}

Although the spontaneous magnetostrictive behaviors of $\mathrm{R}_{2} \mathrm{Fe}_{14} \mathrm{~B}$ compounds are dominated by the Fe sublattice, the contribution of the rare earth sublattice can still be separated and quantified using the non-magnetic $\mathrm{Y}$ ion compound. To a first order approximation, we can subtract the magnetostrain of $\mathrm{Y}_{2} \mathrm{Fe}_{14} \mathrm{~B}$ from that of the $\mathrm{Nd}, \mathrm{Gd}, \mathrm{Er}$ and $\mathrm{Tb}$ compounds to extract the contribution of rare earth sublattice to the magnetostrain. The subtractions as well as the percentage of the contribution of the rare earth sublattice are listed in Table 2-2. Comparing the volumetric contribution from the rare earth sublattice as a function of the total magnetic moment $(\mathrm{g} J)$ of the rare earth ion shows a good linear relation among the $\mathrm{Nd}, \mathrm{Gd}$ and $\mathrm{Tb}$ samples but the Er sample deviates significantly from the line (Figure 2-16). This suggests that the total magnetic moment is not the factor dominating the contribution of the rare earth sublattices. Even though the Er ion has a large total magnetic moment, the spin magnetic moment is only $3 / 2 \mu$, the same value as Nd ion (Table 2-2). Since $\mathrm{Er}$ and Nd sublattices have smaller contributions to the spontaneous magnetostriction of the structure while the contributions from $\mathrm{Gd}$ and $\mathrm{Tb}$ sublattices are much bigger with their larger spin magnetic moments, it would imply that it is the spin moments that contributes to the magnetostrain (Figure 2-17).

Finally, the contribution of the $\mathrm{R}$ sublattice is independent of the sign of the coupling between $\mathrm{R}$ and $\mathrm{Fe}$ sublattices, which is also due to the spin moment of the rare earth. Although the $\mathrm{Gd}, \mathrm{Tb}$ and Er sublattices are coupled antiferromagnetically while the Nd sublattice is coupled ferromagnetically with the Fe sublattice, the spin moment of rare earth and Fe are always antiparallel. ${ }^{8}$ 


\subsubsection{Spontaneous Magnetostrain of the Bonds}

In $\mathrm{R}_{2} \mathrm{Fe}_{14} \mathrm{~B}$ structure, six out of eight sublayers are formed by $\mathrm{Fe}$ atoms and therefore majority of the bonds are between two neighboring Fe sites. For instance, the $\mathrm{Fe}(\mathrm{kI})-\mathrm{Fe}(\mathrm{kl})$ bonds show a large magnetostriction behavior (Figure 2-8) while the $\mathrm{Fe}(\mathrm{k1})-\mathrm{Fe}(\mathrm{k} 2)$ bonds show a much weaker magnetostriction or even linear thermal expansion (Figure2-9). Comparing similar bonds between compounds with different rare earths, the thermal expansion behaviors are very similar. The relative magnetostrain curves are nearly overlapped, suggesting a similar underlying mechanism (Figure 2-18 and Figure 2-19).

The spontaneous magnetostrains of bonds with length less than $4 \AA$ in the studied $\mathrm{R}_{2} \mathrm{Fe}_{14} \mathrm{~B}$ samples are listed in Table 2-3. Some bonds between rare earth and Fe sites show very large magnetostrains; $(\mathrm{R}(\mathrm{f})-\mathrm{Fe}(\mathrm{kl}), \mathrm{R}(\mathrm{f})-\mathrm{Fe}(\mathrm{e})$ and $\mathrm{R}(\mathrm{g})-\mathrm{Fe}(\mathrm{k} 2))$, suggesting that strong exchange coupling does exist between the rare earth and Fe sites and it is independent of the sign of the couplings. Only two bonds between rare earth sites are less than $4 \AA$ and they both show a moderate invar effect. The calculations showed that the $4 \mathrm{f}$ radial matrix elements $\langle\mathrm{r}\rangle_{4 \mathrm{f}}$ are less than $1 \AA$, smaller than the separations of nearest rare earth sites. ${ }^{25} \mathrm{As}$ a result, direct exchange between $\mathrm{R}$ spins is negligible and the $\mathrm{R}-\mathrm{R}$ exchange can be expected to be significantly weaker than $\mathrm{Fe}-\mathrm{Fe}$ and $\mathrm{R}-\mathrm{Fe}$ interactions. Although this point has been emphasized previously ${ }^{26,27,28}$, conflicting studies ${ }^{29,30}$ emphasize that the molecular-field coefficients of the R-R ( $n_{R R}$ ) and $R-F e\left(n_{R F}\right)$ are the same order for some heavy rare earth compounds, suggesting that R-R interactions are non-negligible for those compounds. Our results are consistent with the second argument suggesting that the $\mathrm{R}-\mathrm{R}$ exchange is mediated by the rare earth $5 \mathrm{~d}$ electrons as well. 
It was previously proposed that the very short bonds in the R-Fe compounds are responsible for their large invar effect. ${ }^{31}$ The anomalous thermal expansion in the ferromagnetic region is the results of the competition between magnetic energy and elastic energy. In this theory, the shorter the bond distance, the larger the magnetostrain becomes. But the results of this study show a much more complex behavior. It has also been proposed that the $\mathrm{Fe}-\mathrm{Fe}$ molecular field coefficient $\left(\mathrm{n}_{\mathrm{FF}}\right)$ that describes the $\mathrm{Fe}-\mathrm{Fe}$ exchange interactions is most strongly influenced by local environmental effects, especially the mean local $\mathrm{Fe}$ coordination number. ${ }^{32}$ In the $\mathrm{R}_{2} \mathrm{Fe}_{14} \mathrm{~B}$ structures, the shortest bond distances are between $\mathrm{Fe}(\mathrm{j} 1)-\mathrm{Fe}(\mathrm{j} 1)$ and $\mathrm{Fe}(\mathrm{j} 1)-\mathrm{Fe}(\mathrm{k} 2)$. At room temperature, they are about $0.1 \AA$ shorter than the bonds in $\alpha-\mathrm{Fe}$. The previous neutron diffraction studies show a further shortening when cooled down from $300 \mathrm{k}$ to $20 \mathrm{~K} .^{33,34}$ Our results show the $\mathrm{Fe}(\mathrm{j} 1)-\mathrm{Fe}(\mathrm{j} 1)$ bond distance decreases as cooled from above $T_{c}$ to $10 \mathrm{~K}$ while the $\mathrm{Fe}(\mathrm{j} 1)-\mathrm{Fe}(\mathrm{k} 2)$ bond distance shows a very typical invar effect.

The different $\mathrm{R}$ and $\mathrm{Fe}$ sites contribute differently to the spontaneous magnetostriction, which is determined by the exchange interactions between the site and its first neighbors. For example, all the bonds between $\mathrm{Fe}(\mathrm{j} 2)$ and its neighboring sites have relatively larger bond length and magnetostrain, which may be related to the largest magnetic moment of the $\mathrm{Fe}(\mathrm{j} 2)$ sites. In order to quantify the contribution of different sites, the average magnetostrain of the bonds surrounding the site were calculated (Table 2-4). It can be seen that the $\mathrm{Fe}(\mathrm{j} 1)$ and $\mathrm{Fe}(\mathrm{j} 2)$ sites sustain larger average bonds magnetostrain, which means a greater contribution to the spontaneous magnetostriction. The $\mathrm{Fe}(\mathrm{k} 1)$ and $\mathrm{Fe}(\mathrm{k} 2)$ have moderate contribution whereas the $\mathrm{Fe}(\mathrm{e})$ and $\mathrm{Fe}(\mathrm{c})$ sites have the smallest contributions. 
It has been shown experimentally that the $\mathrm{Fe}(\mathrm{j} 2)$ sites have the largest while $\mathrm{Fe}(\mathrm{e})$ and $\mathrm{Fe}(\mathrm{c})$ have smallest magnetic moments ${ }^{35-39}$ in $\mathrm{R}_{2} \mathrm{Fe}_{14} \mathrm{~B}(\mathrm{R}=\mathrm{Y}, \mathrm{Nd}, \mathrm{Er})$. For the other Fe sites, there are disagreements about the magnitude of the magnetic moment, especially the relative magnitude of $\mathrm{Fe}(\mathrm{j} 1), \mathrm{Fe}(\mathrm{k} 1)$ and $\mathrm{Fe}(\mathrm{k} 2)$ sites. For instance, some experimental work ${ }^{36,37}$ has shown that in $\mathrm{Y}_{2} \mathrm{Fe}_{14} \mathrm{~B}$, the $\mathrm{Fe}(\mathrm{j} 1)$ sites have a larger moment than $\mathrm{Fe}(\mathrm{k} 1)$ and $\mathrm{Fe}(\mathrm{k} 2)$ while others ${ }^{38,39,40}$ have contrary conclusions. In our study, the Fe(j1) and Fe(j2) have comparable and larger contributions than all the other sites. Comparing the site moment of $\mathrm{Fe}(\mathrm{j} 2)$ and $\mathrm{Fe}(\mathrm{k} 1), \mathrm{Fe}(\mathrm{k} 2), \mathrm{Fe}(\mathrm{e})$ and $\mathrm{Fe}(\mathrm{c})$, it is very likely the average bonds magnetostrain around $\mathrm{Fe}$ site is proportional to the magnetic moment of the site. A similar result was obtained and also

from the study of $\mathrm{R}_{2} \mathrm{Fe}_{17}{ }^{41}$ Following that, the $\mathrm{Fe}(\mathrm{j} 1$ ) should have larger moment than all the other sites except Fe(j2).

\subsection{CONCLUSIONS}

During the course of this investigation of spontaneous magnetostriction of $\mathrm{R}_{2} \mathrm{Fe}_{14} \mathrm{~B}$ compounds by high-energy synchrotron $\mathrm{x}$-ray powder diffraction, huge invar effects wete observed and the thermal expansion behaviors were determined quantitatively. Although the light rare earths and heavy rare earths are exchange coupled differently with Fe sublattice, the contributions of the different rare earths sublattice to the spontaneous magnetostriction of unit cell are quite similar and relatively minor compared with those of Fe sublattice. The contribution of the rare earth sublattice to the structural spontaneous magnetostriction is roughly proportional to the spin magnetic moment of the rare earth. The study has confirmed that the spontaneous magnetostriction extends to temperatures substantially above $T_{c}$ and 
supports the argument that the local iron moments in iron base metallic materials do not disappear above $T_{c}$.

The iron sublattice between basal plane and middle mirror plane collapses during the spontaneous magnetostriction. This is consistent with the theoretical calculation of $\mathrm{Fe}$ sublattice spin density distribution. The bonds between $\mathrm{Fe}(\mathrm{j} 2)$ and its neighboring sites have relatively larger magnetostrain, which can be related to its largest magnetic moment. The average bonds magnetostrain around one site may be considered as an indicator of its magnetic moment.

\subsection{ACKNOWLEDGEMENTS}

The work at Ames Laboratory was supported by the United States Department of Energy (USDOE), Office of Science (OS), Office of Basic Energy Sciences (BES), through Iowa State University under Contract W-7405-ENG-82. The Midwest Universities Collaborative Access Team (MUCAT) sector at the APS is supported by the U.S. Department of Energy, Basic Energy Sciences, Office of Science, through the Ames Laboratory under Contract No. W-7405-Eng-82. Use of the Advanced Photon Source was supported by the U.S. Department of Energy, Basic Energy Sciences, Office of Science, under Contract No. W-31-109-Eng-38. 


\subsection{CAPTIONS}

Table 2-1. Curie temperatures $\left(\mathrm{T}_{\mathrm{c}}\right)$, Lattice parameters $a$ and $c$ (room temperature), linear spontaneous magnetostrains $\lambda_{\mathrm{a}}$ and $\lambda_{\mathrm{c}}$ in the basal plane and along the $\mathrm{c}$ axis and volumetric spontaneous magnetostrain $\omega_{\mathrm{s}}(\mathrm{T}=10 \mathrm{~K})$. The thermal expansion coefficients of $\mathrm{R}_{2} \mathrm{Fe}_{14} \mathrm{~B}$ in the paramagnetic range $\alpha_{a}, \alpha_{c}$ and $\alpha_{\mathrm{y}}$.

Table 2-2. The subtraction of the magnetostrain of $\mathrm{Y}_{2} \mathrm{Fe}_{14} \mathrm{~B}$ from that of $\mathrm{Nd}_{2} \mathrm{Fe}_{14} \mathrm{~B}$, $\mathrm{Gd}_{2} \mathrm{Fe}_{14} \mathrm{~B}, \mathrm{~Tb}_{2} \mathrm{Fe}_{14} \mathrm{~B}$ and $\mathrm{Er}_{2} \mathrm{Fe}_{14} \mathrm{~B}$ compounds.

Table 2-3. The bond lengths and spontaneous magnetostrain of all the bonds $(<4 \AA)$ in the studied $\mathrm{R}_{2} \mathrm{Fe}_{14} \mathrm{~B}$ samples, the notations are after Herbst et al.

Table 2-4. The average bonds magnetostrain around the atomic sites in $\mathrm{R}_{2} \mathrm{Fe}_{14} \mathrm{~B}$ samples studied.

Figure 2-1. The temperature dependences of a-axes of studied $\mathrm{R}_{2} \mathrm{Fe}_{14} \mathrm{~B}$ samples.

Figure 2-2. The temperature dependences of $\mathrm{c}$-axes of studied $\mathrm{R}_{2} \mathrm{Fe}_{14} \mathrm{~B}$ samples.

Figure 2-3. The temperature dependences of unit cell volumes of studied $\mathrm{R}_{2} \mathrm{Fe}_{14} \mathrm{~B}$ samples, the arrows indicate the Curie temperatures of samples.

Figure 2-4. The temperature dependence of a-axis along with spin reorientation in $\mathrm{Nd}_{2} \mathrm{Fe}_{14} \mathrm{~B}$.

Figure 2-5. The temperature dependence of $c$-axis along with spin reorientation in $\mathrm{Nd}_{2} \mathrm{Fe}_{14} \mathrm{~B}$.

Figure 2-6. The temperature dependence of unit cell volume along with spin reorientation in $\mathrm{Nd}_{2} \mathrm{Fe}_{14} \mathrm{~B}$.

Figure 2-7. Temperature dependences of the bond lengths between $\mathrm{Fe}(\mathrm{k} 1)$ and $\mathrm{Fe}(\mathrm{k} 1)$ sites in the Fe sublattice.

Figure 2-8. Temperature dependences of the bond lengths between $\mathrm{Fe}(\mathrm{k} 1)$ and $\mathrm{Fe}(\mathrm{k} 2)$ sites in the Fe sublattice. 
Figure 2-9. The volumetric spontaneous magnetostrain of the studied $\mathrm{R}_{2} \mathrm{Fe}_{14} \mathrm{~B}$ phases.

Figure 2-10. The temperature dependences of the length ratio of c-axes over a-axes.

Figure 2-11. The volume of unit cells vs. the covalent radius of rare earth ion.

Figure 2-12. The magnetostrain along c-axes vs. the lattice parameters of c-axes.

Figure 2-13. The temperature dependences of the relative volumetric magnetostrain.

Figure 2-14. The Fe sublattice between $z=0$ and $z=1 / 2$ in $R_{2} \mathrm{Fe}_{14} \mathrm{~B}$ unit cell.

Figure 2-15. The theoretical spin density distribution on the (110) plane of $\mathrm{Nd}_{2} \mathrm{Fe}_{14} \mathrm{~B}$.

Figure 2-16. The volumetric magnetostrain subtraction in Table 2-2 vs. the rare earth ion magnetic moments gJ.

Figure 2-17. The volumetric magnetostrain subtraction in Table 2-2 vs. the rare earth spin magnetic moments $\mathrm{S}$.

Figure 2-18. Temperature dependences of the relative magnetostrains of $R(g) F e(e)$ bonds in the studied samples.

Figure 2-19. Temperature dependences of the relative magnetostrains of $\mathrm{Fe}(\mathrm{j} 2) \_\mathrm{Fe}(\mathrm{k} 1)$ bonds in the studied samples. 
Table 2-1. Curie temperatures $\left(\mathrm{T}_{\mathrm{c}}\right)$, Lattice parameters $a$ and $c$ (room temperature), linear spontaneous magnetostrains $\lambda_{\mathrm{a}}$ and $\lambda_{\mathrm{c}}$ in the basal plane and along the $\mathrm{c}$ axis and volumetric spontaneous magnetostrain $\omega_{s}(T=10 \mathrm{~K})$. The thermal expansion coefficients of $\mathrm{R}_{2} \mathrm{Fe}_{14} \mathrm{~B}$ in the paramagnetic range $\alpha_{a}, \alpha_{c}$ and $\alpha_{\gamma_{\text {. }}}$

\begin{tabular}{|c|c|c|c|c|c|c|c|c|c|}
\hline Sample & $\begin{array}{c}\mathrm{Tc}(\mathrm{DSC}) \\
(\mathrm{K}) \\
( \pm 3 \mathrm{~K})\end{array}$ & $\begin{array}{c}a \\
(\AA) \\
( \pm 0.001)\end{array}$ & $\begin{array}{c}c \\
(\AA) \\
( \pm 0.001)\end{array}$ & $\begin{array}{c}\lambda_{\mathrm{a}} \\
10^{-3} \\
( \pm 0.01)\end{array}$ & $\begin{array}{c}\lambda_{\tau_{c}} \\
10^{-3} \\
( \pm 0.01)\end{array}$ & $\begin{array}{c}\boldsymbol{\omega}_{\mathrm{s}} \\
10^{-3} \\
( \pm 0.03)\end{array}$ & $\begin{array}{c}\alpha_{\mathrm{a}} \\
10^{-5} \mathrm{~K}^{-1} \\
(+0.01)\end{array}$ & $\begin{array}{c}\alpha_{\mathrm{c}} \\
10^{-5} \mathrm{~K}^{-1} \\
( \pm 0.01)\end{array}$ & $\begin{array}{c}\alpha_{\mathrm{V}} \\
10^{-5} \mathrm{~K}^{-\mathrm{t}} \\
( \pm 0.03)\end{array}$ \\
\hline $\mathrm{Y}_{2} \mathrm{Fe}_{14} \mathrm{~B}$ & 564 & 8.751 & 12.035 & 8.22 & 5.41 & 22.60 & 1.26 & 1.26 & 3.82 \\
\hline $\mathrm{Nd}_{2} \mathrm{Fe}_{14} \mathrm{~B}$ & 586 & 8.799 & 12.207 & 8.83 & 5.01 & 22.90 & I. 29 & 1.18 & 3.77 \\
\hline $\mathrm{Gd}_{2} \mathrm{Fe}_{\mathrm{i} 4} \mathrm{~B}$ & 660 & 8.777 & 12.096 & 10.04 & 5.90 & 27.86 & 1.34 & 1.25 & 3.99 \\
\hline $\mathrm{Tb}_{2} \mathrm{Fe}_{14} \mathrm{~B}$ & 621 & 8.765 & 12.064 & 11.57 & 6.93 & 31.07 & 1.32 & 1.19 & 3.89 \\
\hline $\mathrm{Er}_{2} \mathrm{Fe}_{14} \mathrm{~B}$ & 552 & 8.731 & 11.974 & 9.08 & 5.84 & 24.10 & 1.27 & 1.24 & 3.75 \\
\hline
\end{tabular}


Table 2-2. The subtraction of the magnetostrain of $\mathrm{Y}_{2} \mathrm{Fe}_{14} \mathrm{~B}$ from that of $\mathrm{Nd}_{2} \mathrm{Fe}_{14} \mathrm{~B}, \mathrm{Gd}_{2} \mathrm{Fe}_{14} \mathrm{~B}, \mathrm{~Tb}_{2} \mathrm{Fe}_{14} \mathrm{~B}$ and $\mathrm{Er}_{2} \mathrm{Fe}_{14} \mathrm{~B}$ compounds.

\begin{tabular}{|c|c|c|c|c|c|c|c|c|}
\hline Sample & $\begin{array}{c}\mathrm{gJ} \\
\left(\mu^{1} \mathrm{M}\right)\end{array}$ & $\begin{array}{c}S \\
\left(\mu_{M}\right)\end{array}$ & $\begin{array}{c}\lambda_{R, R} \\
10^{-3} \\
( \pm 0.01)\end{array}$ & $\begin{array}{c}\lambda_{\mathrm{es}, \mathrm{R}} \\
10^{-3} \\
( \pm 0.01)\end{array}$ & $\begin{array}{c}\omega_{5, R} \\
10^{-3} \\
( \pm 0.03)\end{array}$ & $\begin{array}{c}\lambda_{\mathrm{a}, \mathrm{R}} / \lambda_{\mathrm{a}} \\
(\%) \\
( \pm 0.01) \\
( \pm 0.0)\end{array}$ & $\begin{array}{c}\lambda_{c, R} / \lambda_{c} \\
(\%) \\
( \pm 0.0 \mathrm{~L})\end{array}$ & $\begin{array}{c}\omega_{s, n} / \omega_{s} \\
(\%) \\
(+0.03)\end{array}$ \\
\hline $\mathrm{Y}_{2} \mathrm{Fe}_{14} \mathrm{~B}$ & 0 & 0 & 0 & 0 & 0 & 0 & 0 & 0 \\
\hline $\mathrm{Nd}_{2} \mathrm{Fe}_{\mathrm{l4}} \mathrm{B}$ & 3.3 & $3 / 2$ & 0.61 & -0.4 & 0.3 & $6.91 \%$ & $-7.98 \%$ & $1.31 \%$ \\
\hline $\mathrm{Gd}_{2} \mathrm{Fe}_{14} \mathrm{~B}$ & 7 & $7 / 2$ & 1.82 & 0.49 & 5.26 & $18.13 \%$ & $8.31 \%$ & $18.88 \%$ \\
\hline $\mathrm{Tb}_{2} \mathrm{Fe}_{14} \mathrm{~B}$ & 9 & 3 & 3.35 & 1.52 & 8.47 & $28.95 \%$ & $21.93 \%$ & $27.26 \%$ \\
\hline $\mathrm{Er}_{2} \mathrm{Fe}_{14} \mathrm{~B}$ & 9 & $3 / 2$ & 0.86 & 0.43 & 1.5 & $9.47 \%$ & $7.36 \%$ & $6.22 \%$ \\
\hline
\end{tabular}


Table 2-3. The bond lengths and spontaneous magnetostrain of all the bonds $(<4 \AA)$ in the studied $\mathrm{R}_{2} \mathrm{Fe}_{14} \mathrm{~B}$ samples, the notations are after Herbst et al.

\begin{tabular}{|c|c|c|c|c|c|c|}
\hline Bond & $\begin{array}{c}\text { Bondlength } \\
(\AA) \\
(300 \mathrm{~K})\end{array}$ & $\begin{array}{c}\mathrm{Y}_{2} \mathrm{Fe}_{14} \mathrm{~B} \\
\lambda \times 10^{-3} \\
( \pm 0.5)\end{array}$ & $\begin{array}{c}\mathrm{Nd}_{2} \mathrm{Fe}_{14} \mathrm{~B} \\
\lambda \times 10^{-3} \\
( \pm 0.5)\end{array}$ & $\begin{array}{c}\mathrm{Gd}_{2} \mathrm{Fe}_{14} \mathrm{~B} \\
\lambda \times 10^{-3} \\
( \pm 0.5)\end{array}$ & $\begin{array}{c}\mathrm{Tb}_{2} \mathrm{Fe}_{14} \mathrm{~B} \\
2 \times 10^{-3} \\
( \pm 0.5)\end{array}$ & $\begin{array}{c}\mathrm{Er}_{2} \mathrm{Fe}_{14} \mathrm{~B} \\
\lambda \times 10^{-3} \\
( \pm 0.5)\end{array}$ \\
\hline$R(f) \_R(g)$ & $3.75-3.79$ & 5.5 & 6.5 & 3.7 & 3.2 & 5.0 \\
\hline$R(f) \_F e(k 1)$ & $3.03-3.07$ & 8.9 & 8.2 & 10.6 & 10.8 & 10.4 \\
\hline $\mathrm{R}(\mathrm{f}) \_\mathrm{Fe}(\mathrm{k} 2)$ & $3.00 \sim 3.07$ & 2.6 & 5.3 & 3.5 & 1.2 & 1.6 \\
\hline$R(f) \_F e(j 1)$ & $3.20 \sim 3.28$ & 2.2 & 1.0 & 0.4 & 0.3 & 3.5 \\
\hline$R(f) \_F e(j 2)$ & $3.00 \sim 3.06$ & 8.5 & 14.1 & 9.0 & 13.3 & 9.7 \\
\hline $\mathrm{R}(\mathrm{f}) \_\mathrm{Fe}(\mathrm{e})$ & $3.18 \sim 3.20$ & 13.4 & 11.6 & 15.4 & 16.3 & 14.6 \\
\hline$R(f) \_F e(c)$ & $3.10 \sim 3.12$ & 9.2 & 8.8 & 8.8 & 9.8 & 9.0 \\
\hline$R(g) \_R(g)$ & $3.54 \sim 3.55$ & 6.3 & 7.6 & 5.0 & 6.2 & 4.5 \\
\hline $\mathrm{R}(\mathrm{g}){ }_{-} \mathrm{Fe}(\mathrm{kl})$ & $3.03-3.07$ & 10.9 & 8.0 & 10.2 & 13.7 & 10.9 \\
\hline $\mathrm{R}(\mathrm{g}) \_\mathrm{Fe}(\mathrm{k} 2)$ & $3.21-3.28$ & 7.7 & 5.7 & 8.2 & 8.3 & 8.4 \\
\hline $\mathrm{R}(\mathrm{g}) \_\mathrm{Fe}(\mathrm{j} 1)$ & $3,21 \sim 3,29$ & 2.3 & 5.2 & 1.9 & 5.1 & 4.8 \\
\hline $\mathbf{R}(\mathrm{g}) \_F e(j 2)$ & $3.08-3.14$ & 5.4 & 4.6 & 4.6 & 4.4 & 5.1 \\
\hline$R(g) \_F e(c)$ & $3.36 \sim 3.39$ & 10.1 & 9.0 & 10.3 & 11.3 & 10.4 \\
\hline $\mathrm{Fe}(\mathrm{kl}) \mathrm{Fe}(\mathrm{kl})$ & $2.59 \sim 2.60$ & 6.8 & 7.1 & 7.1 & 8.9 & 6.7 \\
\hline $\mathrm{Fe}(\mathrm{k} 1) \_\mathrm{Fe}(\mathrm{k} 2) *$ & $2.51 \sim 2.53$ & 6.3 & 6.0 & 7.2 & 6.1 & 5.5 \\
\hline $\mathrm{Fe}(\mathrm{k} 1) \_\mathrm{Fe}(\mathrm{k} 2)^{* *}$ & $2.45-2.46$ & 14.0 & 15.8 & 11.8 & 16.7 & 13.6 \\
\hline $\mathrm{Fe}(\mathrm{k} 1) \_\mathrm{Fe}(j 1)$ & $2.60 \sim 2.61$ & 12.6 & 12.8 & 13.4 & 11.5 & 9.2 \\
\hline $\mathrm{Fe}(\mathrm{kl}) \_\mathrm{Fe}(\mathrm{e})$ & $2.48 \sim 2.50$ & 4.9 & 7.1 & 6.8 & 5.6 & 7.5 \\
\hline $\mathrm{Fe}(\mathrm{k} 1) \_\mathrm{Fe}(\mathrm{c})$ & $2.54-2.58$ & 10.2 & 7.3 & 8.0 & 10.7 & 9.2 \\
\hline $\mathrm{Fe}(\mathrm{k} 2) \_\mathrm{Fe}(\mathrm{k} 2)$ & $2.55 \sim 2.56$ & 4.1 & 5.5 & 3.9 & 8.0 & 6.6 \\
\hline $\mathrm{Fe}(\mathrm{k} 2) \_\mathrm{Fe}(\mathrm{c})$ & $2.44 \sim 2.50$ & 0.7 & 2.2 & 2.3 & 2.1 & 2.0 \\
\hline $\mathrm{Fe}(\mathrm{j} 1) \_\mathrm{Fe}(\mathrm{k} 2)$ & $2.36 \sim 2.39$ & 13.2 & 10.2 & 11.7 & 11.8 & 12.6 \\
\hline $\mathrm{Fe}(\mathrm{jl})_{-} \mathrm{Fe}(\mathrm{jl})$ & $2.39-2.42$ & 4.5 & 8.5 & 5.3 & 5.4 & 5.7 \\
\hline $\mathrm{Fe}(\mathrm{j} 1)_{-} \mathrm{Fe}(\mathrm{e})$ & $2.50-2.52$ & 10.4 & 13.7 & 12.1 & 16.1 & 8.9 \\
\hline $\mathrm{Fe}(\mathrm{j} 2) \_\mathrm{Fe}(\mathrm{k} 1)^{*}$ & $2.72 \sim 2.76$ & 8.3 & 8.6 & 8.0 & 8.2 & 9.4 \\
\hline $\mathrm{Fe}(\mathrm{j} 2) \_\mathrm{Fe}(\mathrm{k} 1)^{* *}$ & $2.69 \sim 2,71$ & 9.9 & 10.4 & 11.9 & 13.3 & 8.8 \\
\hline $\mathrm{Fe}(\mathrm{j} 2)_{-} \mathrm{Fe}(\mathrm{k} 2)^{*}$ & $2.61 \sim 2.64$ & 9.7 & 10.4 & 11.7 & 12.5 & 8.6 \\
\hline $\mathrm{Fe}(\mathrm{j} 2), \mathrm{Fe}(\mathrm{k} 2)^{* *}$ & $2.64-2.66$ & 14.3 & 11.4 & 12.7 & 14.2 & 13.8 \\
\hline$F e(j 2) \_F e(j 1) *$ & $2.77 \sim 2.78$ & 12.9 & 13.1 & 13.5 & 14.0 & 12.0 \\
\hline$F e(j 2)_{-} F e(j 1)^{* *}$ & $2.64 \sim 2.65$ & 9.6 & 8.2 & 7.9 & 8.3 & 8.4 \\
\hline $\mathrm{Fe}(\mathrm{j} 2) \_\mathrm{Fe}(\mathrm{e})$ & $2.75 \sim 2.77$ & 8.5 & 6.4 & 7.2 & 9.1 & 9.5 \\
\hline $\mathrm{Fe}(\mathrm{e}) \mathrm{Fe}(\mathrm{e})$ & $2.76 \sim 2.82$ & 4.6 & 8.4 & 5.4 & 7.0 & 6.2 \\
\hline
\end{tabular}


Table 2-4. The average bonds magnetostrain around the atomic sites in $\mathrm{R}_{2} \mathrm{Fe}_{14} \mathrm{~B}$ samples studied.

\begin{tabular}{cccccc}
\hline & $\mathrm{Y}_{2} \mathrm{Fe}_{14} \mathrm{~B}$ & $\mathrm{Nd}_{2} \mathrm{Fe}_{14} \mathrm{~B}$ & $\mathrm{Gd}_{2} \mathrm{Fe}_{14} \mathrm{~B}$ & $\mathrm{~Tb}_{2} \mathrm{Fe}_{14} \mathrm{~B}$ & $\mathrm{Er}_{2} \mathrm{Fe}_{14} \mathrm{~B}$ \\
Sample & $\lambda \times 10^{-3}$ & $\lambda \times 10^{-3}$ & $\lambda \times 10^{-3}$ & $\lambda \times 10^{-3}$ & $\lambda \times 10^{-3}$ \\
& $( \pm 0.5)$ & $( \pm 0.5)$ & $( \pm 0.5)$ & $( \pm 0.5)$ & $( \pm 0.5)$ \\
& & & & & \\
\hline $\mathrm{R}(\mathrm{g})$ & 6.9 & 7.7 & 7.3 & 7.4 & 7.3 \\
$\mathrm{R}(\mathrm{f})$ & 7.1 & 6.6 & 6.7 & 7.9 & 7.6 \\
$\mathrm{Fe}(\mathrm{k} 1)$ & 9.1 & 9.4 & 9.3 & 10.1 & 8.7 \\
$\mathrm{Fe}(\mathrm{k} 2)$ & 8.3 & 8.4 & 8.2 & 9.9 & 8.7 \\
$\mathrm{Fe}(\mathrm{j} 1)$ & 11.0 & 10.9 & 10.8 & 11.2 & 9.7 \\
$\mathrm{Fe}(\mathrm{j} 2)$ & 10.5 & 9.8 & 10.4 & 11.4 & 10.1 \\
$\mathrm{Fe}(\mathrm{e})$ & 6.9 & 8.6 & 7.9 & 8.9 & 8.0 \\
$\mathrm{Fe}(\mathrm{c})$ & 5.5 & 4.8 & 5.2 & 6.4 & 5.6 \\
\hline
\end{tabular}




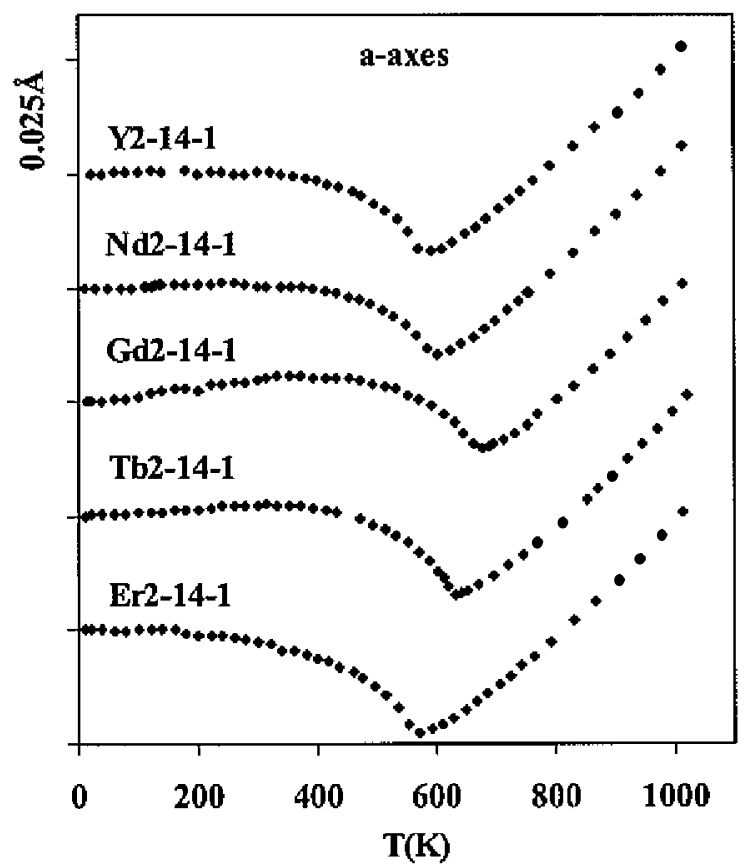

Figure 2-1. The temperature dependences of a-axes of studied $\mathrm{R}_{2} \mathrm{Fe}_{14} \mathrm{~B}$ samples. 


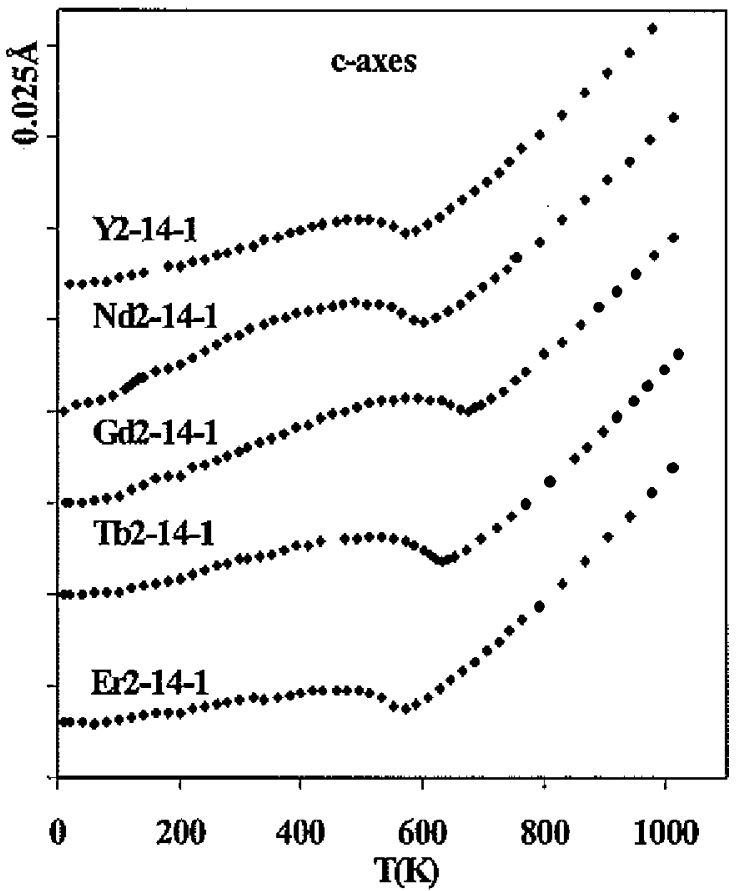

Figure 2-2. The temperature dependences of c-axes of studied $\mathrm{R}_{2} \mathrm{Fe}_{14} \mathrm{~B}$ samples. 


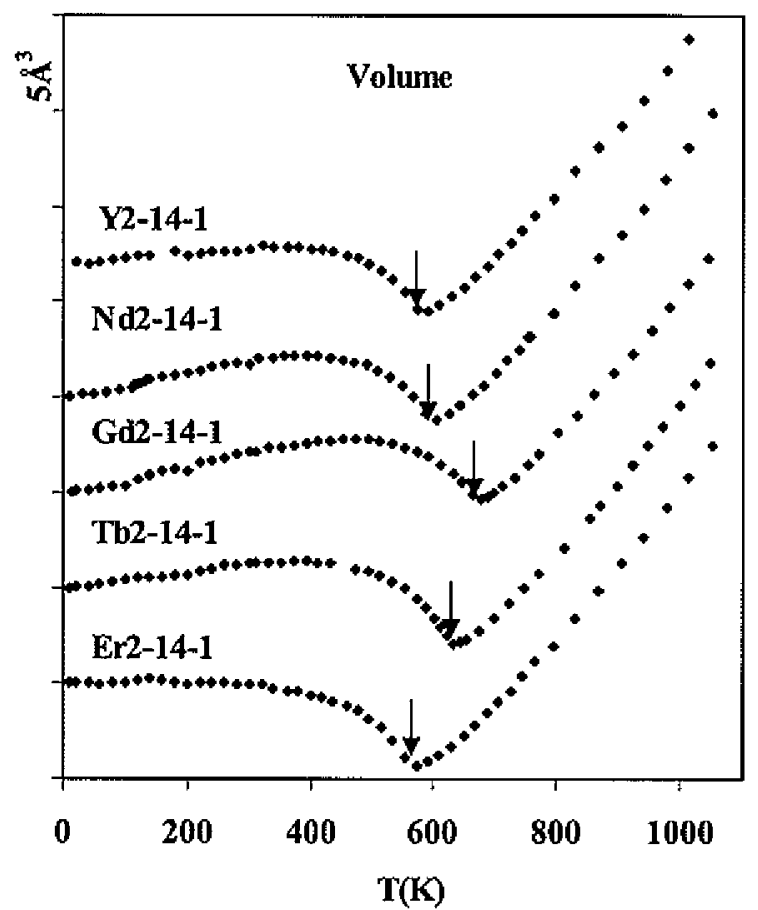

Figure 2-3. The temperature dependences of unit cell volumes of studied $\mathrm{R}_{2} \mathrm{Fe}_{14} \mathrm{~B}$ samples, the arrows indicate the Curie temperatures of samples. 


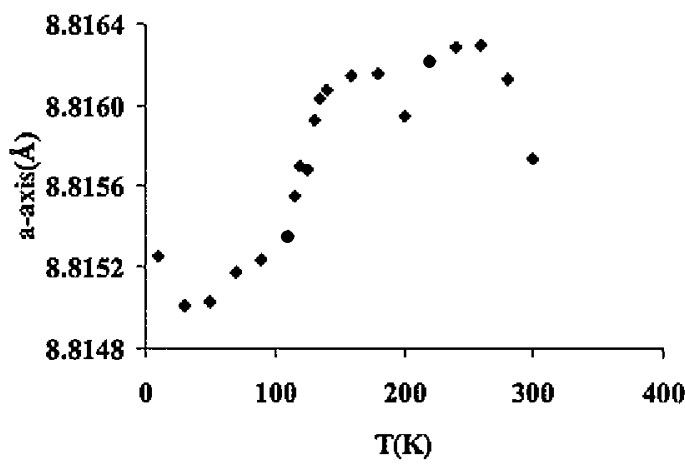

Figure 2-4. The temperature dependence of a-axis along with spin reorientation in $\mathrm{Nd}_{2} \mathrm{Fe}_{14} \mathrm{~B}$. 


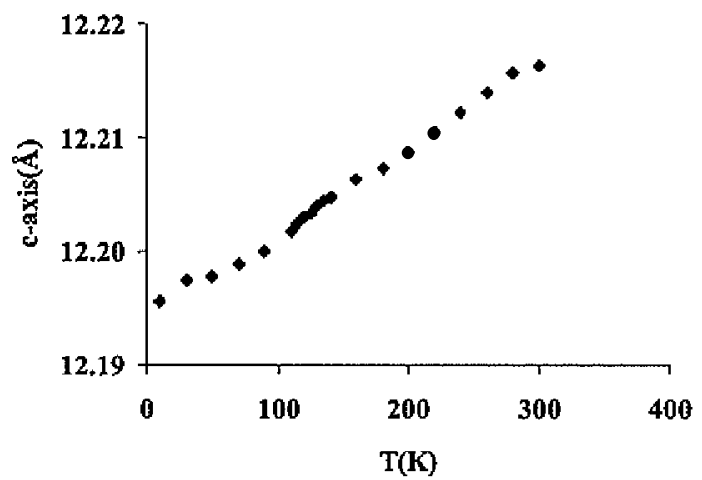

Figure 2-5. The temperature dependence of c-axis along with spin reorientation in $\mathrm{Nd}_{2} \mathrm{Fe}_{14} \mathrm{~B}$. 


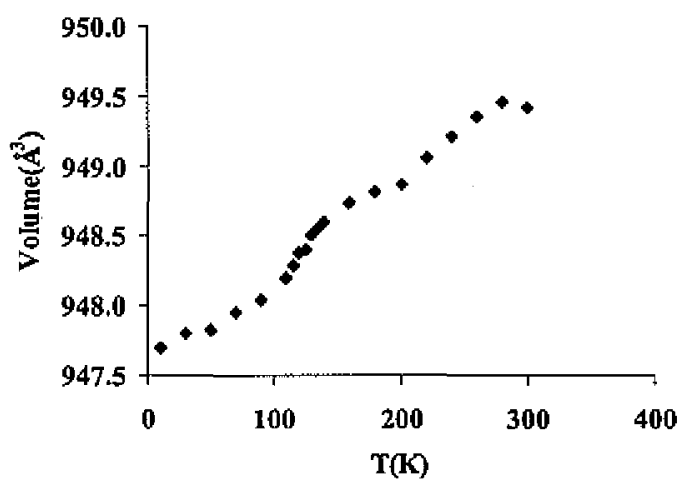

Figure 2-6. The temperature dependence of unit cell volume along with the spin reorientation in $\mathrm{Nd}_{2} \mathrm{Fe}_{14} \mathrm{~B}$. 


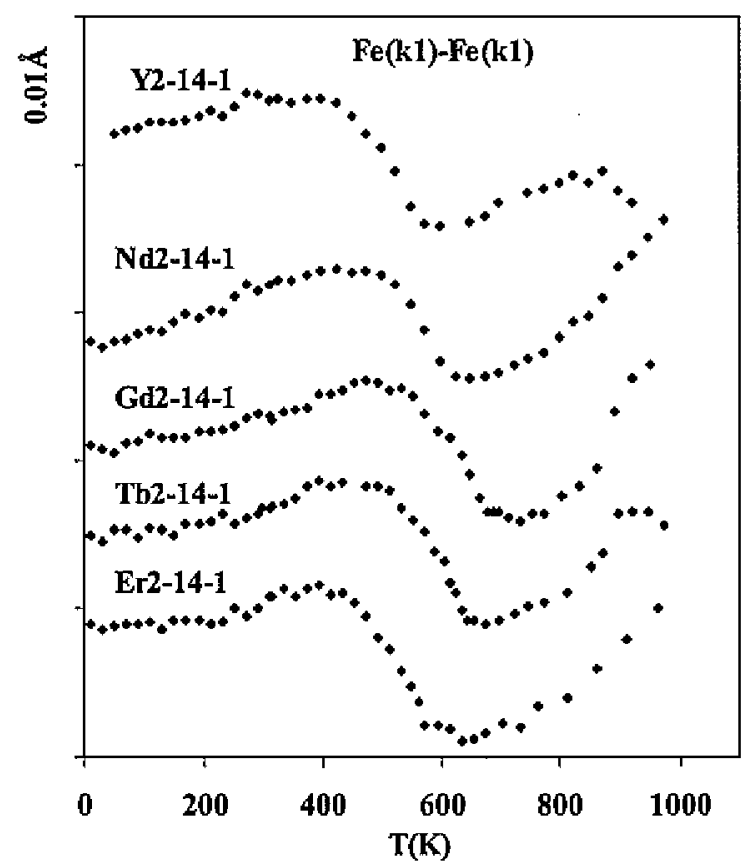

Figure 2-7. Temperature dependences of the bond lengths between $\mathrm{Fe}(\mathrm{k} 1)$ and $\mathrm{Fe}(\mathrm{kl})$ sites in the $\mathrm{Fe}$ sublattice. 


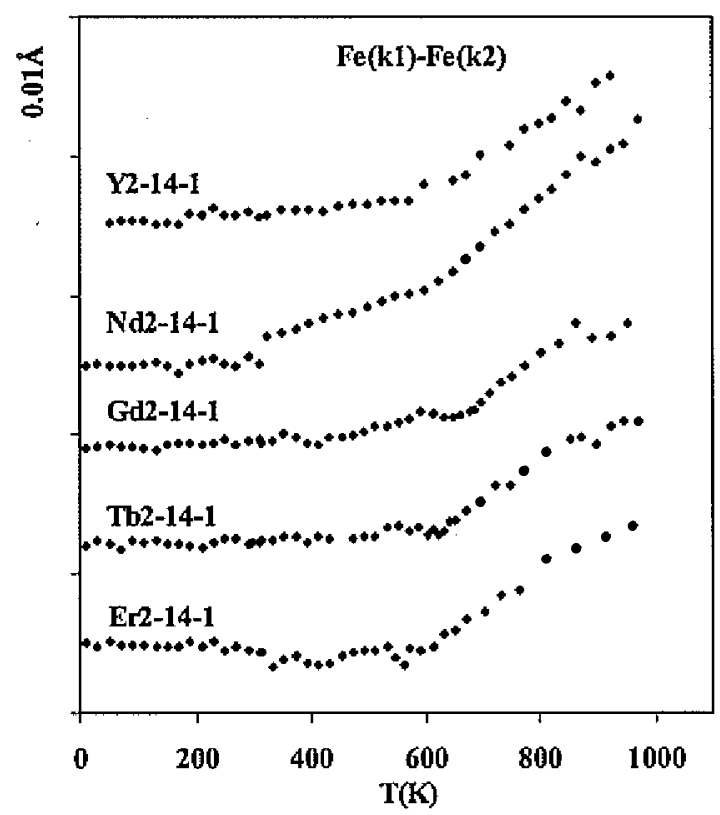

Figure 2-8. Temperature dependence of the bonds length between $\mathrm{Fe}(\mathrm{k} 1)$ and $\mathrm{Fe}(\mathrm{k} 2)$ sites in the Fe sublattice. 


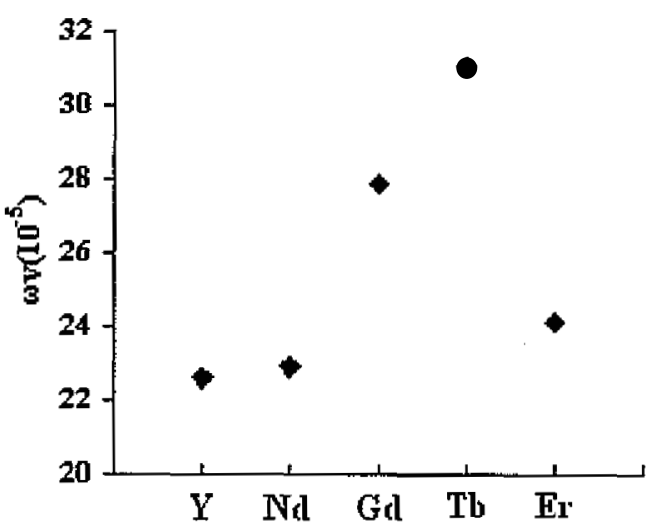

Figure 2-9. The volumetric spontaneous magnetostrain of the studied $\mathrm{R}_{2} \mathrm{Fe}_{14} \mathrm{~B}$ phases. 


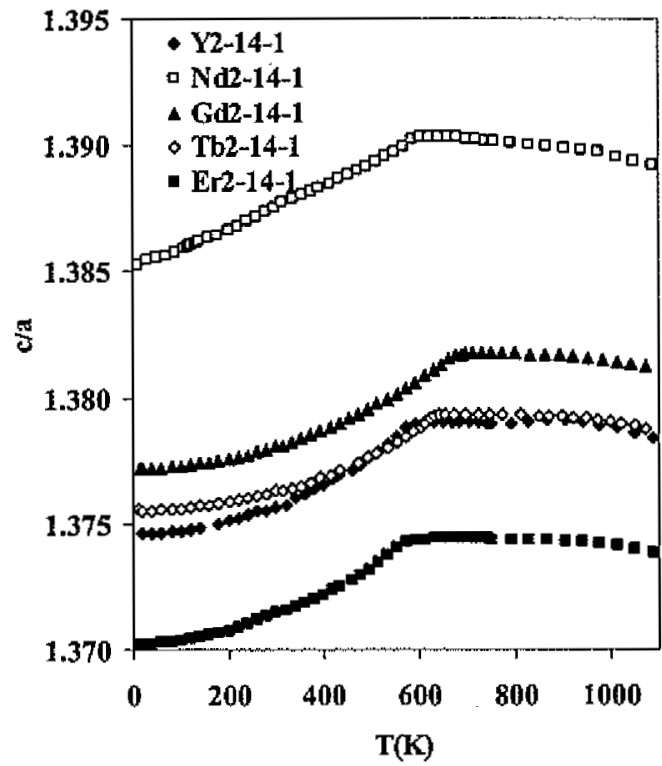

Figure 2-10. The temperature dependences of the length ratio of c-axes over a-axes. 


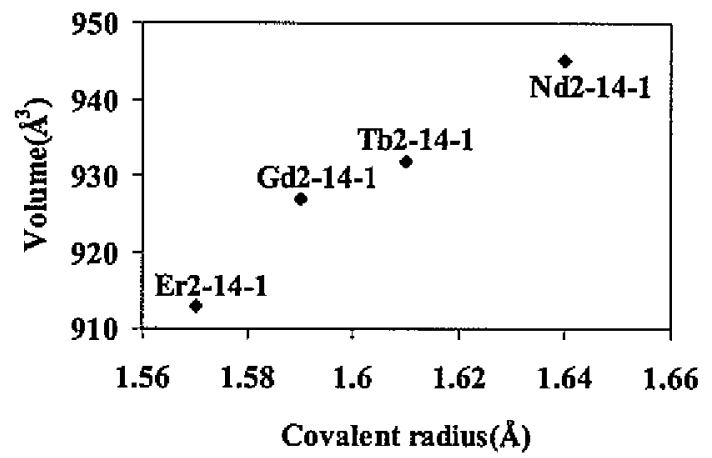

Figure 2-11. The volume of unit cells vs. the covalent radius of rare earth ion. 


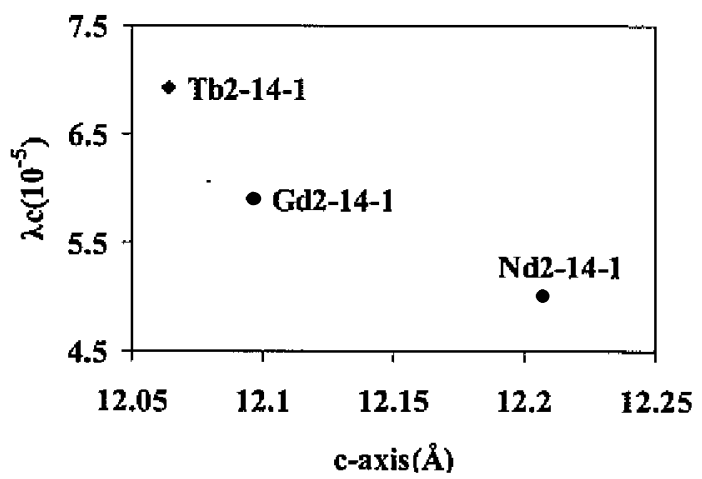

Figure 2-12. The magnetostrain along c-axes vs. the lattice parameters of c-axes. 


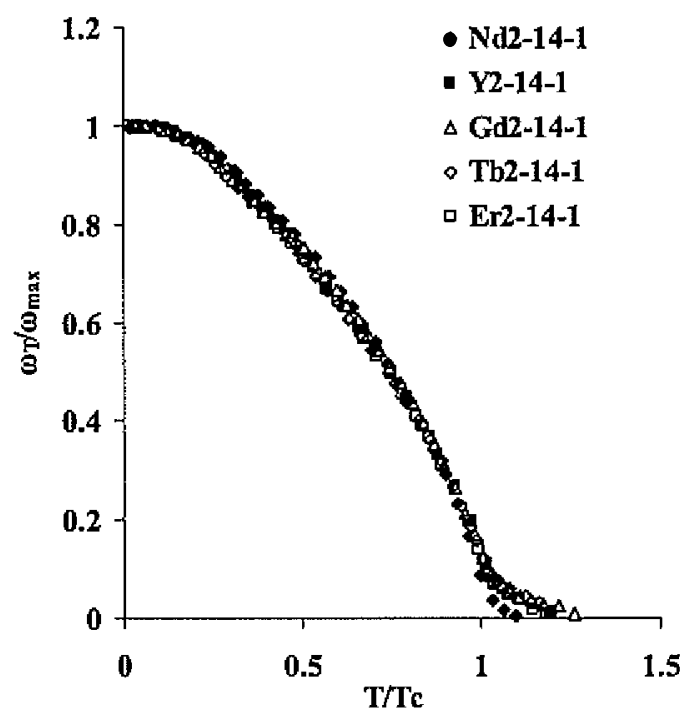

Figure 2-13. The temperature dependences of the relative volumetric magnetostrain. 


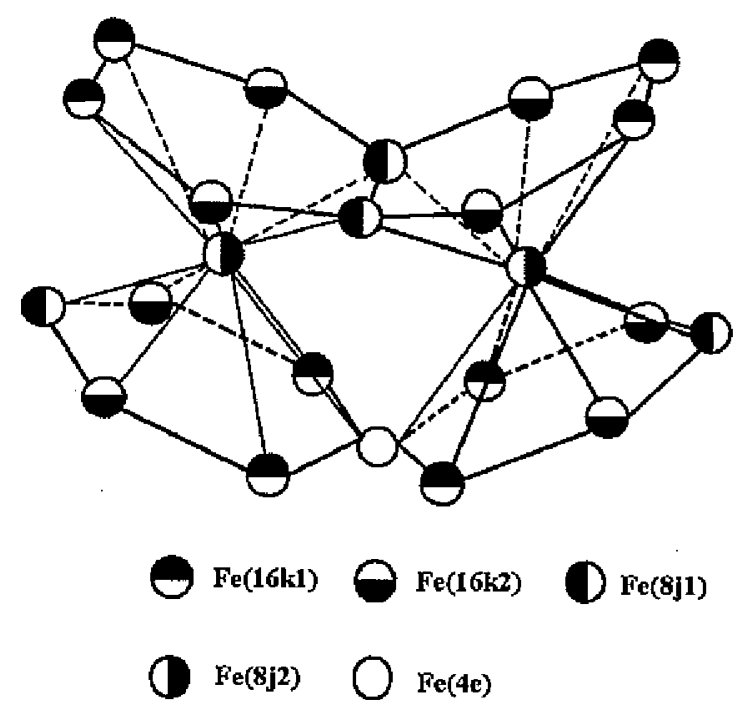

Figure 2-14. The Fe sublattice between $z=0$ and $z=1 / 2$ in $\mathrm{R}_{2} \mathrm{Fe}_{14} \mathrm{~B}$ unit cell. 


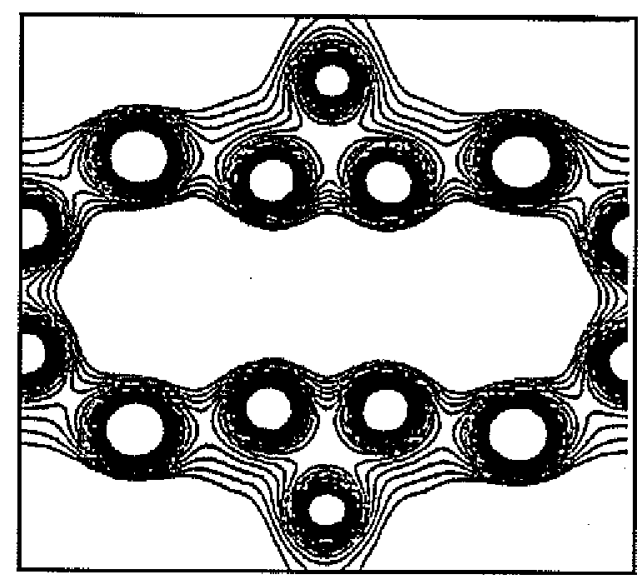

Figure 2-15. The theoretical spin density distribution on the (110) plane of $\mathrm{Nd}_{2} \mathrm{Fe}_{14} \mathrm{~B}$. 


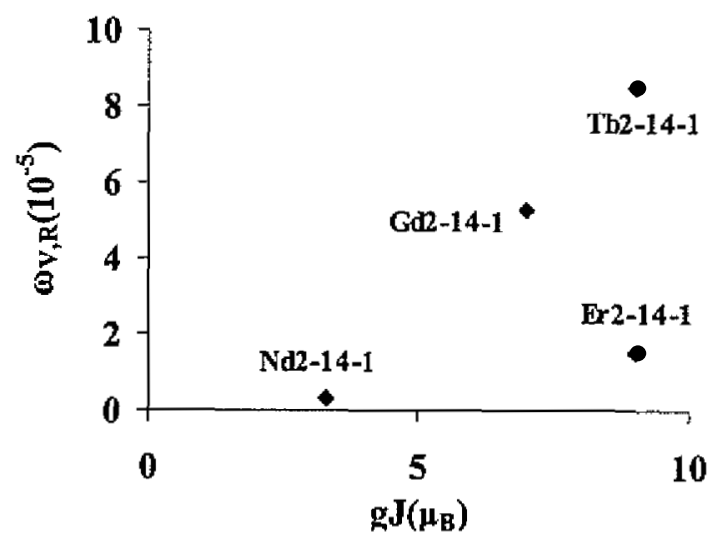

Figure 2-16. The volumetric magnetostrain subtraction in Table $2-2$ vs. the rare earth ion magnetic moments gJ. 


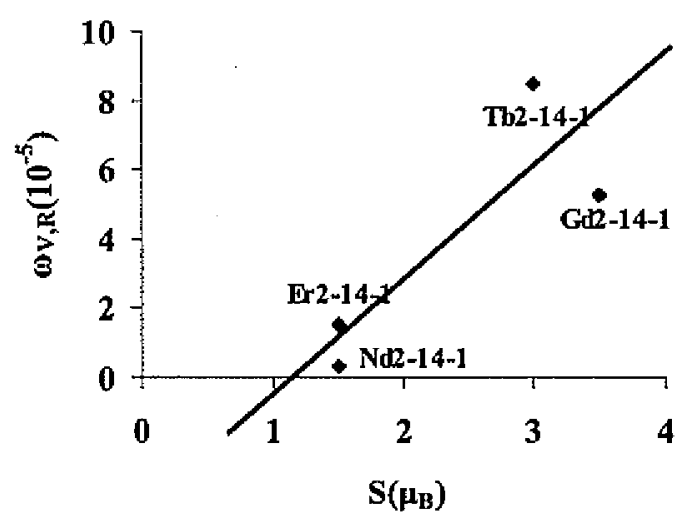

Figure 2-17. The volumetric magnetostrain subtraction in Table $2-2$ vs. the rare earth spin magnetic moments $S$. 


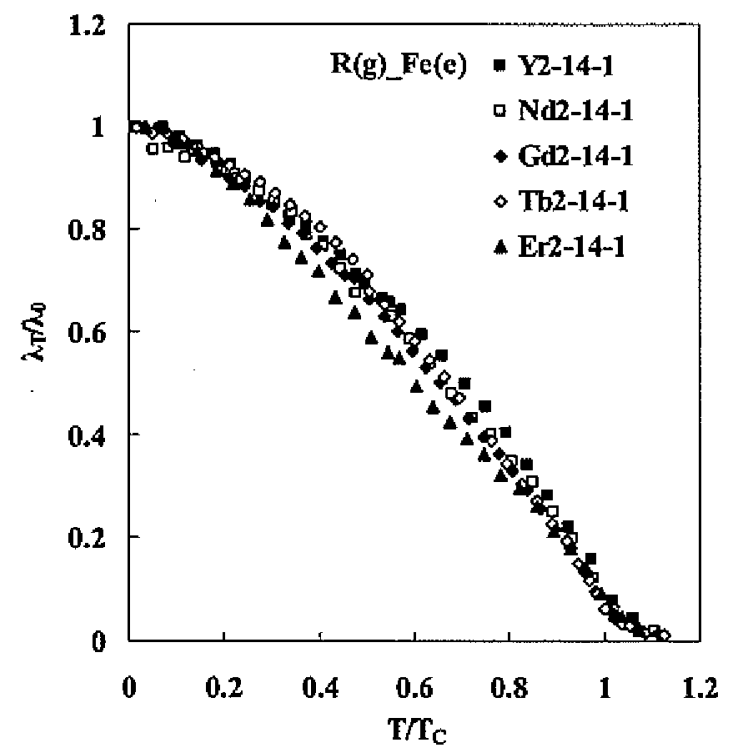

Figure 2-18. Temperature dependences of the relative magnetostrains of $\mathrm{R}(\mathrm{g}) \_\mathrm{Fe}(\mathrm{e})$ bonds in the studied samples. 


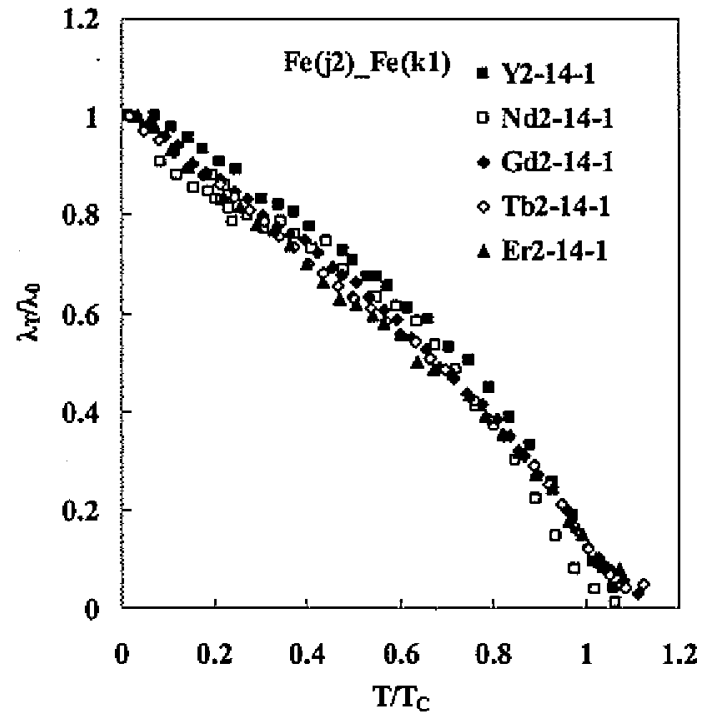

Figure 2-19. Temperature dependences of the relative magnetostrains of $\mathrm{Fe}(\mathrm{j} 2) \_\mathrm{Fe}(\mathrm{kl})$ bonds in the studied samples. 


\subsection{REFERENCE}

${ }^{1}$ J. J. Croat, J. F. Herbst, R. W. Lee, and F. E. Pinkerton, Appl. Phys. Lett., 44 (1984) 148.

2 J. J. Croat, J. F. Herbst, R. W. Lee, and F. E. Pinkerton, J. Appl. Phys., 55 (1984) 2078.

${ }^{3}$ N. C. Koon and B. N. Das, J. Appl. Phys., 55 (1984) 2063.

${ }^{4}$ G. C. Hadjipanayis, R. C. Hazelton and K. R. Lawless, Appl. Phys. Lett., 43 (1983) 797.

${ }^{5}$ A.V. Andreev, A.V. Deryagin, S.M. Zadvorkin and S.V. Terent'ev, Sov. Phys. Solid State., 27(6) (1985) 987.

${ }^{6} \mathrm{~K}$. H. J. Buschow and R. Grossinger, J. of the Less-Common Met., 135 (1987) 39.

${ }^{7}$ H. Fujii, H. Nagata, Y. Uwatoko, T. Okamoto, J. Magn. Magn. Mater., 70 (1987) 331.

${ }^{8}$ J. F. Herbst, Rev. Mod. Phys., 63 (1991) 819.

${ }^{9}$ L. Margulies, M. J. Kramer, R. W. McCallum, S. Cycia, D. R. Haeffner, J. C. Lang and A. I. Goldman, Review of Scientific Instruments, 70, No. 9 (1999) 3554.

${ }^{10}$ M. J. Kramer, N. Yang, L.H. Lewis, R.W. McCallum and K.W. Dennis, J. AppI. Phys., 91 (2002) 8156.

${ }^{11}$ A. P. Hammersley, S .O. Svensson, M. Hanfland, A. N. Fitch and D. Häusermann, "TwoDimensional Detector Software: From Real Detector to Idealized Image or Two-Theta Scan", High Pressure Research, 14 (1996) pp235-248.

${ }^{12}$ A.C. Larson and R.B. Von Dreele, "General Structure Analysis System (GSAS)", Los Alamos National Laboratory Report LAUR 86-748 (2000).

${ }_{13}^{13}$ B. H. Toby, EXPGUI, a graphical user interface for GSAS, J. Appl. Cryst, 34 (2001) 210.

${ }^{14}$ D. Gignoux, D. Givord, F. Givord and R. Lemaire, J. Magn. Magn. Mater., 10 (1979) 288.

${ }^{15}$ K.H.J. Buschow, J. of the Less-Common Met., 144 (1988) 65-69.

${ }^{16}$ A. V. Andreev, F.R. de Boer, T.H. Jacobs and K.H.J. Buschow, J. Magn, Magn. Mater., 104-107 (1992) 1305-1307.

${ }^{17}$ P. C. Ezekwenna, M. Shumsky, W.J. James, Ph. l' Heritier, J. Magn. Magn. Mater., 168 (1997) 149-153.

${ }^{18}$ H. Christina. Chen, Marlin S. Walmer and Michael H. Walmer, J.Appl. Phys., 85 (1999) 5669.

${ }^{19}$ R. Grössinger, X. K. Sun, R. Eibler, K. H. J. Buschow and H. R. Kirchmayr, J. Magn. Magn. Mater., 58 (1986) 55.

${ }^{20}$ D. Givord, H. S. Li and R. Perrier de la Bâthie, Solid State Commun., 51 (1984) 857.

${ }^{21}$ K. Tokuhara, Y. Ohtsu, F. Ono, O. Yamada, M. Sagawa and Y. Matsuura, Solid State Commun., 56 (1985) 333.

${ }^{22}$ D. Givord, R. Lemaire, IEEE Trans. Magn., MAG-110 (1974) 109.

${ }^{23}$ K. H. J. Buschow, R.Grössinger., J. of Less-Common Metals, 135 (1987) 39-46.

${ }^{24}$ Zong-Quan Gu and W.Y.Ching, Phys. Rev. B., 36 (1987) 8530.

${ }^{25}$ J. F. Herbst and J. W. Wilkins, Phys. Rev. B., 20 (1979) 2999.

${ }^{26}$ K. H. J. Buschow, Mat. Res. Rep., 1 (1986) 1.

${ }^{27}$ R. J. Z . Radwanski, Phys. B., 65 (1986) 65.

${ }^{28}$ E. Belorizky, M. A. Fremy, J. P. Gavigan, D. Givord and H. S. Li, J. Appl. Phys., 61 (1987) 3971.

${ }^{29}$ H. S. Li, Z.-W. Zhang and M.-Z. Dang, J. Magn. Magn. Mater., 71(1988) 355. 
${ }^{30}$ Yan Yu, Zhao Xiao-hong and Jin Han-min, J. Magn. Magn. Mater., 127 (1993) Ll.

${ }^{31}$ D. Gignoux, D. Givord, F. Givord and R. Lemaire, J. Magn. Magn. Mater., 10 (1979) 288.

32 J. P. Gavigan, D. Givord, H. S. Li and J. Voiron, Physica B., 149 (1988) 345.

${ }^{33}$ P. Wolfers, S. Obbade, D. Fruchart, R. Verhoef, J. Alloys Comp., 242 (1996) 74-79.

${ }^{34}$ D. Fruchart, S.Miraglia, S. Obbade, R. Verhoef and P.Wolfers, Physica B., 180 (1992) 578.

${ }^{35}$ Olivier Isnard and Daniel Fruchart, Journal of Alloys and Compounds, 205 (1994) 1-15.

${ }^{36}$ R. Fruchart, P. L'Héritier, P. Dalmas de Réotier, D. Fruchart, P. Wolfers, J. M. D. Coey, L. P. Ferreira, R. Guillen, P. Vulliet and A. Yaouanc, J. Phys. F, 17 (1987) 483.

${ }^{37}$ D . Givord, H. S. Li and F. Tasset, J. AppI. Phys., 57 (1985) 4100.

${ }^{38} \mathrm{H}$. Onodera, H. Yamauchi, M. Yamadạ, H. Yamamoto, M. Sagawa and S. Hirosawa, J. Magn. Magn. Mater., 68 (1987) 15.

${ }^{39}$ J. M. Friedt, A. Vasquez, J. P. Sanchez, P. L'Héritier and R. Fruchart, J. Phys. F, 16(1986) 651.

${ }^{40}$ H. M. Van Noort, D. B. de Mooij and K. H. J. Buschow, J. Less-Common Met., 115 (1986) 155.

${ }^{41}$ Ning Yang, K. W. Dennis, R.W. McCallum, M. J. Kramer, Yuegang Zhang and Peter L. Lee, Physical Review B, to be submitted. 


\title{
CHAPTER 3
}

\section{SPONTANEOUS MAGNETOSTRICTION OF $\mathbf{R}_{2} \mathrm{Fe}_{17}(\mathrm{R}=\mathrm{Y}, \mathrm{Nd}, \mathrm{Gd}, \mathbf{T b}$, Er) AND THEIR CARBIDES}

\author{
Ning Yang ${ }^{1}{ }^{2}$, K. W. Dennis ${ }^{1}$, R.W. McCallum ${ }^{1}$, and M. J. Kramer ${ }^{1}$ \\ Yuegang Zhang ${ }^{2}$ and Peter L. Lee ${ }^{2}$ \\ A paper prepared for Physical Review B
}

\subsection{ABSTRCT}

High-energy synchrotron $x$-ray have been used to study the spontaneous magnetostriction of $\mathrm{R}_{2} \mathrm{Fe}_{17}(\mathrm{R}=\mathrm{Y}, \mathrm{Nd}, \mathrm{Gd}, \mathrm{Tb}, \mathrm{Er})$ and their carbides in the temperature range $10 \mathrm{~K}$ to $1100 \mathrm{~K}$. The $\mathrm{R}_{2} \mathrm{Fe}_{17}$ compounds show large and anisotropic $\left(\lambda_{c}>\lambda_{\mathrm{a}}\right)$ spontaneous magnetostriction below their Curie temperatures. Addition of interstitial carbon greatly increases both the Curie temperature and the spontaneous magnetostrain while reducing the anisotropy of the magnetostrain compared to the parent compounds. In the paramagnetic state, the thermal expansion anisotropy of the $\mathrm{R}_{2} \mathrm{Fe}_{17}$ is $\alpha_{3}>\alpha_{\mathrm{c}}$ while the carbides is $\alpha_{\mathrm{a}}<\alpha_{\mathrm{c}}$. The Fe sublattice is shown to dominate the magnetostriction in both of the $\mathrm{R}_{2} \mathrm{Fe}_{17}$ and its carbide. The rare earth sub-lattice contribution to the spontaneous magnetostriction of $\mathrm{R}_{2} \mathrm{Fe}_{17}$ appears more likely to be dominated by the crystallographic factors instead of the magnetic properties of the rare earth.

\footnotetext{
${ }^{1}$ Ames Laboratory and the Department of Materials Science and Engineering, Iowa State University, Ames, lowa 50010.

${ }^{2}$ Advanced Photon Source, Argonne National Laboratory, Argonne, IL 60439.
} 


\subsection{INTRODUCTION}

The rare-earth (R) $\mathrm{R}_{2} \mathrm{Fe}_{17}$ are not suitable for permanent magnet application due to their low Curie temperature $\left(\mathrm{T}_{c}\right)$ and room temperature planar anisotropy. The low $T_{c}$ of these compounds is usually attributed to the negative exchange interactions between the Fe sites with very short distances [1]. Research efforts on improving the magnetic properties of the $\mathrm{R}_{2} \mathrm{Fe}_{17}$ compounds has focused on increasing the $\mathrm{T}_{\mathrm{c}}[2,3,4]$. Partial substitution of $\mathrm{Al}$ or $\mathrm{Si}$ for Fe results in a moderate increase of $T_{c}[5,6] . T_{c}$ enhancements have also been achieved within the $\mathrm{R}_{2} \mathrm{Fe}_{17}$ phases containing interstitial atoms: $\mathrm{H}, \mathrm{C}, \mathrm{N}[7,8]$. In particular, $\mathrm{Sm}_{2} \mathrm{Fe}_{17} \mathrm{~N}_{3}$ is a promising candidate for permanent magnet applications.

There are two polymorphs for $\mathrm{R}_{2} \mathrm{Fe}_{17}$, the hexagonal $\left(\mathrm{Th}_{2} \mathrm{Ni}_{17}\right.$ structural type with space group $\mathrm{P}_{3} / \mathrm{mmc}$ ) and the rhombohedral $\left(\mathrm{Th}_{2} \mathrm{Zn}_{17}\right.$ structural type with space group $\left.\mathrm{R}-3 \mathrm{~m}\right)$. Both of these structures are based on the $\mathrm{CaCu}_{5}$ type structure. The 2-17 structure can be formed by stacking of these 1:5 blocks where one of the $R$ atoms is substituted by two $3 \mathrm{~d}$ transition elements, typically Fe or Co. The replacement can be described as $3 \mathrm{RFe}_{5}-\mathrm{R}+2 \mathrm{Fe}$ $=\mathrm{R}_{2} \mathrm{Fe}_{17}$. The dimension of the structural block along c-axis is very close to that of the $1: 5$ structure, which is about $0.4 \mathrm{~nm}$. The hexagonal polymorph is formed by a double-layer stacking of these structural blocks, the resulting unit cell having the dimensions; a-axis $\approx$ $8.4 \AA$, c-axis $=8.3 \AA$ and contains 2 formula units. In the case of the rhombohedra structural modification, there are three stacking blocks with a-axis $\approx 8.4 \AA$, c-axis $\approx 12.6 \AA$ and there are three formula units in the unit cell.

The negative thermal expansion in $\mathrm{R}_{2} \mathrm{Fe}_{17}$ with increasing temperature (invar-anomaly) below the Curie temperature was observed $[9,10,11,12,13,14,15,16,17]$ and explained as a result of a distance dependence of the magnetic interaction, which is decreasing with 
temperature, coupled to a smaller phonon mediated thermal expansion. In the $\mathrm{R}_{2} \mathrm{Fe}_{17}$ structures, the interstitial atoms expand the lattice and offer a new local configuration and environment. As expected, these changes affect the anomalous thermal expansion $[12,15$, 16].

In all the previous studies, there has not been a concerted effort to systematically study the role of the crystal chemistry on the spontaneous magnetostriction, i.e., the decrease of the lattice parameters with temperature up to the Curie temperature. Knowing how the individual moments of the atoms interact over distance will help us better understanding the exchange interactions that enhance ferromagnetism. The effect of the lattice parameters changes and atomic site distortions due to various rare earth substitutions and the carbon interstitials is slightly different. We can systematically study these effects as a function of composition and temperature. In the case of the rare earth, each has a different ionic radii and magnetic moment while carbon expands the unit cell volume. In this paper, we report the thermal expansion behaviors of $\mathrm{R}_{2} \mathrm{Fe}_{17}(\mathrm{R}=\mathrm{Y}, \mathrm{Nd}, \mathrm{Gd}, \mathrm{Tb}, \mathrm{Er})$ and their carbides from $10 \mathrm{~K}$ to 1100 $\mathrm{K}$ using high-energy synchrotron $\mathrm{x}$-ray powder diffraction.

\subsection{EXPERIMENTAL METHODS}

\subsubsection{Sample Preparation}

The samples are made by first arc-melting high purity rare earth elements $(\mathrm{Y}, \mathrm{Nd}, \mathrm{Gd}, \mathrm{Tb}$, Er all greater than $99.99 \%$ pure), $\mathrm{Fe}(99.9 \%)$ and $\mathrm{C}(99.9 \%)$ under Ar atmosphere. Approximately 6 to $8 \mathrm{~g}$ ingots were then melt spun at $25 \mathrm{~m} / \mathrm{s}$ in 250 torr He atmosphere. The as-quenched ribbons were then annealed at $1173 \mathrm{~K}$ for 12 hours to insure homogeneity and fully crystallize the alloy. The carbides were $\mathrm{R}_{2} \mathrm{Fe}_{17} \mathrm{C}_{2}$ except for $\mathrm{Y}_{2} \mathrm{Fe}_{17} \mathrm{C}_{\mathrm{x}}(\mathrm{x}=1$ and 2). 
Extra care was taken to insure minimal mass loss with the $\mathrm{C}$ addition and raising the superheat to fully homogenize the samples.

\subsubsection{Characterization}

The Curie temperatures $\left(\mathrm{T}_{\mathfrak{c}}\right)$ were measured by both superconducting quantum interference device (DC SQUID) magnetometer and differential scanning calorimeter (DSC). For the samples with very low $T_{c} s, D C$ SQUID gave more accurate measurements. For the DSC measurements, the $T_{c} s$ were determined by averaging the peak positions of differential heating and cooling curves.

The lattice parameters and bond length changes were determined by using Rietveld refinement of high-energy $\mathrm{x}$-ray diffraction patterns. The experiments were performed at 6 IDD of Advanced Photon Source, Argonne National Laboratory. For the temperature range of $10 \mathrm{~K}$ to $300 \mathrm{~K}$, a cryostat with a large kapton window which allowed the measurement of whole Debye rings on a $2 \mathrm{D}$ area detector (MAR345) was used. For the temperatures above room temperature, a specially designed high temperature furnace was used [18]. The energy of synchrotron $\mathrm{x}$-ray beam was set to $\sim 80 \mathrm{KeV}(\lambda \approx 0.155 \AA)$ allowing for whole sample penetration (2mm) and large wave momentum numbers $\left(Q=\frac{4 \pi \sin (\Theta)}{\lambda}\right)$ required for refining lattice parameters, atomic coordinates and thermal parameters simultaneously and accurately. The area detector was placed about $900 \mathrm{~mm}$ away from the sample. The diffraction patterns were taken every $20 \mathrm{~K}$. The wavelength was determined using an energy dispersive detector while the detector distance to the sample was calibrated using NIST $640 \mathrm{C}$ Si standard. The full Debye ring patterns were processed and reduced to intensity versus $2 \theta$ 
spectra using Fit2D software [19]. Rietveld refinement was done using GSAS software package $[20,21]$.

\subsubsection{The Rietveld refinement}

Both polymorphic structures of $\mathrm{R}_{2} \mathrm{Fe}_{17}$ phases were observed. In all of the samples, a small amount of pure $\alpha-\mathrm{Fe}$ phase was observed with the phase fraction varying from $5 \%$ to $10 \%$. The lack of phase purity is due to the peritectic nature of the solidification in these alloys. The peak shape profile was fitted with a pseudo-voigt function. The lattice parameters, atomic positions and thermal parameters were all refined simultaneously. The thermal parameters increase linearly with the temperature, as expected. In all cases, the wRp were no more than $7 \%$ and $5 \%$ for hexagonal and rhombohedral structure respectively.

\subsection{RESULTS}

The structures and the lattice parameters of all the samples studied are listed in Table 3-1. The heavy rare earths $(\mathrm{Y}, \mathrm{Gd}, \mathrm{Tb}$ and $\mathrm{Er})$ have the hexagonal polymorph while the Nd has rhombohedral form. All the carbides have the rhombohedral form with expanded lattices over the binary compounds. In the rhombohedral structure, the carbon atom occupies the interstitial 9e sites [22] and as a result, the a-axes expands more than the c-axes (Figure 3-1). Due to difficulty in synthesizing the $\mathrm{Nd}_{2} \mathrm{Fe}_{17} \mathrm{C}_{\mathrm{x}}$ compound, only carbides of the heavy $\mathrm{R}$ atoms were studied. All the carbides have a much higher Curie temperatures than the binary compounds (Figure 3-2).

The change of the lattice parameters with temperature shows strong spontaneous mangetostriction for all compounds below their Curie temperatures (Figure 3-3, Figure 3-4, 
Figure 3-5 for $\mathrm{R}_{2} \mathrm{Fe}_{17}$ and Figure 3-6, Figure 3-7, Figure 3-8 for the carbides). The inflection points of the magnetostriction curves of $\mathrm{R}_{2} \mathrm{Fe}_{17}$ are $30-40 \mathrm{~K}$ higher than their respective Curie temperatures while the $\mathrm{R}_{2} \mathrm{Fe}_{17} \mathrm{C}_{\mathrm{x}}$ are $20-30 \mathrm{~K}$ higher. The persistence in the magnetostrain above the $T_{\mathfrak{c}}$ has been attributed to the short range ordering in layers of iron hexagons $[11,12$, 15]. The higher the $T_{0}$, the weaker is the short range ordering and the less is the magnetostrain above $T_{c-}$

Figure 3-9, Figure 3-10 and Figure 3-11 show the temperature dependences of the $a$-axes, $c$-axes and unit cell volume respectively for $\mathrm{Y}_{2} \mathrm{Fe}_{17} \mathrm{C}_{\mathrm{x}}(0 \leq \mathrm{x} \leq 2)$. While the Curie temperature increases linearly monotonic with increasing carbon, the increase of lattice parameters is not linearly proportional to the increase of carbon content. Increasing carbon from 0 to 1 expands the $c$-axis by $0.7 \%$ while increasing $x$ from 1 to 2 expands the c-axis by only $0.2 \%$. In the temperature range of 20 to $510 \mathrm{~K}$, the volumetric thermal expansion coefficient of $Y_{2} \mathrm{Fe}_{17} \mathrm{C}$ is very small for $\mathrm{x}=1.3 \times 10^{-6} \mathrm{~K}^{-1}$ making it a good example of invar alloy.

\subsection{DISCUSSION}

\subsubsection{The thermal expansion of $\mathrm{R}_{2} \mathrm{Fe}_{17}$ and their carbides}

Compare Figure 3-1 and Figure 3-2, we can see the c-axes have stronger spontaneous magnetostriction than a-axes in the $\mathrm{R}_{2} \mathrm{Fe}_{17}$ samples, which is related to their planar magnetic anisotropy. In $\mathrm{R}_{2} \mathrm{Fe}_{17}$, the moments are aligned parallel to the basal plane and the dumbbell structures are along the c-axis, which induce more lattice contraction along c-axis as temperature increased. With introduction of the carbon interstitial, the magnetostriction of both a-axes and c-axes increase as a result of expanded lattice. The spontaneous 
magnetostriction of the a-axes have stronger enhancement than the c-axes, which makes the spontaneous magnetostriction of carbides more uniform.

The thermal expansion of the compounds depends on two contributions, the lattice phonon expansion and the magnetic ordering. The change of lattice parameters for different temperatures normalized to the values expected in the absence of magnetic moments is its magnetostrain, defined as:

$$
\begin{aligned}
& \lambda_{a}=\left(a-a_{0}\right) / a_{0} \\
& \lambda_{c}=\left(c-c_{0}\right) / c_{0} \\
& \omega_{S}=\left(V-V_{0}\right) / V_{0}
\end{aligned}
$$

where $a_{0}, c_{0}$ and $V_{0}$ are values extrapolated from paramagnetic state. The extrapolations were based on Debye theory,

$$
a_{T}=a_{0}+A T F(\theta / T)
$$

where $\mathrm{A}$ is a constant and $F(\theta / T)=\frac{1}{T} \int_{0}^{T} C_{V} d T$ is a tabulated function. The calculated magnetostrains are listed in Table 3-1. In all the compounds, the c-axes show larger magnetostrain than a-axes. Among $\mathrm{R}_{2} \mathrm{Fe}_{17}$ samples, the $\mathrm{Gd}_{2} \mathrm{Fe}_{17}$ has the largest volumetric spontaneous magnetostrain. The carbon doped samples have larger volumetric spontaneous magnetostrain than their parent compounds (Figure 3-12), which is consistent with previous results [12].

The ratio of the c-axes and a-axes as a function of temperature illustrates the anisotropy of the spontaneous magnetostriction (Figure 3-12 and Figure 3-13). In these figures, the ratio curves are normalized to their maximum values while the temperature axis is scaled to the Curie temperatures. From Figure 3-12, it can be seen that the c/a ratios of $\mathrm{R}_{2} \mathrm{Fe}_{17}$ 
monotonically decrease over the whole temperature range, which means that the c-axes have smaller thermal expansion coefficients than a-axes at any temperature. With the carbon addition, the thermal expansion coefficients of c-axes are still smaller than a-axes below the Curie temperatures. However, above the Curie temperatures, the c-axes have larger thermal expansion coefficients than the a-axes (Figure 3-14).

It has been proposed that the thermal expansion anisotropy is due to the magnetocrystalline anisotropy, which results from a competition between the $R$ and $.3 \mathrm{~d}$ sublattice anisotropies [23]. The electrostatic crystal field acting on the rare earth elements dominates the anisotropy in these compounds. Our results are in good agreement with nitrogen doping of $\mathrm{R}_{2} \mathrm{Fe}_{17}$ [15]. This can be as attributed to the nitrogen or carbon doping producing a crystal field modification, which would change the rare earth and Fe sublattice anisotropies, as well as the structural magnetic anisotropy.

\subsubsection{The Role of the Fe Sublattice}

The normalized volumetric spontaneous magnetostriction can be used to compare the effects of varying the crystal chemistry in these compounds. The value of $\omega_{s}(T) / \omega_{s}(10 \mathrm{~K})$ for the various $\mathrm{R}_{2} \mathrm{Fe}_{17}$ and $\mathrm{R}_{2} \mathrm{Fe}_{17} \mathrm{C}_{2}$ compounds versus reduced temperature $\mathrm{T} / \mathrm{T}_{\mathrm{c}}$ overlapped over a very large temperature range, deviating only above the Curie temperature (Figure 3-15 and Figure 3-16). At $\mathrm{T}_{\mathrm{c}}$, about $20 \%$ of $\omega_{\mathrm{s}}(10 \mathrm{~K})$ still remains in all the samples. The similarity in the volumetric spontaneous magnetostriction implies a single mechanism, which can be attributed to the Fe sublattice [12].

The following expression have been proposed to calculate the contribution to the magnetostriction of the structure from the $4 \mathrm{f}$-sublattice $\omega_{\mathrm{s}, \mathrm{f}}$ and the $3 \mathrm{~d}$-sublattice $\omega_{\mathrm{s}, \mathrm{d}}$. 


$$
\begin{aligned}
& \omega_{\mathrm{s}, \mathrm{\ell}}=\kappa\left[C_{R R}(g-1)^{2} J(J+1) \frac{d J_{R R}}{d V}+C_{R T}|(g-1) J| m_{T} \frac{d J_{R T}}{d V}\right] \\
& \omega_{s, d}=\kappa C M_{r}^{2}
\end{aligned}
$$

where $\kappa$ is the compressibility, $C_{R R}$ and $C_{R T}$ are constants, and $J_{R R}$ and $J_{R T}$ are the exchange coupling constants between the $\mathrm{R}$ moments and between the $\mathrm{R}$ and $\mathrm{T}$ moments, respectively. $C$ is the mangetovolume coupling constant including both band and localized effects and $m_{T}$ and $M_{T}$ are the Fe moments and the Fe-sublattice moments respectively [14, 24]. The magnetovolume effect due to the iron moment is proportional to the squared magnetization, as seen in equation 3-4, which should follow a parabolic curve. Since the relative volumetric spontaneous magnetostrictive for all $\mathrm{R}_{2} \mathrm{Fe}_{17}$ compounds do follow the parabolic curve closely up to the Curie temperatures, it can be assumed that the Fe sublattice dominates the magnetostriction.

The $\mathrm{R}_{2} \mathrm{Fe}_{17} \mathrm{C}_{2}$ differ from the stoichiometric compounds in their relative magnetostrain curves do not all follow the same parabolic curve. This result is in disagreement with previous results [12]. This is probably due to the change of the magnetic properties of $\mathrm{Fe}-$ subnets induced by the doping of carbon atoms. The carbon atoms reside at the $9 \mathrm{e}$ position, which are on the edges of the Fe hexagon. Although the total composition of carbon is small, the insertion of the carbon atoms distorts the shape of Fe sub-lattice and results in the change of the bond structure of the 3d-band as for $\mathrm{N}$ doping [25]. 


\subsubsection{Role of Rare Earth Sublattice}

In Table 3-1, it is shown that the $\mathrm{Nd}_{2} \mathrm{Fe}_{17}$ has even smaller volumetric spontaneous magnetostrain than $\mathrm{Y}_{2} \mathrm{Fe}_{17}$, which is in good agreement with the result of Kajitani (1993) [9]. Using neutron diffraction, he found the $\mathrm{Nd}_{2} \mathrm{Fe}_{17}$ had a similar thermal expansion behavior with other $\mathrm{R}_{2} \mathrm{Fe}_{17}$. From the values he reported, $\omega_{\mathrm{s}}$ for $\mathrm{Nd}_{2} \mathrm{Fe}_{17}$ is close but smaller than that of $\mathrm{Y}_{2} \mathrm{Fe}_{17}$. A.V. Andreev argued that this result was due to the underestimation of the thermal expansion coefficient [9], but our study shows the same result as Kajitani.

Since the $\mathrm{Y}$ ion is non-magnetic, subtracting the magnetostrain of $\mathrm{Y}_{2} \mathrm{Fe}_{17}$ from other $\mathrm{R}_{2} \mathrm{Fe}_{17}$ will give the contribution from the rare earth sub-lattice (Table 3-2). The Nd and Er provide a negative contribution to the volumetric spontaneous magnetostriction while for the Gd and $\mathrm{Tb}$ subnets, the contribution is very small. This differs from the result of $\mathrm{R}_{2} \mathrm{Fe}_{14} \mathrm{~B}$ compounds which shows that the contribution from the rare earth sub-lattice is roughly proportional to the magnetic spin moment of the rare earth [26]. Comparing the result of $\mathrm{R}_{2} \mathrm{Fe}_{17}$ and $\mathrm{R}_{2} \mathrm{Fe}_{14} \mathrm{~B}$, the contribution of rare earth sub-lattice is more likely to be influenced by the nuances of the surrounding environment in $\mathrm{R}_{2} \mathrm{Fe}_{17}$, i.e., bond lengths and degree of electron sharing. In $\mathrm{R}_{2} \mathrm{Fe}_{14} \mathrm{~B}$, the $\mathrm{R}$ sublattice is well separated from the major Fe sublattice with its own sublayer structure. In $\mathrm{R}_{2} \mathrm{Fe}_{17}$, the $\mathrm{R}$ and $\mathrm{Fe}$ sublattices interpenetrate each other so that the exchange interaction between $F e$ sublattice and $R$ sublattice is much more complicated.

As mentioned before, the relative volumetric magnetostriction curves do not follow the parabolic curve very well, which means a reduced contribution from the Fe sublattice. So the increase of the magnetostrain can only be attributed to the increased contribution from the R- 
Fe exchange interaction. The detailed discussion on this aspect will be in the following paper [27].

\subsection{CONCLUSION}

The $\mathrm{R}_{2} \mathrm{Fe}_{17}$ and their carbides show a large but similar spontaneous magnetostriction. The carbides have much higher Curie temperatures and stronger magnetostriction than the parents compounds; however, the magnetostrictive anisotropy is lower. The thermal expansion anisotropy of the $\mathrm{R}_{2} \mathrm{Fe}_{17}$ in the paramagnetic temperature range is $\alpha_{a}>\alpha_{c}$ while that of the carbides is $\alpha_{a}<\alpha_{0}$,

The spontaneous magnetostriction of $\mathrm{R}_{2} \mathrm{Fe}_{17}$ and their carbides are dominated by the $\mathrm{Fe}$ sublattice although the reduced spontaneous magnetostriction curves of $\mathrm{R}_{2} \mathrm{Fe}_{17} \mathrm{C}_{2}$ deviate from the parabolic curve deduced from the square law of Fe sub-lattice magnetization. The rare earth sub-lattice contribution to the spontaneous magnetostriction of $\mathrm{R}_{2} \mathrm{Fe}_{17}$ appears more likely to be dominated by the structural factors instead of the magnetic properties of the rare earth.

\subsection{ACKNOWLEDGEMENTS}

The author would like to thanks David Welch for his insightful comments. The work at Ames Laboratory was supported by the United States Department of Energy (USDOE), Office of Science (OS), Office of Basic Energy Sciences (BES), through Iowa State University under Contract W-7405-ENG-82. The Midwest Universities Collaborative Access Team (MUCAT) sector at the APS is supported by the U.S. Department of Energy, Basic Energy Sciences, Office of Science, through the Ames Laboratory under Contract No. 
W-7405-Eng-82. Use of the Advanced Photon Source was supported by the U.S. Department of Energy, Basic Energy Sciences, Office of Science, under Contract No. W-31-109-Eng-38. 


\subsection{CAPTIONS}

Table 3-1. The structural data for $\mathrm{R}_{2} \mathrm{Fe}_{17}$ and their carbides, the second column is the space group (h-hexagonal, r-rhombohedral), a and c are the lattice parameters. $\lambda_{\mathrm{a}}, \lambda_{\mathrm{c}}, \omega_{\mathrm{s}}$ are the spontaneous magnetostrain of a-axes, c-axes and unit cell volume at $10 \mathrm{~K}$. $\alpha_{a}, \alpha_{c}, \alpha_{v}$ are the thermal expansion coefficients of a-axes, c-axes and unit cell volume in the paramagnetic temperature range. The last column shows the Curie temperatures of the compounds.

Table 3-2. The contribution of the rare earth sublattice to the spontaneous magnetostriction of $\mathrm{R}_{2} \mathrm{Fe}_{17}$ and their carbides.

Figure 3-1. The a and c lattice expansion with interstitial carbon $(x=2)$ in the $\mathrm{R}_{2} \mathrm{Fe}_{17}$ samples studied.

Figure 3-2. The Curie temperature increases with the interstitial carbon in the samples studied.

Figure 3-3. The temperature dependences of a-axes of $\mathrm{R}_{2} \mathrm{Fe}_{17}$ samples.

Figure 3-4. The temperature dependence of $\mathrm{c}$-axes of $\mathrm{R}_{2} \mathrm{Fe}_{17}$ samples.

Figure 3-5. The temperature dependences of unit cell volume of $\mathrm{R}_{2} \mathrm{Fe}_{17}$ samples.

Figure 3-6. The temperature dependences of a-axes of $\mathrm{R}_{2} \mathrm{Fe}_{17} \mathrm{C}_{2}$ samples.

Figure 3-7. The temperature dependences of c-axes of $\mathrm{R}_{2} \mathrm{Fe}_{17} \mathrm{C}_{2}$ samples.

Figure 3-8. The temperature dependences of unit cell volume of $\mathrm{R}_{2} \mathrm{Fe}_{17} \mathrm{C}_{2}$ samples.

Figure 3-9. The temperature dependences of a-axes of $\mathrm{Y}_{2} \mathrm{Fe}_{17}, \mathrm{Y}_{2} \mathrm{Fe}_{17} \mathrm{C}$ and $\mathrm{Y}_{2} \mathrm{Fe}_{17} \mathrm{C}_{2}$ samples.

Figure 3-10. The temperature dependences of c-axes of $\mathrm{Y}_{2} \mathrm{Fe}_{17}, \mathrm{Y}_{2} \mathrm{Fe}_{17} \mathrm{C}$ and $\mathrm{Y}_{2} \mathrm{Fe}_{17} \mathrm{C}_{2}$ samples. 
Figure 3-11. The temperature dependences of unit cell volume of $\mathrm{Y}_{2} \mathrm{Fe}_{17}, \mathrm{Y}_{2} \mathrm{Fe}_{17} \mathrm{C}$ and $\mathrm{Y}_{2} \mathrm{Fe}_{17} \mathrm{C}_{2}$ samples.

Figure 3-12. The comparison of volumetric spontaneous magnetostrictions of the $\mathrm{R}_{2} \mathrm{Fe}_{17}$ and their carbides.

Figure 3-13. The normalized temperature dependence of the $\mathrm{c} / \mathrm{a}$ of $\mathrm{R}_{2} \mathrm{Fe}_{17}$ samples, the temperature axis is also normalized to Curie temperature.

Figure 3-14. The temperature dependence of the $c / a$ of $\mathrm{R}_{2} \mathrm{Fe}_{17} \mathrm{C}_{2}$ samples, the temperature axis is also normalized to Curie temperature.

Figure 3-15. The temperature dependences $\left(T / T_{c}\right)$ of the relative volumetric spontaneous magnetostrain of $\mathrm{R}_{2} \mathrm{Fe}_{17}$ samples with Hexagonal structure.

Figure 3-16. The temperature dependence $\left(T / T_{c}\right)$ of the relative volumetric spontaneous magnetostrain of $\mathrm{R}_{2} \mathrm{Fe}_{17} \mathrm{C}_{2}$ samples with rhombohedral structure. 


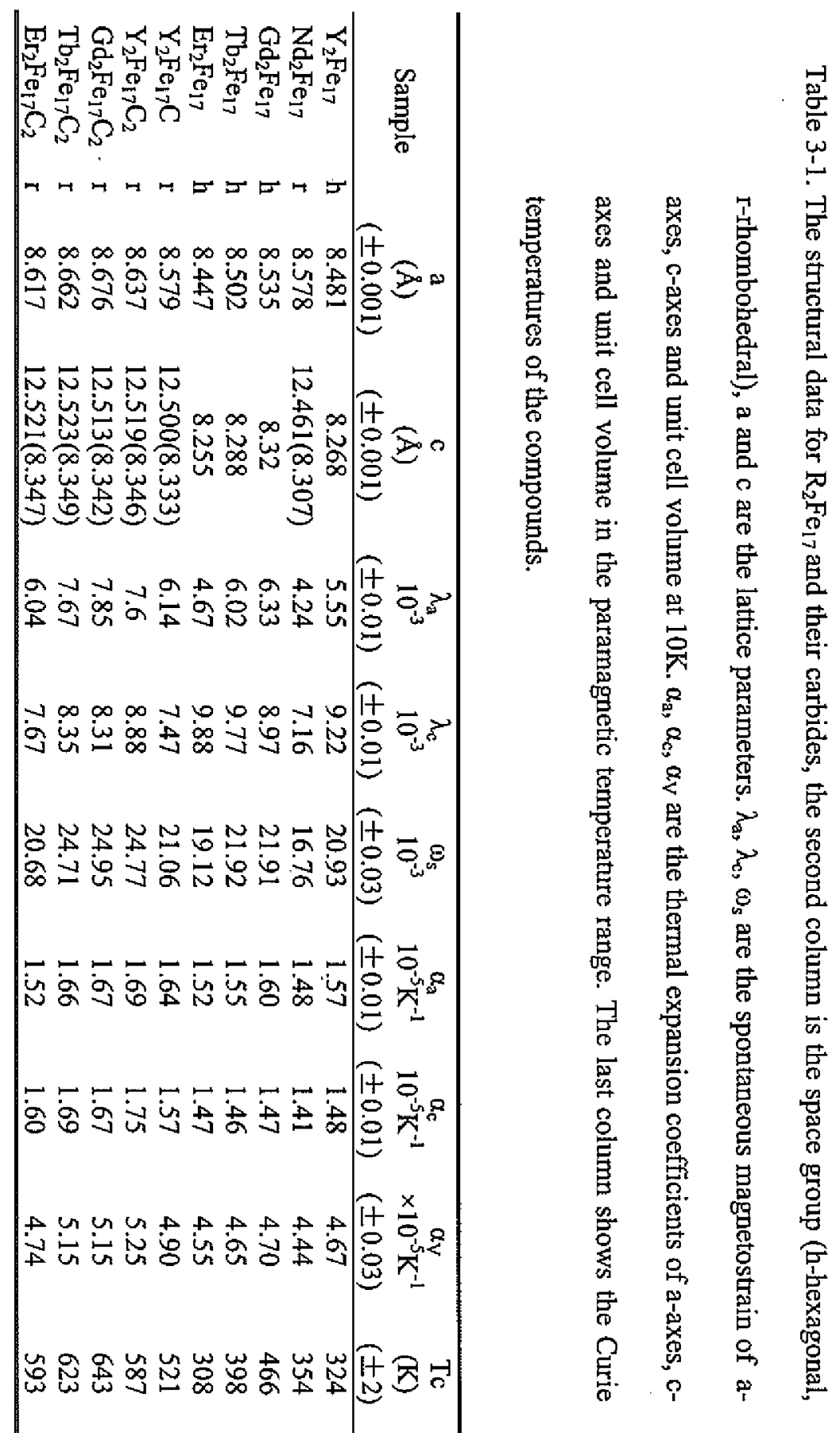


Table 3-2. The contribution of the rare earth sublattice to the spontaneous magnetostriction of $\mathrm{R}_{2} \mathrm{Fe}_{17}$ and their carbides.

\begin{tabular}{|c|c|c|c|c|c|c|}
\hline Sample & $\begin{array}{c}\lambda_{\mathrm{a}, \mathrm{R}} \\
10^{-3} \\
( \pm 0,01)\end{array}$ & $\begin{array}{c}\lambda_{r, R} \\
10^{-3} \\
( \pm 0.01) \\
\end{array}$ & $\begin{array}{c}\omega_{\mathrm{s}}, \mathrm{R} \\
10^{-3} \\
( \pm 0.03) \\
\end{array}$ & $\begin{array}{c}\lambda_{\mathrm{a}, \mathrm{R}} / \lambda_{\mathrm{a}} \\
(\%) \\
( \pm 0.01)\end{array}$ & $\begin{array}{c}\lambda_{c_{,} \mathrm{R}} / \lambda_{\mathrm{L}} \\
(\%) \\
( \pm 0.01)\end{array}$ & $\begin{array}{c}\omega_{\mathrm{s}, \mathrm{R}} / \omega_{\mathrm{s}} \\
(\%) \\
( \pm 0.03)\end{array}$ \\
\hline $\mathrm{Y}_{2} \mathrm{Fe}_{17}$ & 0 & 0 & 0 & 0 & 0 & 0 \\
\hline $\mathrm{Nd}_{2} \mathrm{Fe}_{17}$ & -1.31 & -2.06 & -4.17 & $-30.90 \%$ & $-28.77 \%$ & $-24.88 \%$ \\
\hline $\mathrm{Gd}_{2} \mathrm{Fe}_{17}$ & 0.78 & -0.25 & 0.98 & $12.32 \%$ & $-2.79 \%$ & $4.47 \%$ \\
\hline $\mathrm{Tb}_{2} \mathrm{Fe}_{17}$ & 0.47 & 0.55 & 0.99 & $7.81 \%$ & $5.63 \%$ & $4.52 \%$ \\
\hline $\mathrm{Et}_{2} \mathrm{Fe}_{17}$ & -0.88 & 0.66 & -1.81 & $-18.84 \%$ & $6.68 \%$ & $-9.47 \%$ \\
\hline $\mathrm{Y}_{2} \mathrm{Fe}_{17} \mathrm{C}_{2}$ & 0 & 0 & 0 & 0 & 0 & 0 \\
\hline $\mathrm{Gd}_{2} \mathrm{Fe}_{17} \mathrm{C}_{2}$ & 0.25 & -0.57 & 0.18 & $3.18 \%$ & $-6.86 \%$ & $0.72 \%$ \\
\hline $\mathrm{Tb}_{2} \mathrm{Fe}_{17} \mathrm{C}_{2}$ & 0.07 & -0.53 & -0.06 & $0.91 \%$ & $-6.35 \%$ & $-0.24 \%$ \\
\hline $\mathrm{Er}_{2} \mathrm{Fe}_{17}, \mathrm{C}_{2}$ & -1.56 & -1.21 & -4.09 & $-25.83 \%$ & $-15.78 \%$ & $-19.78 \%$ \\
\hline
\end{tabular}




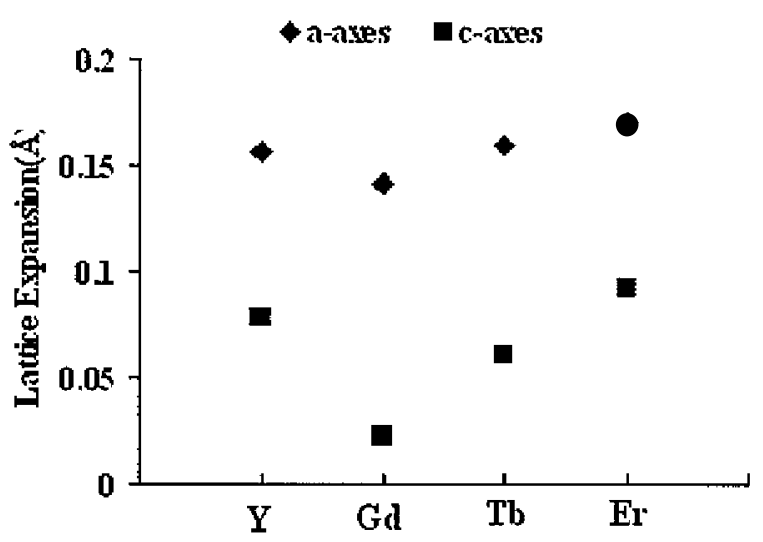

Figure 3-1. The a and $c$ lattice expansion with interstitial carbon $(x=2)$ in the $\mathrm{R}_{2} \mathrm{Fe}_{17}$ samples studied. 


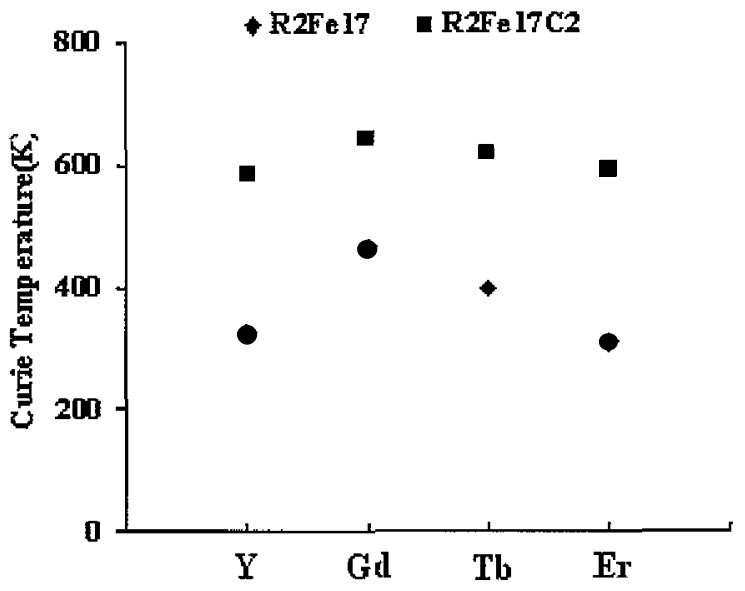

Figure 3-2. The Curie temperature increases with the interstitial carbon in the samples studied. 


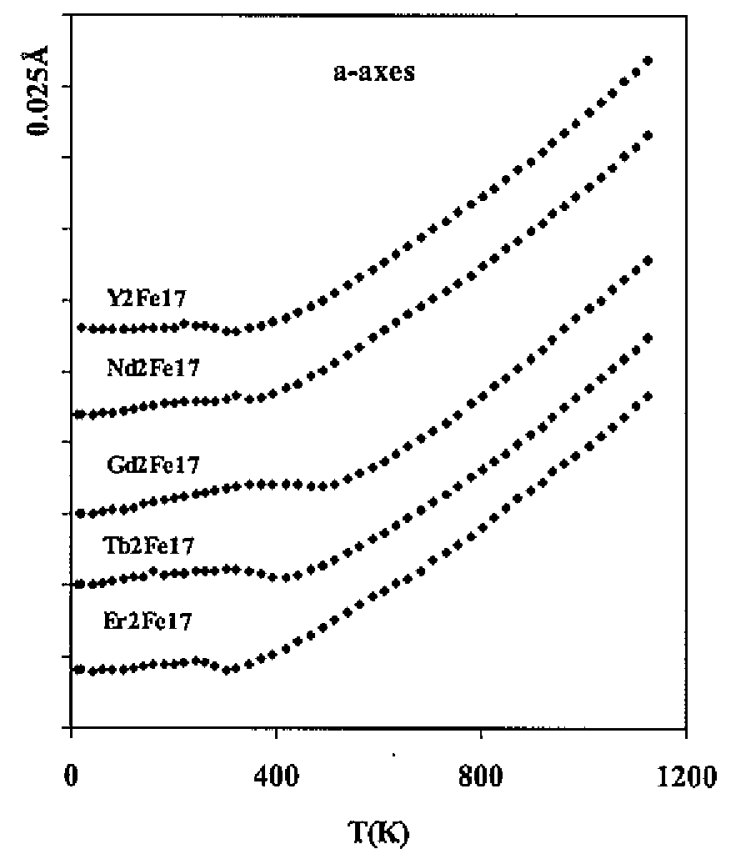

Figure 3-3. The temperature dependences of a-axes of $\mathrm{R}_{2} \mathrm{Fe}_{17}$ samples. 


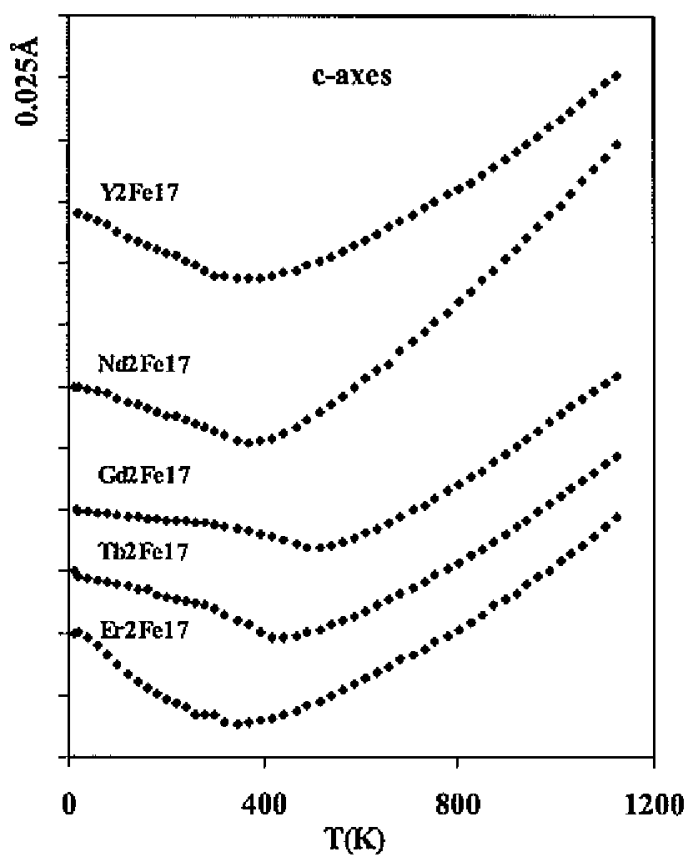

Figure 3-4. The temperature dependence of c-axes of $\mathrm{R}_{2} \mathrm{Fe}_{17}$ samples. 


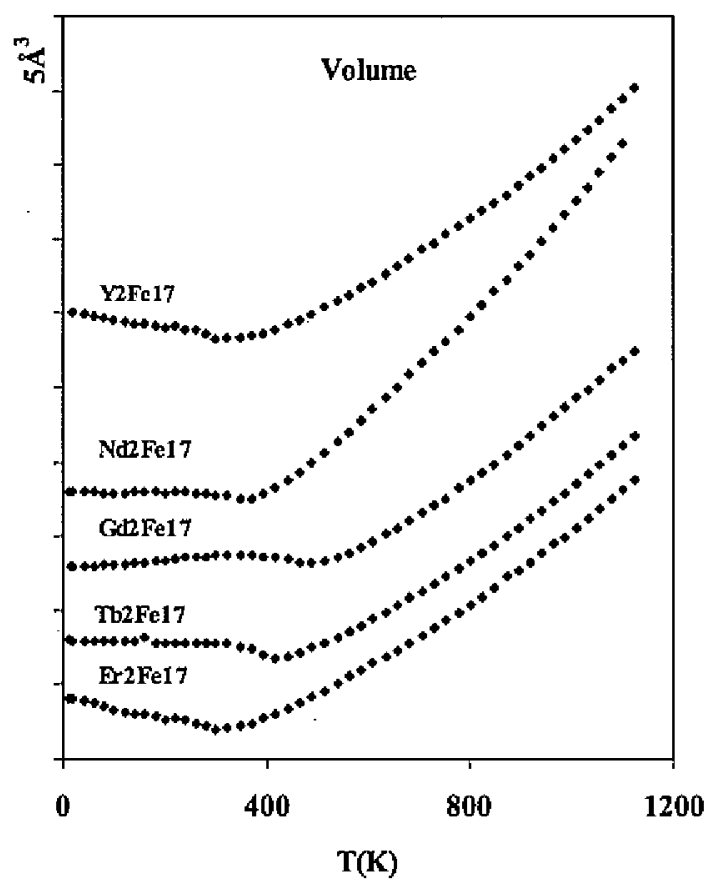

Figure 3-5. The temperature dependences of unit cell volume of $\mathrm{R}_{2} \mathrm{Fe}_{17}$ samples. 


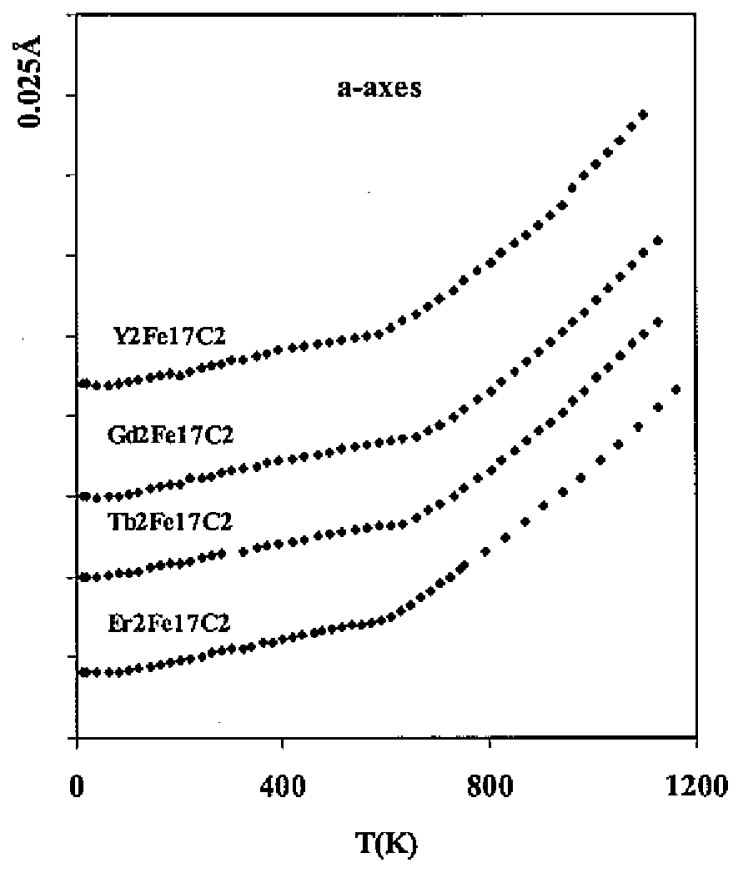

Figure 3-6. The temperature dependences of a-axes of

$\mathrm{R}_{2} \mathrm{Fe}_{17} \mathrm{C}_{2}$ samples. 


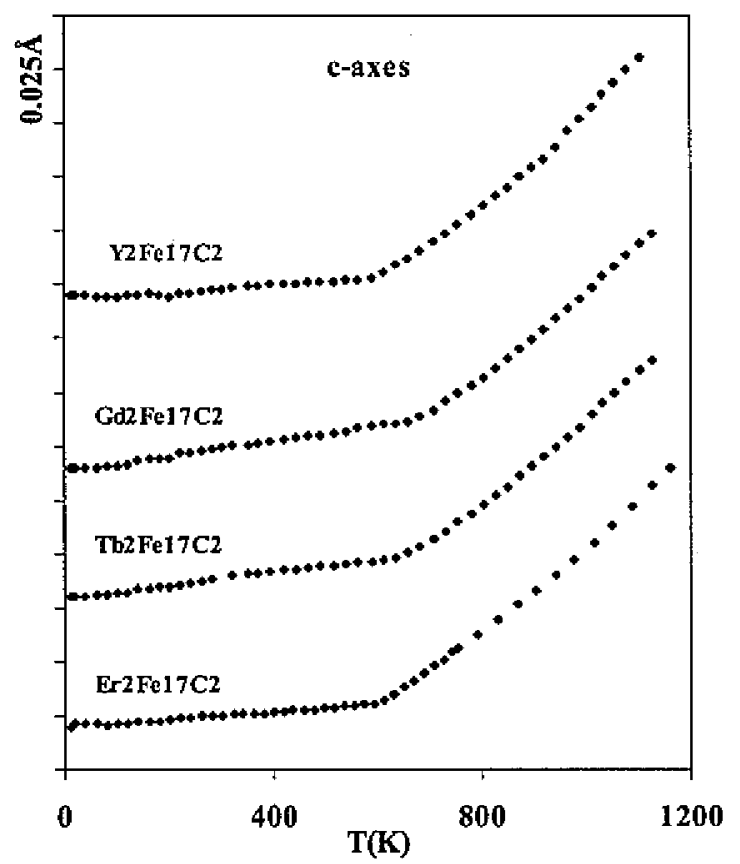

Figure 3-7. The temperature dependences of c-axes of

$\mathrm{R}_{2} \mathrm{Fe}_{17} \mathrm{C}_{2}$ samples. 


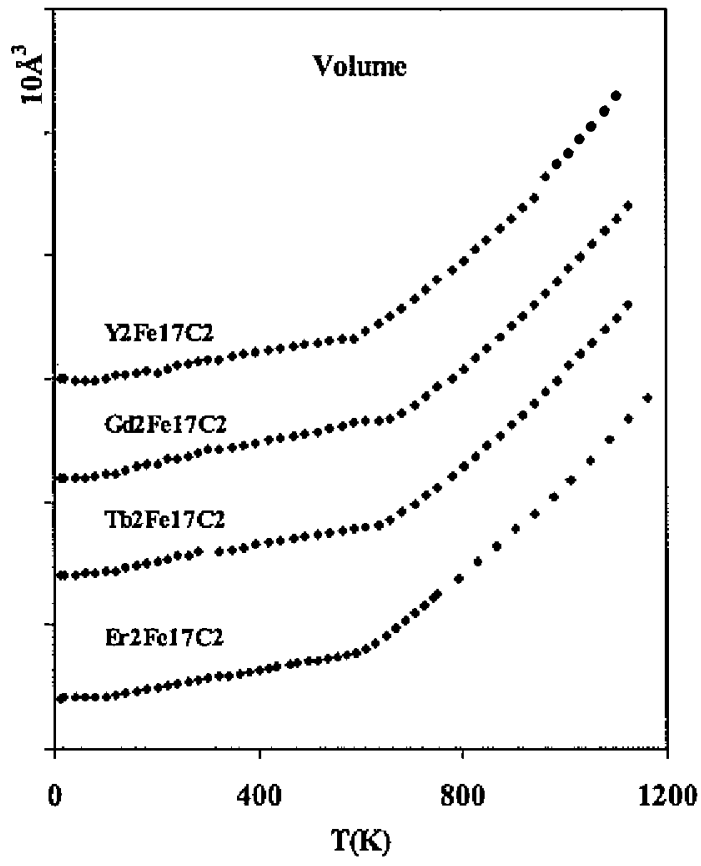

Figure 3-8. The temperature dependences of unit cell volume of $\mathrm{R}_{2} \mathrm{Fe}_{17} \mathrm{C}_{2}$ samples. 


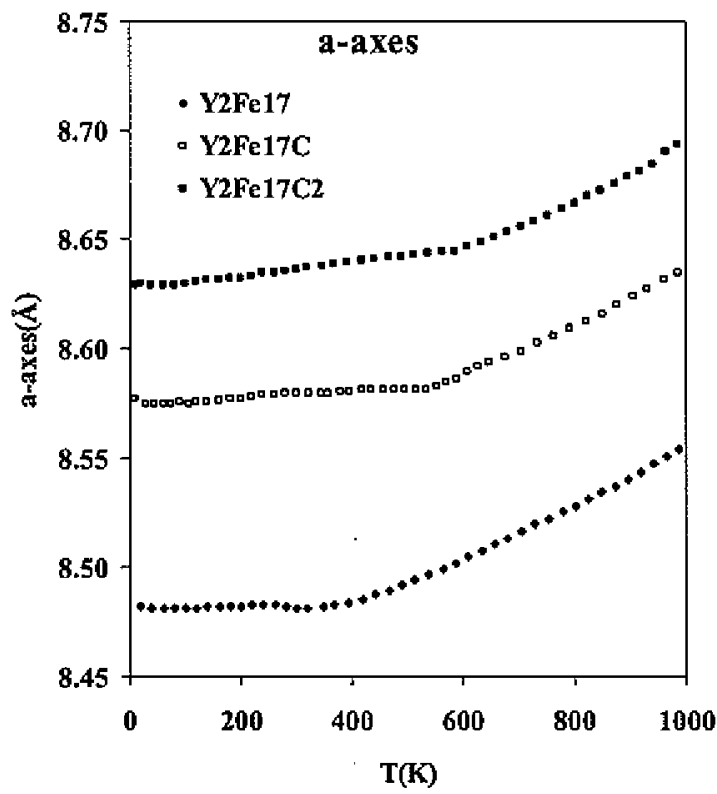

Figure 3-9. The temperature dependences of a-axes of $\mathrm{Y}_{2} \mathrm{Fe}_{17}$, $\mathrm{Y}_{2} \mathrm{Fe}_{17} \mathrm{C}$ and $\mathrm{Y}_{2} \mathrm{Fe}_{17} \mathrm{C}_{2}$ samples. 


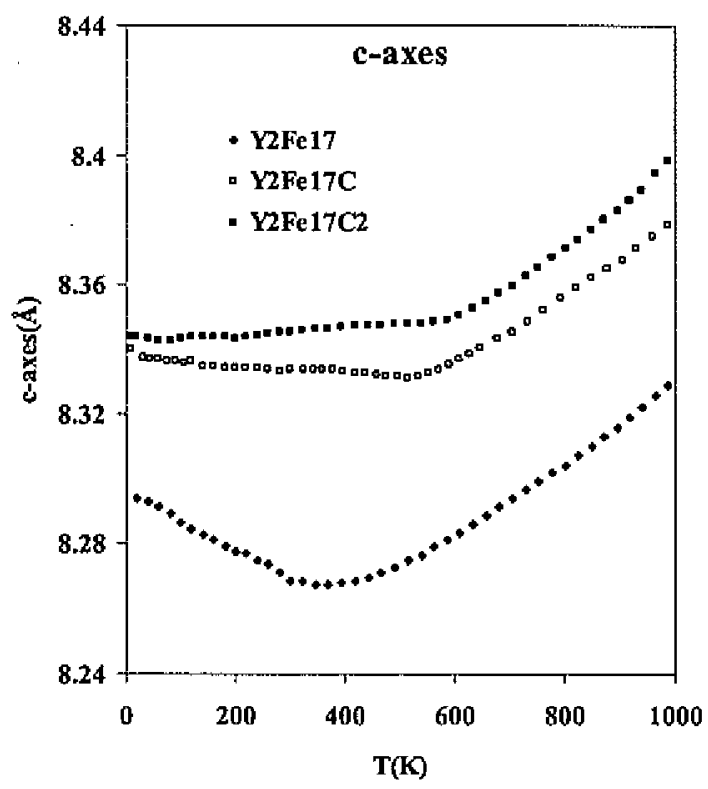

Figure 3-10. The temperature dependences of c-axes of $\mathrm{Y}_{2} \mathrm{Fe}_{17}$,

$\mathrm{Y}_{2} \mathrm{Fe}_{17} \mathrm{C}$ and $\mathrm{Y}_{2} \mathrm{Fe}_{17} \mathrm{C}_{2}$ samples. 


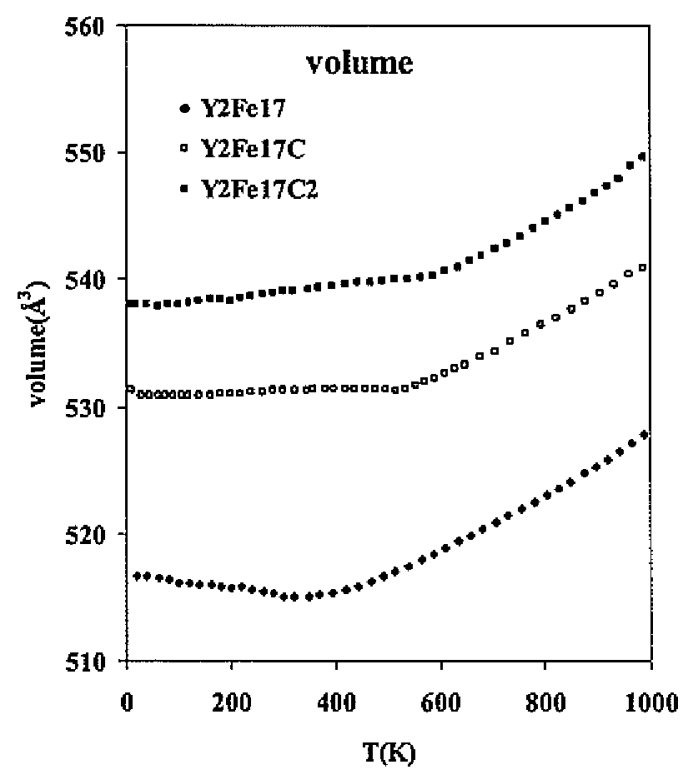

Figure 3-11. The temperature dependences of unit cell volume of $\mathrm{Y}_{2} \mathrm{Fe}_{17}, \mathrm{Y}_{2} \mathrm{Fe}_{17} \mathrm{C}$ and $\mathrm{Y}_{2} \mathrm{Fe}_{17} \mathrm{C}_{2}$ samples. 


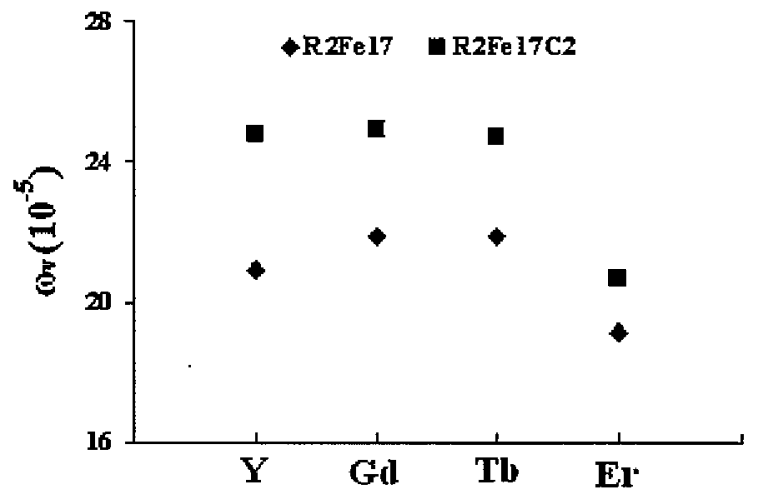

Figure 3-12. The comparison of volumetric spontaneous magnetostriction of the $\mathrm{R}_{2} \mathrm{Fe}_{17}$ and their carbides. 


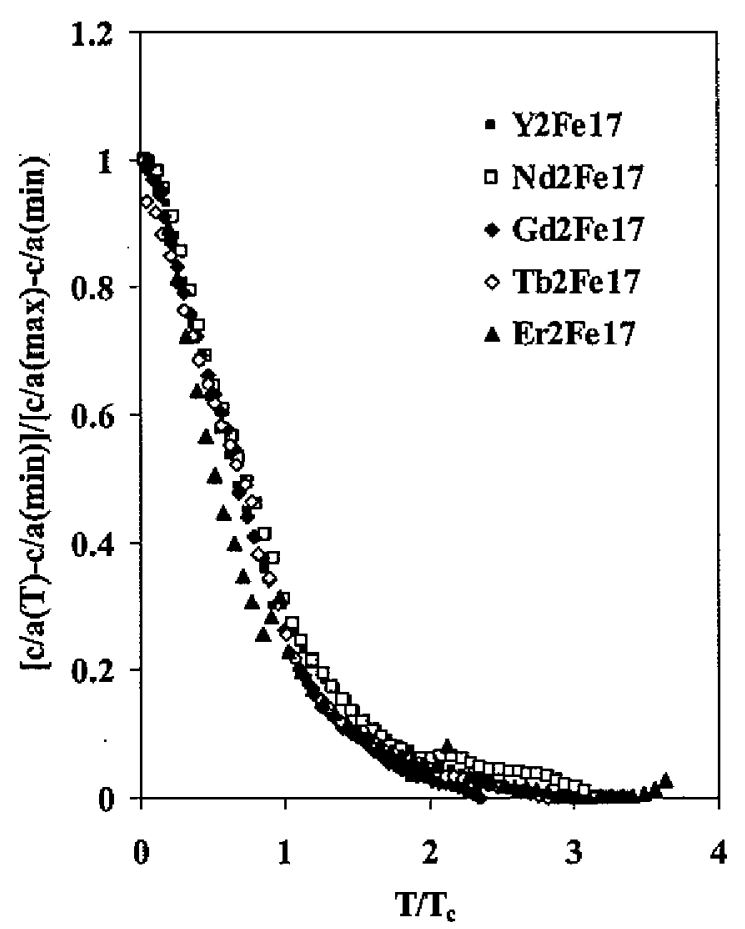

Figure 3-13. The normalized temperature dependence of the c/a of $\mathrm{R}_{2} \mathrm{Fe}_{17}$ samples, the temperature axis is also normalized to Curie temperature. 


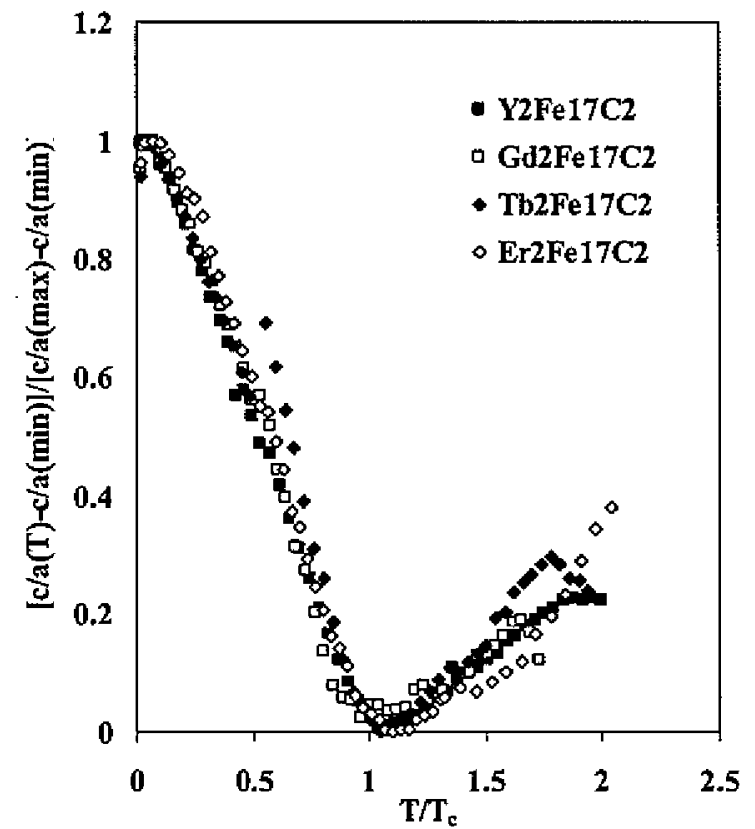

Figure 3-14. The temperature dependence of the $\mathrm{c} / \mathrm{a}$ of

$\mathrm{R}_{2} \mathrm{Fe}_{17} \mathrm{C}_{2}$ samples, the temperature axis is also normalized to Curie temperature. 


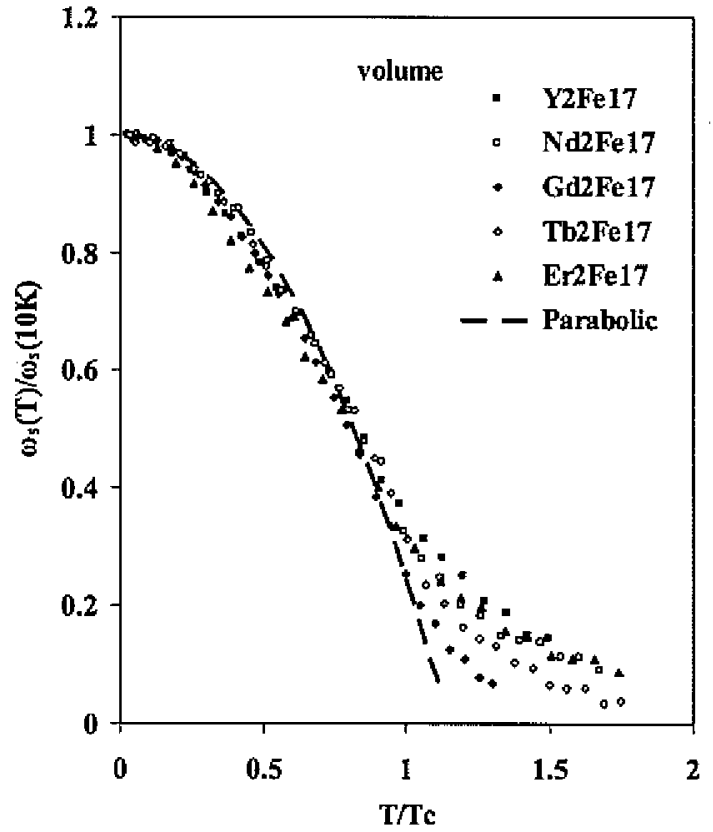

Figure 3-15. The temperature dependences $\left(T / T_{c}\right)$ of the relative volumetric spontaneous magnetostrain of $\mathrm{R}_{2} \mathrm{Fe}_{17}$ samples with Hexagonal structure. 


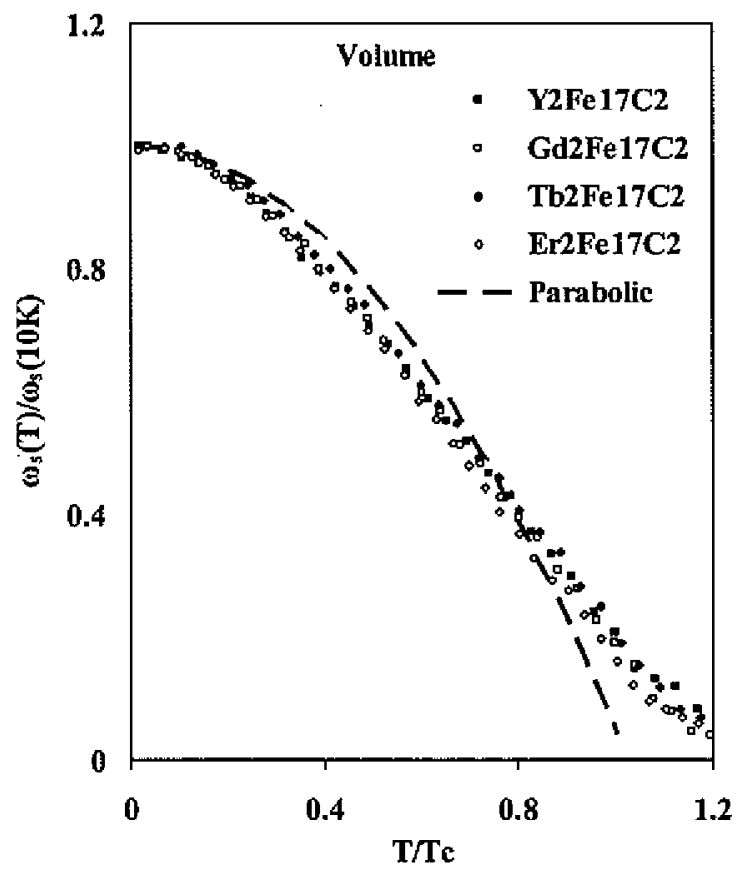

Figure 3-16. The temperature dependence $\left(T / T_{c}\right)$ of the relative volumetric spontaneous magnetostrain of $\mathrm{R}_{2} \mathrm{Fe}_{17} \mathrm{C}_{2}$ samples with rhombohedral structure. 


\subsection{REFERENCE}

${ }^{1}$ K.H.L Buschow, Ferromagnetic Materials, E.P. Wohlfarth, Vol. 1 (1980) P.297.

${ }^{2}$ O. Isnard, S. Miraglia, J.L. Soubeyroux, D. Fruchart, A. Stergious, J. Less-Common Met., 162 (1990) 273.

${ }^{3}$ X.C. Kou, R. Gtössinger, T.H. Jacobs, K.H.J. Buschow, J. Magn. Magn. Mater., 88 (1990) 1.

${ }^{4}$ X.P. Zhong, R.J. Radwański, F.R. de Boer, T.H. Jacobs, K.H.J. Buschow, J. Magn. Magn. Mater., 86(1990) 333.

${ }^{5}$ K.S.V.L Narasimhan, W.E. Wallace, R.D. Hutchens and J.E. Greedan, AIP Conf. Proc, 18,2 (1974) 1212.

${ }^{6}$ R. van Mens, J. Magn. Magn. Mater, 61 (1986) 24.

${ }^{7}$ D.B. de Mooij and K.H.J. Buschow, J. Less-Common Met., 142 (1998) 349.

${ }^{8}$ J.M.D. Coey and H. Sun, J. Magn. Magn. Mater., 87 (1990) L251.

${ }^{9}$ A.V. Andreev, Hand Book of the Magnetic Materials, Volume 8 (1995).

${ }^{10}$ D. Givord, R. Lemaire, IEEE Trans. Magn., MAG-110 (1974) 109.

11 D. Gignoux, D. Givord, F. Givord and R. Lemaire, J. Magn. Magn. Mater., 10 (1979) 288293.

${ }^{12}$ A.V. Andreev, F.R. de Boer, T.H. Jacobs and K.H.J. Buschow, J. Magn. Magn. Mater., 104-107 (1992) 1305-1307.

${ }^{13}$ A.V. Andreev and M.L. Bartashevich, J. of Less-Common Met., 162 (1990) 33-37.

${ }^{14}$ T.H. Jacobs, K.H.J. Buschow, H.Muller, R. Grossinger. J. Magn. Magn. Mater., 115 (1992) 260.

${ }^{15}$ P.C. Ezekwenna, M. Shumsky, W.J. James, Ph. l' Heritier. J. Magn. Magn. Mater., 168 (1997) 149-153.

${ }^{16}$ S.A. Nikitin, E.A. Ovtchenkov, I.S. Tereshina, A.A. Salamova and V.N. Verbetsky, J. Magn. Magn. Mater., 195 (1999) 464.

${ }^{17}$ T. Kamimori, K.Kinoshita, J. Mochimaru, K.Konishi and H. Tange, J. Magn. Magn. Mater., 226-230 (2001) 993.

${ }_{18}$ Margulies, L., M. J. Kramer, R. W. McCallum, S. Cycia, D. R. Haeffner, J. C. Lang and A. I. Goldman, Review of Scientific Instruments, 70, No. 9 (1999) 3554.

${ }^{19}$ A P Hammersley, S O Svensson, M Hanfland, A N Fitch, and D Häusermann, "TwoDimensional Detector Software: From Real Detector to Idealized Image or Two-Theta Scan", High Pressure Research, 14 (1996) 235-248.

${ }^{20}$ A.C. Larson and R.B. Von Dreele, "General Structure Analysis System (GSAS)", Los Alamos National Laboratory Report LAUR, 86 (2000) 748.

${ }_{21}$ B. H. Toby, EXPGUI, a graphical user interface for GSAS, J. Appl. Cryst, 34 (2001) 210213.

${ }^{22}$ O. Isnard, S. Miraglia, J.L. Soubeyroux and D. Fruchart, J. Alloys Comp., 190 (1992) 129135.

${ }^{23}$ Christina H. Chen, Marlin S. Walmer and Michael H. Walmer, J.Appl, Phys., 85 (1999) 5669.

${ }^{24}$ K.H.J. Buschow, R.Grössinger. J. of Less-Common Metals, 135(1987) 39-46.

${ }^{25}$ S.S. Jaswal, W.B. Yelon, G.C. Hadjipanayis, Y.Z. Wang and D.J. Sellmyer, Phys. Rev. 
Lett., 67 (1991) 644.

${ }^{26}$ Ning Yang, K. W. Dennis, R.W. McCallum, M. J. Kramer, Yuegang Zhang and Peter L. Lee, J. Magn. Magn. Mater., to be submitted.

${ }^{27}$ Ning Yang, K.W. Dennis,R.W. McCallum, M. J. Kramer, Yuegang Zhang and Peter L. Lee, Physical Review B, to be submitted. 


\title{
CHAPTER 4
}

\section{CRITICAL BOND LENGTHS AND THEIR ROLE IN SPONTANEOUS MAGNETOSTRICTION OF $\mathrm{R}_{2} \mathrm{Fe}_{17} \mathrm{C}_{\mathrm{X}}(\mathrm{R}=\mathrm{Y}, \mathrm{Nd}, \mathrm{Gd}, \mathrm{Tb}, \mathrm{Er})$}

\author{
Ning Yang ${ }^{1,2}$, K. W. Dennis ${ }^{1}$, R.W. McCallum ${ }^{1}$, M. J. Kramer ${ }^{1}$ \\ Yuegang Zhang ${ }^{2}$ and Peter L. Lee ${ }^{2}$ \\ A paper prepared for Physical Review B
}

\subsection{ABSTRACT}

High-energy high-flux synchrotron $\mathrm{x}$-ray has been used to study the spontaneous magnetostriction of $\mathrm{R}_{2} \mathrm{Fe}_{17}(\mathrm{R}=\mathrm{Y}, \mathrm{Nd}, \mathrm{Gd}, \mathrm{Tb}, \mathrm{Er})$ and their carbides in the temperature range 10-1100 K. Addition of interstitial carbon greatly increases both the Curie temperature and the spontaneous magnetostrain while reducing the anisotropy of the magnetostrain by expanding the distances between rare earth and neighboring Fe sites. The increase of Curie temperature with carbon is due to the increased spatial separation of the Fe hexagon layers. On the basal plane, the Fe hexagons are squeezed and the contribution of Fe sublattice to spontaneous magnetostriction is attenuated, while that of rare earth sublattice is enhanced. The average bond magnetostrains around $\mathrm{Fe}$ sites are in linear relation with their hyperfine field intensity.

\footnotetext{
${ }^{1}$ Ames Laboratory and the Department of Materials Science and Engineering, Iowa State University, Ames, Iowa 50010.

${ }^{2}$ Advanced Photon Source, Argonne National Laboratory, Argonne, IL 60439.
} 


\subsection{INTRODUCTION}

Large spontaneous magnetostriction has been observed in the $\mathrm{R}_{2} \mathrm{Fe}_{17}$ phase with or without interstitial atoms $(\mathrm{H}, \mathrm{C}, \mathrm{N})[1,2,3,4,5,6,7,8,9]$. It has been proposed that the large spontaneous magnetostriction is due to the short bond length in the structure, especially between specific Fe sites [10]. The negative exchange interaction is not fulfilled because of the overall structural interaction is positive. Therefore, the lattice expands to compromise the increase of the magnetic energy.

Spontaneous magnetostriction involves a complex interplay within the crystal structure (Figure 4-1) and the specific moments of the magnetic ions in the structure. Interstitials play an important role in mediating the bond lengths in many complex intermetallic compounds $[11,12]$. We investigated the role of ionic size and moment on altering the magnetostriction in the $\mathrm{R}_{2} \mathrm{Fe}_{17}(\mathrm{R}=\mathrm{Y}, \mathrm{Nd}, \mathrm{Gd}, \mathrm{Tb}, \mathrm{Er})$ family of compounds and their carbides in the temperature range $10-1100 \mathrm{~K}$. The temperature response of the bond lengths provides an indirect probe to the moments and understanding the temperature dependencies will provide further insight into the magnetic structure of this class of compounds.

In our previous paper [13], temperature dependences of the lattice parameters of the $\mathrm{R}_{2} \mathrm{Fe}_{17} \mathrm{C}_{\mathrm{x}}(\mathrm{x}=0,2)$ samples and the role of the $\mathrm{Fe}$ and rare earth sublattices on the spontaneous magnetostriction were discussed. In this paper, we will focus on the role of carbon interstitial on the structural modification and bond lengths, as well as the contribution of bonds to the spontaneous magnetostriction.

\subsection{Experimental Methods}


The experimental methods have been stated in details in the previous paper [13], but will be reviewed briefly for completeness.

The lattice parameters and bond length changes were determined by Rietveld refinement of high-energy $x$-ray diffraction patterns using GSAS software package $[14,15]$. The energy of synchrotron $x$-ray beam was set to around $80 \mathrm{KeV}(\lambda \approx 0.155 \AA)$ allowing for whole sample penetration $(2 \mathrm{~mm})$ and large wave momentum numbers $\left(Q=\frac{4 \pi \sin (\Theta)}{\lambda}\right)$ required for refining lattice parameters, atomic coordinates and thermal parameters simultaneously and accurately. The number of the individual reflections is generally 3-4 times of the total parameters refined, which will provide reliable results [16]. Using an area detector with high energy $x$-rays, we were able to demonstrate the ability to refine not only the lattice parameters to a high level of precision, but the unprecedented data quality is sufficiently precise over a large temperature range to quantify the bond length changes as a function of temperature. The thermal parameters increased linearly with temperature as expected. The accuracy of the refined atomic coordinates is at $10^{-4}$ and that of the calculated bond lengths is at $10^{-3} \AA$. We will break the results into two subsections, the modification of structure as well as bond lengths with carbon interstitial and the magnetostrain of the bonds.

\subsection{RESULTS}

The $\mathrm{R}_{2} \mathrm{Fe}_{17}$ samples were determined to be hexagonal structure. With the carbon insertion, the structure transformed to rhombohedra structure and the lattices are also expanded. The length of the analogue bonds in the two structures before and after carbonation for $\mathrm{Y}_{2} \mathrm{Fe}_{17}$, $\mathrm{Gd}_{2} \mathrm{Fe}_{17}$ and $\mathrm{Tb}_{2} \mathrm{Fe}_{17}$ are listed in Table 4-1, Table 4-2 and Table 4-3 respectively. 
The magnetostrain of the bonds were calculated in the similar way for lattice parameters [13]. The bond lengths due to phononic thermal expansion were extrapolated from paramagnetic range to the $10 \mathrm{~K}$ and the difference between the extrapolated and measured bond lengths were calculated. The magnetostrain is determined as the difference of these values divided by the measured bond length. The results are listed in Table 4-4, Table 4-5 and Table 4-6 for $\mathrm{R}_{2} \mathrm{Fe}_{17}$ with hexagonal structure, $\mathrm{Nd}_{2} \mathrm{Fe}_{17}$ and $\mathrm{R}_{2} \mathrm{Fe}_{17} \mathrm{C}_{2}$ respectively. The temperature dependences of bond lengths (Fe(4f)_Fe(6c), $\mathrm{Fe}(4 \mathrm{f}) \_\mathrm{Fe}(12 \mathrm{k}), \mathrm{Fe}(4 \mathrm{f}) \mathrm{Fe}(12 \mathrm{j})$, $\left.\mathrm{Fe}(6 \mathrm{c}) \mathrm{Fe}(12 \mathrm{k}), \mathrm{Fe}(12 \mathrm{j}) \_\mathrm{Fe}(12 \mathrm{j})\right)$ in the samples with hexagonal structure are plotted

(Figure 4-2 to Figure 4-6) and that of bond lengths ( $\mathrm{Fe}(6 \mathrm{c}) \_\mathrm{Fe}(9 \mathrm{~d}), \mathrm{Fe}(6 \mathrm{c}) \mathrm{Fe}(18 \mathrm{f})$, $\mathrm{Fe}(6 \mathrm{c}) \_\mathrm{Fe}(18 \mathrm{~h})$ in $\mathrm{Nd}_{2} \mathrm{Fe}_{17}$ are plotted in Figure 4-8.

In order to distinguish the contribution of different $\mathrm{Fe}$ sites, the average bond magnetostrain around Fe sites were calculated and listed in Table 4-7. The average bond magnetostrain versus the hyperfine field intensity of the different site in samples are shown in Figure 4-9.

\subsection{DISCUSSION}

\subsubsection{The Bond Length Change with Interstitial Carbon}

The interstitial atoms in the $\mathrm{R}_{2} \mathrm{Fe}_{17}$ structure expand the lattice and induce a polymorphic transformation of the hexagonal $\left(\mathrm{P} 6_{3} / \mathrm{mmc}\right)$ to the rhombohedral $(\mathrm{R}-3 \mathrm{~m})$ space group. The atomic position of carbon is at 9e site [17]. Although the space group and total number of the atoms in one unit cell are different in the two variants, both of them are strongly related to the $\mathrm{CaCu}_{5}$ structure. Comparing the analogous $\mathrm{Fe}$ and rare earth sublattices in the two 
variants with and without carbon will provide a direct measurement of the role the bond lengths have in mediating the magnetic interactions.

Table 4-1, Table 4-2 and Table 4-3 list the comparison of the similar bonds between the two variants of $\mathrm{R}_{2} \mathrm{Fe}_{17}$ and their carbides with $\mathrm{R}=\mathrm{Y}, \mathrm{Gd}$, Tb respectively. The effect of the carbon is to increase the distance between the rare earths and their neighboring Fe sites. This is in agreement with other's result [18]. J.P. Liu studied the magnetic coupling in a series of interstitial $\mathrm{Er}_{2} \mathrm{Fe}_{17} \mathrm{C}_{\mathrm{x}}$ compounds using a high field free-powder method (HFFP) [19]. It was reported that a monotonical decrease of the Er-Fe exchange interaction occurred with the increasing carbon content, which was attributed to the increasing spatial separation and the distance dependence of the interatomic $3 \mathrm{~d}-5 \mathrm{~d}$ interaction. A reduction in hybridization between the $3 \mathrm{~d}$ and $5 \mathrm{~d}$ shell occurs with increasing interatomic distance and thus a larger spatial separation between $3 \mathrm{~d}$ and $5 \mathrm{~d}$ shells. Our result is a direct observation of the increased spatial separation and provides strong support for their explanations.

On the other hand, the bond lengths in the Fe sublattice primarily decreased with carbon. The largest effect is the bonds between dumbbell sites and its neighboring sites; $\mathrm{Fe}(4 \mathrm{f}) \_\mathrm{Fe}(6 \mathrm{~g}), \mathrm{Fe}(4 \mathrm{f}) \_\mathrm{Fe}(12 \mathrm{j}), \mathrm{Fe}(4 \mathrm{f}) \_\mathrm{Fe}(12 \mathrm{k})$ in hexagonal variant and $\mathrm{Fe}(6 \mathrm{c}) \mathrm{Fe}(9 \mathrm{~d})$, $\mathrm{Fe}(6 \mathrm{c}) \_\mathrm{Fe}(18 \mathrm{f}), \mathrm{Fe}(6 \mathrm{c}) \mathrm{Fe}(18 \mathrm{~h})$ in rhombohedral variant respectively. The bonds in the hexagons above and below the dumbbell sites also shrink; ( $F e(6 g) \_F e(12 k), F e(12 j) \_F e(12 j)$ in hexagonal variant and $\mathrm{Fe}(9 \mathrm{~d}) \_\mathrm{Fe}(18 \mathrm{~h}), \mathrm{Fe}(18 \mathrm{f}) \_\mathrm{Fe}(18 \mathrm{f})$ in rhombohedral variant. The distances between the two hexagonal layers are enlarged. The increased Curie temperature of the interstitially modified $\mathrm{R}_{2} \mathrm{Fe}_{17}$ has been attributed to the larger cell volume and stronger exchange interactions between $\mathrm{Fe}$ sites. Our results show that not all the $\mathrm{Fe}-\mathrm{Fe}$ bond distances are expanded, but those bonds critical to the increase of the Curie temperature do 
increase; $\mathrm{Fe}(6 \mathrm{~g}) \mathrm{Fe}(12 \mathrm{j}), \mathrm{Fe}(12 \mathrm{k}) \_\mathrm{Fe}(12 \mathrm{j})$ in hexagonal variant and $\mathrm{Fe}(9 \mathrm{~d}) \_\mathrm{Fe}(18 \mathrm{f})$, Fe(18h)_Fe(18f) in rhombohedral variant respectively [18].

\subsubsection{The spontaneous magnetostriction of the bonds}

\subsubsection{The Hexagonal Structure}

The $\mathrm{Y}_{2} \mathrm{Fe}_{17}, \mathrm{Gd}_{2} \mathrm{Fe}_{17}, \mathrm{~Tb}_{2} \mathrm{Fe}_{17}$ and $\mathrm{Er}_{2} \mathrm{Fe}_{17}$ are the hexagonal variant (Figure 4-1). The dumbbell structure $(\mathrm{Fe}(4 \mathrm{f}) \mathrm{Fe}(4 \mathrm{f}))$ has the shortest bond length while these atoms have the largest magnetic moment in this structure. This atom pair is magnetically and crystallographically cognate with the $\mathrm{Fe}(\mathrm{j} 2)$ sites in the $\mathrm{R}_{2} \mathrm{Fe}_{14} \mathrm{~B}[20]$.

The magnetostrains of the bonds are listed in Table 4-5. Comparing the temperature dependences of the same bonds in samples with different rare earths, the trend in the change of the bond lengths with the temperature are very similar even though the magnetostrains differ. This confirms that the spontaneous magnetostriction of the $\mathrm{R}_{2} \mathrm{Fe}_{17}$ is dominated by the Fe sublattice [13] but the exchange interactions between neighboring sites are modified by the rare earth atoms.

The Fe(4f) sites have the largest magnetic moment and the highest coordination number [20]. The average bond length of $\mathrm{Fe}(4 \mathrm{f}) \mathrm{Fe}(6 \mathrm{~g}), \mathrm{Fe}(4 \mathrm{f}) \_\mathrm{Fe}(12 \mathrm{k}), \mathrm{Fe}(4 \mathrm{f}) \_\mathrm{Fe}(12 \mathrm{j})$ are $2.68 \AA$, $2.73 \AA, 2.84 \AA$ respectively, which are the largest bond lengths between $\mathrm{Fe}$ sites in the hexagonal structure. It has been suggested that local environment (Wigner-Seitz atomic cell volume) determines the local magnetic moments of the Fe sites by changing the degree of the orbital overlapping with the surrounding atoms [21]. The largest $\mathrm{Fe}(4 \mathrm{f})$ associated bonds induce the largest Wigner-Seitz atomic cell volume of $\mathrm{Fe}(4 \mathrm{f})$ sites, resulting the largest magnetic moment[21]. 
The temperature dependences of those bond lengths are plotted in Figure 4-2, Figure 4-3 and Figure 4-4. Comparing these figures, the spontaneous magnetostriction of the $\mathrm{Fe}(4 \mathrm{f}) \mathrm{Fe}(12 \mathrm{j})$ is larger than that of $\mathrm{Fe}(4 \mathrm{f}) \_\mathrm{Fe}(6 \mathrm{~g})$ and $\mathrm{Fe}(4 \mathrm{f}) \_\mathrm{Fe}(12 \mathrm{k})$ bonds while the average magnetostrain for these three bonds is roughly proportional to their bond lengths (Table 4-5). This is contrary to the argument that the shorter the bonds length, the larger the magnetostrain.

The bond length of the dumbbell structure is the shortest one in the structure $(\approx 2.30 \AA)$ and remains fairly constant or decreases with increasing temperature. It is the only bond exhibiting such behavior and is probably due to the strong magnetic couplings between $\mathrm{Fe}(4 \mathrm{f})$ and $\mathrm{Fe}(12 \mathrm{j})$. The dumbbell pairs penetrate the hexagons of $\mathrm{Fe}(12 \mathrm{j})$ sites so that the strong magnetostrain between $\mathrm{Fe}(4 \mathrm{f})$ and $\mathrm{Fe}(\mathrm{j} 2)$ prevents the bond length of dumbbell structure from increasing.

The sublattices centered on the Fe(4f) sites (Figure 4-5) play an important role on the spontaneous magnetostriction of the structure. This is very similar to the contribution of the hexagonal sublattice in the $\mathrm{R}_{2} \mathrm{Fe}_{14} \mathrm{~B}$ phases [20]. The hexagons themselves also play an important role on the magnetostriction of the structure. Figure 4-5 and Figure 4-6 illustrate the temperature dependence of the bond lengths in the hexagon formed by $\mathrm{Fe}(12 \mathrm{j})$ sites and by $\mathrm{Fe}(6 \mathrm{~g})$ and $\mathrm{Fe}(12 \mathrm{k})$ sites respectively. The $\mathrm{Fe}(12 \mathrm{j}) \mathrm{Fe}(12 \mathrm{j})$ bonds show stronger magnetostrain than the $\mathrm{Fe}(6 \mathrm{~g}) \mathrm{Fe}(12 \mathrm{k})$ bonds.

\subsubsection{The Rhombohedral Structure}

Although the space group symmetry and structure are different between hexagonal and rhombohedral polymorphs, there are similar Fe sublattices in the two structures (Figure 4-7), 
except that the Fe sites have different Wycoff notations $F e(4 c), F e(6 g), F e(12 j)$ and $F e(12 k)$ in hexagonal variant are $\mathrm{Fe}(6 \mathrm{f}), \mathrm{Fe}(9 \mathrm{~d}), \mathrm{Fe}(18 \mathrm{f})$ and $\mathrm{Fe}(18 \mathrm{~h})$ in rhombohedral variant respectively. The $\mathrm{Fe}(4 \mathrm{f})$ in the hexagonal and the $\mathrm{Fe}(6 \mathrm{c})$ in rhombohedral structures have the largest coordination numbers and the largest magnetic moments.

Figure 4-8 shows the temperature dependences of the bonds between the $\mathrm{Fe}(6 \mathrm{c})$ and its neighboring sites in $\mathrm{Nd}_{2} \mathrm{Fe}_{17}$, from which we can see that the $\mathrm{Fe}(6 \mathrm{c}) \mathrm{Fe}(18 \mathrm{f})$ bond shows a relatively larger magnetostrain than $\mathrm{Fe}(6 \mathrm{c}) \mathrm{Fe}(9 \mathrm{~d})$ and $\mathrm{Fe}(6 \mathrm{c}) \_\mathrm{Fe}(18 \mathrm{~h})$ bonds. This is very similar to the results in the hexagonal structure.

The carbon interstitial modifies the bond lengths of the Fe sublattice and their local environment, inducing changes of the magnetostrain of the bonds. The calculated magnetostrain listed in Table.4-7 shows the $\mathrm{Fe}(6 \mathrm{c}) \mathrm{Fe}(18 \mathrm{f})$ bond still retain a higher magnetostrain than $\mathrm{Fe}(6 \mathrm{c}) \_\mathrm{Fe}(9 \mathrm{~d})$ and $\mathrm{Fe}(6 \mathrm{c}) \mathrm{Fe}(18 \mathrm{~h})$ bonds. But compared with their analogue bonds in their parent phases, the ones in the compounds with carbon have smaller magnetostrains. This can be attributed to the shotter bond lengths. While the carbon atoms expand the lattice, the Fe sublattice is squeezed due to the neighboring carbons site. As a result, the carbon interstitials attenuates the contribution of the Fe sublattice to the total spontaneous magnetostriction.

On whole, the lattice magnetostrain of the $\mathrm{R}_{2} \mathrm{Fe}_{17} \mathrm{C}_{2}$ phases are higher than their parent compound, which can only be due to enhanced magnetostrain of rare earth sublattice or the intersublattice of rare earth and Fe. The bond lengths between two neighboring rare earth sites are about $4 \AA$ and the direct interaction between two rare earth sites hardly exists. So the interaction between the rare earth and Fe sites is the only possible reason for the increase of the lattice magnetostrain. The interstitial carbon atoms expand the bond length between the 
rare earth and Fe sites and the exchange interactions which were proposed, appear to be decreased [19]. Comparing the magnetostrain of the analogue $\mathrm{R}-\mathrm{Fe}$ bonds in both phases, the expanded R-Fe bonds result in higher magnetostrains. This suggests that the magnetostrain of rare earth $\mathrm{Fe}$ bonds is reverse proportional to the strength of the rare earth $\mathrm{Fe}$ exchange interaction. This is probably due to the antiparallel spin magnetic moment of rare earth and Fe. The Fe-Fe exchange interaction as well as the magnetostrain is proportional to the spatial separation and the spin moment of Fe sites are parallel to each other. With the antiparalleI spin moments, the exchange interactions are reverse proportional to the spatial separation but the magnetostrain is proportional to the spatial separations. Therefore, the higher structural magnetostrain of the $\mathrm{R}_{2} \mathrm{Fe}_{17} \mathrm{C}_{2}$ comes from the higher magnetostrain between rare earth and Fe sites. It also explains the non-parabolic behaviors of the relative spontaneous magnetostriction curve of $\mathrm{R}_{2} \mathrm{Fe}_{17} \mathrm{C}_{2}$ [13].

\subsubsection{The Contribution of $R$ and Fe Sites}

There are four different Fe sites in both structures, contributing differently to the structural magnetostriction due to their different environments and magnetic moments. The coordination numbers for the $\mathrm{Fe}(4 \mathrm{f}), \mathrm{Fe}(6 \mathrm{~g}), \mathrm{Fe}(12 \mathrm{j})$ and $\mathrm{Fe}(12 \mathrm{k})$ in hexagonal structure are $13,10,10$ and 10 respectively and for the $F e(6 c), F e(9 d), F e(18 f)$ and $F e(18 h)$ in the rhombohedral structure are $13,10,10$ and 9 respectively. The contribution of the different sites can be quantified by averaging the magnetostrain of the surrounding bonds (Table 4-8). It can be seen that the $\mathrm{Fe}(4 \mathrm{f})$ in hexagonal structure and $\mathrm{Fe}(6 \mathrm{c})$ in the rhombohedral structure have the largest values, which is very likely related to their largest magnetic moment in the whole structure [20]. The magnitude of the average bond magnetostrain is consistent with 
that of magnetic moments measured at $4 \mathrm{~K}$ for $\mathrm{Nd}_{2} \mathrm{Fe}_{17}$ [17], which suggests that careful structural analysis can be used to determine the magnitude magnetic moment on the atomic site .

The local, site-dependent information regarding magnetic moments can also be obtained from the Mössbauer spectroscopy. The hyperfine field intensity of each crystallographic site for $\mathrm{R}_{2} \mathrm{Fe}_{17}$ and the interstitial compounds have been measured $[22,23,24]$ and are proportional to their magnetic moments. The average bond magnetostrains versus their hyperfine field intensities are shown in Figure 4-9. The linear plots imply a strong relation between the hyperfine field intensities and the average bond magnetostrains. The hyperfine field in metals

is largely due to the Fermi contact term $B_{s}$, which is proportional to the unpaired spin density at the nucleus [25]. As a result, the spin density at the nucleus is proportional to the average magnetostrain of bonds around it. This confirms again that the spin density determines the interactions between $\mathrm{Fe}$ sites and therefore the magnetostrain between the sites [26].

It also can be seen that the average magnetostrain around $\mathrm{Fe}$ sites in the carbides have smaller values than those similar sites in the parent compounds, which again confirms that the carbon interstitial decreases the contribution of Fe sublattice. On the contrary, the $R(6 c)$ sites in the carbides have a larger average magnetostrain value than the $R(2 b)$ and $R(2 d)$ sites in the parent compounds, which implies an increased contribution from rare earth $\mathrm{Fe}$ intersublattice with the carbon interstitials.

\subsection{CONCLUSION}

The bond length calculation shows that the interstitial carbon expands the distances between rare earth and the neighboring Fe sites but squeeze the Fe hexagons. The higher 
Curie temperature with carbon interstitial atoms is due to the further separation of the two hexagonal sublayers.

The magnetostrain calculation of different bonds in the structure of $\mathrm{R}_{2} \mathrm{Fe}_{17}$ shows that all the bonds associated with $\mathrm{Fe}(4 \mathrm{f})$ and $\mathrm{Fe}(6 \mathrm{c})$ have relatively larger values, which are related to the largest magnetic moment on those sites. The magnetostrains of the analogue $\mathrm{Fe}-\mathrm{Fe}$ bonds were decreased with shorter bond length in the $\mathrm{R}_{2} \mathrm{Fe}_{17} \mathrm{C}_{2}$ phases compared with $\mathrm{R}_{2} \mathrm{Fe}_{17}$ phases, but those of R-Fe bonds were increased. The magnetostrain for both $\mathrm{Fe}-\mathrm{Fe}$ bonds and $\mathrm{R}-\mathrm{Fe}$ bonds seem to be proportional to their bond lengths, which is contrary to the deduction from the negative interaction theory. The average bond magnetostrain around one site is strongly related to its hyperfine field strength, which may suggest a new way to determine the relative magnetic moments of the atomic sites.

\subsection{ACKNOWLEDGEMENTS}

The author would like to thanks David Welch for his insightful comments. The work at Ames Laboratory was supported by the United States Department of Energy (USDOE), Office of Science (OS), Office of Basic Energy Sciences (BES), through Iowa State University under Contract W-7405-ENG-82. The Midwest Universities Collaborative Access Team (MUCAT) sector at the APS is supported by the U.S. Department of Energy, Basic Energy Sciences, Office of Science, through the Ames Laboratory under Contract No. W-7405-Eng-82. Use of the Advanced Photon Source was supported by the U.S. Department of Energy, Basic Energy Sciences, Office of Science, under Contract No. W-31-109-Eng-38. 


\subsection{CAPTIONS}

Table 4-1. The bond length change upon the carbonation in $\mathrm{Y}_{2} \mathrm{Fe}_{17}$, the unit is $\AA$.

Table 4-2. The bond length change upon the carbonation in $\mathrm{Gd}_{2} \mathrm{Fe}_{17}$, the unit is $\AA$.

Table 4-3. The bond length change upon the carbonation in $\mathrm{Tb}_{2} \mathrm{Fe}_{17}$, the unit is $\AA$.

Table 4-5. The magnetostrain of the bonds $(\angle 4 \AA)$ in the $\mathrm{R}_{2} \mathrm{Fe}_{17}$ with Hexagonal structure.

Table 4-6. The magnetostrain of the bonds $(<4 \AA)$ in the $\mathrm{Nd}_{2} \mathrm{Fe}_{17}$ structure with rhombohedral modification.

Table 4-7. The magnetostrains of the bonds ( $<4 \AA)$ in $\mathrm{R}_{2} \mathrm{Fe}_{17} \mathrm{C}_{2}$ samples.

Table 4-8. The average magnetostrain of the bonds around different sites in the sample studied.

Figure 4-1. Crystal structure of $\mathrm{R}_{2} \mathrm{Fe}_{17}$, a. Hexagonal modification, $\mathrm{Th}_{2} \mathrm{Ni}_{17}$ type; b. Rhombohedral modification, $\mathrm{Th}_{2} \mathrm{Zn}_{17}$ type.

Figure 4-2. The temperature dependences of $\mathrm{Fe}(4 \mathrm{f}) \_\mathrm{Fe}(6 \mathrm{~g})$ bond lengths in $\mathrm{R}_{2} \mathrm{Fe}_{17}$ samples with hexagonal structure.

Figure 4-3. The temperature dependences of $\mathrm{Fe}(4 \mathrm{f}) \mathrm{Fe}(12 \mathrm{k})$ bond lengths in $\mathrm{R}_{2} \mathrm{Fe}_{17}$ samples with hexagonal structure.

Figure 4-4. The temperature dependences of $\mathrm{Fe}(4 \mathrm{f}) \_\mathrm{Fe}(12 \mathrm{j})$ bond lengths in $\mathrm{R}_{2} \mathrm{Fe}_{17}$ samples with hexagonal structure.

Figure 4-5. The temperature dependences of $\mathrm{Fe}(6 \mathrm{~g})$ Fe(12k) bond lengths in $\mathrm{R}_{2} \mathrm{Fe}_{17}$ samples with hexagonal structure.

Figure 4-6. The temperature dependences of $\mathrm{Fe}(12 \mathrm{j}) \mathrm{Fe}(12 \mathrm{j})$ bond lengths in $\mathrm{R}_{2} \mathrm{Fe}_{17}$ samples with hexagonal structure.

Figure 4-7. The Fe sublattice in $\mathrm{R}_{2} \mathrm{Fe}_{17} \mathrm{C}_{\mathrm{x}}(\mathrm{x}=0,2)$ structure. 
Figure 4-8. The temperature dependences of $\mathrm{Fe}(6 \mathrm{c}) \mathrm{Fe}(9 \mathrm{~d}), \mathrm{Fe}(6 \mathrm{c}) \mathrm{Fe}(18 \mathrm{f})$ and $\mathrm{Fe}(6 \mathrm{c}) \_\mathrm{Fe}(18 \mathrm{~h})$ bond lengths in $\mathrm{Nd}_{2} \mathrm{Fe}_{17}$ sample.

Figure 4-9. The average magnetostrains of sites vs. the Mössbauer hyperfine field intensity in some samples studied. 
Table 4-1. The bond length change upon the carbonation in $\mathrm{Y}_{2} \mathrm{Fe}_{17}$, the unit is $\AA$.

\begin{tabular}{|c|c|c|c|c|}
\hline $\begin{array}{c}\text { Bonds } \\
\text { (Hexagonal) }\end{array}$ & $\begin{array}{c}\text { Bonds } \\
\text { (Rhombohedral) }\end{array}$ & $\begin{array}{r}\mathrm{Y}_{2} \mathrm{Fe}_{17} \\
( \pm 0.005) \\
\end{array}$ & $\begin{array}{r}\mathrm{Y}_{2} \mathrm{Fe}_{17} \mathrm{C}_{2} \\
( \pm 0.005)\end{array}$ & $\begin{array}{c}\mathrm{Y}_{2} \mathrm{Fe}_{17} \mathrm{C}_{2^{2}} \mathrm{Y}_{2} \mathrm{Fe}_{17} \\
( \pm 0.01)\end{array}$ \\
\hline$Y(2 d) \_F e(6 g)$ & $\mathrm{Y}(6 \mathrm{c}) \_\mathrm{Fe}(9 \mathrm{~d})$ & 3.211 & 3.288 & 0.08 \\
\hline $\mathrm{Y}(2 \mathrm{~d}) \_\mathrm{Fe}(12 \mathrm{j})$ & $\mathrm{Y}(6 \mathrm{c}) \_\mathrm{Fe}(18 \mathrm{f})$ & 2.982 & 3.075 & 0.09 \\
\hline $\mathrm{Y}(2 \mathrm{~b}) \ldots \mathrm{Fe}(12 \mathrm{k}) \mathbf{a}$ & $\mathrm{Y}(6 \mathrm{c}) \_\mathrm{Fe}(18 \mathrm{~h}) 1$ & 3.185 & 3.182 & 0 \\
\hline $\mathrm{Y}(2 \mathrm{~b}) \_\mathrm{Fe}(12 \mathrm{k}) \mathrm{b}$ & $\mathrm{Y}(6 \mathrm{c}) \_\mathrm{Fe}(18 \mathrm{~h}) 2$ & 3.146 & 3.170 & 0.02 \\
\hline $\mathrm{Y}(2 \mathrm{~d}) \_\mathrm{Fe}(12 \mathrm{k})$ & $Y(6 c) \_F e(18 h) 3$ & 3.239 & 3.327 & 0.09 \\
\hline $\mathrm{Fe}(4 f) \_F e(4 f)$ & $\mathrm{Fe}(6 \mathrm{c}) \_\mathrm{Fe}(6 \mathrm{c})$ & 2.320 & 2.314 & 0 \\
\hline $\mathrm{Fe}(4 \mathrm{f}) \_\mathrm{Fe}(6 \mathrm{~g})$ & $\mathrm{Fe}(6 \mathrm{c}) \_\mathrm{Fe}(9 \mathrm{~d})$ & 2.662 & 2.664 & 0 \\
\hline $\mathrm{Fe}(4 \mathrm{f}) \_\mathrm{Fe}(\mathrm{I} 2 \mathrm{j})$ & $\mathrm{Fe}(6 \mathrm{c}) \_\mathrm{Fe}(18 \mathrm{f})$ & $2.89 \mathrm{I}$ & 2.777 & -0.11 \\
\hline $\mathrm{Fe}(4 \mathrm{f}) \_\mathrm{Fe}(12 \mathrm{k})$ & $\mathrm{Fe}(6 \mathrm{c}) \_\mathrm{Fe}(18 \mathrm{~h})$ & 2.730 & 2.680 & -0.05 \\
\hline $\mathrm{Fe}(6 \mathrm{~g}) \_\mathrm{Fe}(12 \mathrm{j})$ & $\mathrm{Fe}(9 \mathrm{~d}) \_\mathrm{Fe}(18 \mathrm{f})$ & 2.490 & 2.450 & -0.04 \\
\hline $\mathrm{Fe}(6 \mathrm{~g}) \_\mathrm{Fe}(12 \mathrm{k})$ & $\mathrm{Fe}(9 \mathrm{~d}) \_\mathrm{Fe}(18 \mathrm{~h})$ & 2.484 & 2.480 & 0 \\
\hline $\mathrm{Fe}(12 \mathrm{j}) \_\mathrm{Fe}(12 \mathrm{j})$ & $\mathrm{Fe}(18 \mathrm{f}) \_\mathrm{Fe}(18 \mathrm{f})$ & 2.750 & 2.520 & -0.23 \\
\hline $\mathrm{Fe}(12 \mathrm{k}) \_\mathrm{Fe}(12 \mathrm{j}) \mathrm{a}$ & $\mathrm{Fe}(18 \mathrm{f}) \_\mathrm{Fe}(18 \mathrm{~h}) \mathrm{a}$ & 2.564 & 2.563 & 0 \\
\hline $\mathrm{Fe}(12 \mathrm{k}) \_\mathrm{Fe}(12 \mathrm{j}) \mathrm{b}$ & $\mathrm{Fe}(18 \mathrm{f}) \_\mathrm{Fe}(18 \mathrm{~h}) \mathrm{b}$ & 2.489 & 2.662 & 0.17 \\
\hline $\mathrm{Fe}(12 \mathrm{k}) \_\mathrm{Fe}(12 \mathrm{k})$ & $\mathrm{Fc}(18 \mathrm{~h}) \_\mathrm{Fe}(18 \mathrm{~h})$ & 2.394 & 2.541 & 0.15 \\
\hline
\end{tabular}


Table 4-2. The bond length change upon the carbonation in

$$
\mathrm{Gd}_{2} \mathrm{Fe}_{17} \text {, the unit is } \AA \text {. }
$$

\begin{tabular}{|c|c|c|c|c|}
\hline $\begin{array}{c}\text { Bond } \\
\text { (Hexagonal) }\end{array}$ & $\begin{array}{c}\text { Bonds } \\
\text { (Rhombohedral) }\end{array}$ & $\begin{array}{l}\mathrm{Gd}_{2} \mathrm{Fe}_{17} \\
( \pm 0.005)\end{array}$ & $\begin{array}{c}\mathrm{Gd}_{2} \mathrm{Fe}_{17} \mathrm{C}_{2} \\
( \pm 0.005)\end{array}$ & $\begin{array}{c}\mathrm{Gd}_{2} \mathrm{Fe}_{17} \mathrm{C}_{2}-\mathrm{Gd}_{2} \mathrm{Fe}_{17} \\
( \pm 0.01)\end{array}$ \\
\hline$\overline{G D}(2 \mathrm{~d}) \_F e(6 \mathrm{~g})$ & $\mathrm{GD}(6 \mathrm{c}) \_\mathrm{Fe}(9 \mathrm{~d})$ & 3.222 & 3.321 & 0.10 \\
\hline $\mathrm{GD}(2 \mathrm{~d}) \_\mathrm{Fe}(12 \mathrm{j})$ & $\mathrm{GD}(6 \mathrm{c}) \_\mathrm{Fe}(18 \mathrm{f})$ & 2.915 & 3.115 & 0.2 \\
\hline $\mathrm{GD}(2 \mathrm{~b}) \_\mathrm{Fe}(12 \mathrm{k}) 1$ & $\mathrm{GD}(6 \mathrm{c}) \_\mathrm{Fe}(18 \mathrm{~h}) 1$ & 3.213 & 3.190 & -0.02 \\
\hline $\mathrm{GD}(2 \mathrm{~b}) \_\mathrm{Fe}(12 \mathrm{k}) 2$ & $\mathrm{GD}(6 \mathrm{c}), \mathrm{Fe}(18 \mathrm{~h}) 2$ & 3.165 & 3.142 & -0.02 \\
\hline $\mathrm{GD}(2 \mathrm{~d}) \_\mathrm{Fe}(12 \mathrm{k})$ & $\mathrm{GD}(6 \mathrm{c}) \_\mathrm{Fe}(18 \mathrm{~h}) 3$ & 3.233 & 3.333 & 0.1 \\
\hline$F e(4 f) \_F e(4 f)$ & $\mathrm{Fe}(6 \mathrm{c}) \_\mathrm{Fe}(6 \mathrm{c})$ & 2.340 & 2.345 & 0 \\
\hline $\mathrm{Fe}(4 \mathrm{f}) \_\mathrm{Fe}(6 \mathrm{~g})$ & $\mathrm{Fe}(6 \mathrm{c}) \_\mathrm{Fe}(9 \mathrm{~d})$ & 2.752 & 2.668 & -0.08 \\
\hline $\mathrm{Fe}(4 \mathrm{f}) \_\mathrm{Fe}(12 \mathrm{j})$ & $\mathrm{Fe}(6 \mathrm{c}) \_\mathrm{Fe}(18 \mathrm{f})$ & 2.853 & 2.755 & -0.10 \\
\hline $\mathrm{Fe}(4 \mathrm{f})_{m} \mathrm{Fe}(12 \mathrm{k})$ & $\mathrm{Fe}(6 \mathrm{c}) \_\mathrm{Fe}(18 \mathrm{~h})$ & 2.808 & 2.688 & -0.12 \\
\hline $\mathrm{Fe}(6 \mathrm{~g}) \_\mathrm{Fe}(12 \mathrm{j})$ & $\mathrm{Fe}(9 \mathrm{~d}) \_\mathrm{Fe}(18 \mathrm{f})$ & 2.494 & 2.456 & -0.04 \\
\hline $\mathrm{Fe}(6 \mathrm{~g}) \_\mathrm{Fe}(12 \mathrm{k})$ & $\mathrm{Fe}(9 \mathrm{~d}) \_\mathrm{Fe}(18 \mathrm{~h})$ & 2.485 & 2.491 & 0.01 \\
\hline $\mathrm{Fe}(12 \mathrm{j}) \mathrm{Fe}(12 \mathrm{j})$ & $\mathrm{Fe}(18 \mathrm{f}) \_\mathrm{Fe}(18 \mathrm{f})$ & 2.746 & 2.493 & -0.25 \\
\hline $\mathrm{Fe}(12 \mathrm{k}) \_\mathrm{Fe}(12 \mathrm{j}) \mathrm{a}$ & $\mathrm{Fe}(18 \mathrm{f}) \_\mathrm{Fe}(18 \mathrm{~h}) \mathrm{a}$ & 2.558 & 2.583 & 0.02 \\
\hline $\mathrm{Fe}(12 \mathrm{k})_{-} \mathrm{Fe}(12 \mathrm{j}) \mathrm{b}$ & $\mathrm{Fe}(18 \mathrm{f})_{-} \mathrm{Fe}(18 \mathrm{~h}) \mathrm{b}$ & 2.514 & 2.673 & 0.16 \\
\hline $\mathrm{Fe}(12 \mathrm{k}) \mathrm{Fe}(12 \mathrm{k})$ & $\mathrm{Fe}(18 \mathrm{~h}) \mathrm{Fe}(18 \mathrm{~h})$ & 2.419 & 2.565 & 0.15 \\
\hline
\end{tabular}


Table 4-3. The bond length change upon the carbonation in

$\mathrm{Tb}_{2} \mathrm{Fe}_{17}$, the unit is $\AA$.

\begin{tabular}{|c|c|c|c|c|}
\hline $\begin{array}{c}\text { Bonds } \\
\text { (Hexagonal) }\end{array}$ & $\begin{array}{c}\text { Bonds } \\
\text { (Rhombohedral) }\end{array}$ & $\begin{array}{l}\mathrm{Tb}_{2} \mathrm{Fe}_{17} \\
( \pm 0.005)\end{array}$ & $\begin{array}{r}\mathrm{Tb}_{2} \mathrm{Fe}_{17} \mathrm{C}_{2} \\
( \pm 0.005)\end{array}$ & $\begin{array}{c}\mathrm{Tb}_{2} \mathrm{Fe}_{17} \mathrm{C}_{2}-\mathrm{Tb}_{2} \mathrm{Fe}_{17} \\
( \pm 0.01)\end{array}$ \\
\hline $\mathrm{TB}(2 \mathrm{~d}) \_\mathrm{Fe}(6 \mathrm{~g})$ & $\mathrm{TB}(6 \mathrm{c}) \_\mathrm{Fe}(9 \mathrm{~d})$ & 3.214 & 3.310 & 0.10 \\
\hline $\mathrm{TB}(2 \mathrm{~d})_{\ldots} \mathrm{Fe}(12 \mathrm{j})$ & $\mathrm{TB}(6 \mathrm{c}) \_\mathrm{Fe}(18 \mathrm{f})$ & 2.899 & 3.093 & 0.2 \\
\hline $\mathrm{TB}(2 \mathrm{~b}) \_\mathrm{Fe}(12 \mathrm{k}) \mathrm{a}$ & $T B(6 c) \_F e(18 h) 1$ & 3.146 & 3.175 & 0.03 \\
\hline $\mathrm{TB}(2 \mathrm{~b}) \_F e(12 \mathrm{k}) \mathrm{b}$ & $\mathrm{TB}(6 \mathrm{c}) \_\mathrm{Fe}(18 \mathrm{~h}) 2$ & 3.214 & 3.144 & -0.07 \\
\hline $\mathrm{TB}(2 \mathrm{~d}) \_\mathrm{Fe}(12 \mathrm{k})$ & $\mathrm{TB}(6 \mathrm{c}) \_\mathrm{Fe}(18 \mathrm{~h}) 3$ & 3.217 & 3.344 & 0.13 \\
\hline $\mathrm{Fe}(4 \mathrm{f}) \_\mathrm{Fe}(4 \mathrm{f})$ & $\mathrm{Fe}(6 \mathrm{c}){ }_{1} \mathrm{Fe}(6 \mathrm{c})$ & 2.317 & 2.320 & 0 \\
\hline $\mathrm{Fe}(4 \mathrm{f}) \_\mathrm{Fe}(6 \mathrm{~g})$ & $\mathrm{Fe}(6 \mathrm{c}) \_\mathrm{Fe}(9 \mathrm{~d})$ & 2.719 & 2.771 & 0.05 \\
\hline $\mathrm{Fe}(4 \mathrm{f})_{\mathrm{F}} \mathrm{Fe}(12 \mathrm{j})$ & $\mathrm{Fe}(6 \mathrm{c}) \_\mathrm{Fe}(\mathrm{I} 8 \mathrm{f})$ & 2.832 & 2.768 & -0.06 \\
\hline $\mathrm{Fe}(4 \mathrm{f}) \_\mathrm{Fe}(12 \mathrm{k})$ & $\mathrm{Fe}(6 \mathrm{c}) \_\mathrm{Fe}(18 \mathrm{~h})$ & 2.784 & 2.696 & -0.09 \\
\hline $\mathrm{Fe}(6 \mathrm{~g}) \_\mathrm{Fe}(12 \mathrm{j})$ & $\mathrm{Fe}(9 \mathrm{~d}) \_\mathrm{Fe}(18 \mathrm{f})$ & 2.483 & 2.460 & -0.02 \\
\hline $\mathrm{Fe}(6 \mathrm{~g}) \_\mathrm{Fe}(12 \mathrm{k})$ & $\mathrm{Fe}(9 \mathrm{~d}) \_\mathrm{Fe}(18 \mathrm{~h})$ & 2.480 & 2.488 & 0.01 \\
\hline $\mathrm{Fe}(12 \mathrm{j}) \_\mathrm{Fe}(12 \mathrm{j})$ & $\mathrm{Fe}(18 \mathrm{f}) \_\mathrm{Fe}(18 \mathrm{f})$ & 2.717 & 2.517 & -0.20 \\
\hline $\mathrm{Fe}(12 \mathrm{k}) \_\mathrm{Fe}(12 \mathrm{j}) \mathrm{a}$ & $\mathrm{Fe}(18 \mathrm{f}) \_\mathrm{Fe}(18 \mathrm{~h}) \mathrm{a}$ & 2.560 & 2.594 & 0.03 \\
\hline $\mathrm{Fe}(12 \mathrm{k}) \_\mathrm{Fe}(12 \mathrm{j}) \mathrm{b}$ & $\mathrm{Fe}(18 \mathrm{f}) \_\mathrm{Fe}(18 \mathrm{~h}) \mathrm{b}$ & 2.511 & 2.649 & 0.14 \\
\hline $\mathrm{Fe}(12 \mathrm{k}) \_\mathrm{Fe}(12 \mathrm{k})$ & $\mathrm{Fe}(18 \mathrm{~h}) \mathrm{Fe}(18 \mathrm{~h})$ & 2.412 & 2.563 & 0.15 \\
\hline
\end{tabular}


Table 4-5. The magnetostrain of the bonds $(<4 \AA)$ in the $\mathrm{R}_{2} \mathrm{Fe}_{17}$

with Hexagonal structure.

\begin{tabular}{|c|c|c|c|c|c|}
\hline Bond & $\begin{array}{l}\text { Bondlength } \\
(\AA) \\
(300 \mathrm{~K})\end{array}$ & $\begin{array}{l}\mathrm{Y}_{2} \mathrm{Fe}_{17} \\
\lambda \times 10^{-3} \\
( \pm 0.7)\end{array}$ & $\begin{array}{l}\mathrm{Gd}_{2} \mathrm{Fe}_{17} \\
\lambda \times 10^{-3} \\
( \pm 0.7)\end{array}$ & $\begin{array}{l}\mathrm{Tb}_{2} \mathrm{Fe}_{17} \\
\lambda \times 10^{-3} \\
( \pm 0.7)\end{array}$ & $\begin{array}{l}\mathrm{Er}_{2} \mathrm{Fe}_{17} \\
\lambda \times 10^{-3} \\
( \pm 0.7)\end{array}$ \\
\hline $\mathrm{R}(2 \mathrm{~b}) \_\mathrm{Fe}(12 \mathrm{k}) \mathrm{a}$ & $3.11 \sim 3.20$ & 7.2 & 9.3 & 7.8 & 8.7 \\
\hline $\mathrm{R}(2 \mathrm{~b}) \_\mathrm{Fe}(12 \mathrm{k}) \mathrm{b}$ & $3.18 \sim 3.24$ & 3.8 & 5.3 & 4.4 & 2.4 \\
\hline$R(2 b) \_F e(12 j)$ & $2.86 \sim 2.93$ & 0.5 & 4.0 & -0.9 & -0.3 \\
\hline $\mathrm{R}(2 \mathrm{~d}) \_\mathrm{Fe}(4 \mathrm{f})$ & $3.01 \sim 3.24$ & 18.3 & 13.4 & 19.4 & 14.5 \\
\hline $\mathrm{R}(2 \mathrm{~d}) \_\mathrm{Fe}(6 \mathrm{~g})$ & $3.19 \sim 3.22$ & 7.2 & 8.8 & 7.8 & 6.9 \\
\hline $\mathrm{R}(2 \mathrm{~d}) \_\mathrm{Fe}(12 \mathrm{k})$ & $3.16 \sim 3.30$ & 6.3 & 8.5 & 1.8 & 11.4 \\
\hline $\mathrm{R}(2 \mathrm{~d}) \_\mathrm{Fe}(12 \mathrm{j})$ & $2.78 \sim 2.98$ & 0.3 & 2.2 & 2.9 & -2.8 \\
\hline $\mathrm{Fe}(4 f) \_\mathrm{Fe}(4 f)$ & $2.30-2.35$ & 12.7 & 13.2 & 13.5 & 11.7 \\
\hline $\mathrm{Fe}(4 \mathrm{f}) \_\mathrm{Fe}(6 \mathrm{~g})$ & $2.66 \sim 2.75$ & I I. 8 & 10.4 & 12.2 & 7.6 \\
\hline $\mathrm{Fe}(4 \mathrm{f}) \_\mathrm{Fe}(12 \mathrm{k})$ & $2.68 \sim 2.78$ & 12.4 & 13.8 & 14.5 & 7.7 \\
\hline $\mathrm{Fe}(4 f) \_\mathrm{Fe}(12 \mathrm{j})$ & $2.78 \sim 2.90$ & 13.3 & 14.3 & 13.6 & 15.1 \\
\hline $\mathrm{Fe}(6 \mathrm{~g}) \_\mathrm{Fe}(12 \mathrm{k})$ & $2.45 \sim 2.49$ & 7.1 & 8.7 & 8.9 & 6.0 \\
\hline $\mathrm{Fe}(6 \mathrm{~g})_{-} \mathrm{Fe}(12 \mathrm{j})$ & $2.44 \sim 2.50$ & 10.9 & 9.5 & 12.1 & 10.0 \\
\hline $\mathrm{Fe}(12 \mathrm{k}) \_\mathrm{Fe}(12 \mathrm{k})$ & $2.41 \sim-2.43$ & 3.4 & 1.9 & 3.9 & 1.9 \\
\hline $\mathrm{Fe}(12 \mathrm{k}) \_\mathrm{Fe}(12 \mathrm{j}) \mathrm{a}$ & $2.55-2.59$ & 2.5 & 4.5 & 3.4 & 3.6 \\
\hline $\mathrm{Fe}(12 \mathrm{k})_{m} \mathrm{Fe}(12 \mathrm{j}) \mathrm{b}$ & $2.48 \sim 2.51$ & 9.0 & 11.0 & 7.9 & 6.3 \\
\hline $\mathrm{Fe}(12 \mathrm{j}) \_\mathrm{Fe}(12 \mathrm{j}) \mathrm{a}$ & $2.60 \sim 2.75$ & 17.1 & 14.0 & 21.5 & 16.6 \\
\hline $\mathrm{Fe}(12 \mathrm{j}) \_\mathrm{Fe}(12 \mathrm{j}) \mathrm{b}$ & $2.50-2.70$ & 17.7 & 18.9 & 14.5 & 21.9 \\
\hline
\end{tabular}


Table 4-6. The magnetostrain of the bonds $(<4 \AA)$ in the $\mathrm{Nd}_{2} \mathrm{Fe}_{17}$ structure with rhombohedral modification.

\begin{tabular}{|c|c|c|}
\hline Bond & $\begin{array}{c}\text { Bondlength } \\
(\AA) \\
(300 \mathrm{~K})\end{array}$ & $\begin{array}{l}\mathrm{Nd}_{2} \mathrm{Fe}_{17} \\
\lambda \times 10^{33} \\
( \pm 0.7)\end{array}$ \\
\hline $\mathrm{Nd}(6 \mathrm{c}) \_\mathrm{Nd}(6 \mathrm{c})$ & 3.96 & 10.5 \\
\hline $\mathrm{Na}(6 \mathrm{c}) \mathrm{Fe}(6 \mathrm{c})$ & 3.07 & 6.7 \\
\hline $\mathrm{Nd}(6 \mathrm{c}) \_\mathrm{Fe}(9 \mathrm{~d})$ & 3.30 & 4.8 \\
\hline $\mathrm{Nd}(6 \mathrm{c}) \_F e(18 \mathrm{f})$ & 3.05 & 0.4 \\
\hline $\mathrm{Nd}(6 \mathrm{c})_{m} \mathrm{Fe}(18 \mathrm{~h}) \mathrm{a}$ & 3.20 & 11.9 \\
\hline $\mathrm{Nd}(2 \mathrm{~d}) \_\mathrm{Fe}(18 \mathrm{~h}) \mathrm{b}$ & 3.27 & 0.3 \\
\hline $\mathrm{Nd}(2 \mathrm{~d}) \_\mathrm{Fe}(18 \mathrm{~h}) \mathrm{c}$ & 3.12 & 11.3 \\
\hline $\mathrm{Fe}(6 \mathrm{c}) \mathrm{Fe}(6 \mathrm{c})$ & 2.35 & 14.8 \\
\hline $\mathrm{Fe}(6 \mathrm{c})_{2} \mathrm{Fe}(9 \mathrm{~d})$ & 2.63 & 5.8 \\
\hline $\mathrm{Fe}(6 \mathrm{c}) \_\mathrm{Fe}(18 \mathrm{f})$ & 2.76 & 12.8 \\
\hline $\mathrm{Fe}(6 \mathrm{c}) \_\mathrm{Fe}(18 \mathrm{~h})$ & 2.65 & 3.6 \\
\hline $\mathrm{Fe}(9 \mathrm{~d}) \_\mathrm{Fe}(18 \mathrm{f})$ & 2.44 & 8.3 \\
\hline $\mathrm{Fe}(9 \mathrm{~d}) \_\mathrm{Fe}(18 \mathrm{~h})$ & 2.46 & 5.5 \\
\hline $\mathrm{Fe}(18 f) \_F e(18 f)$ & 2.50 & 14.7 \\
\hline $\mathrm{Fe}(18 \mathrm{f}) \_F e(18 \mathrm{~h})$ & 2.54 & 0.3 \\
\hline $\mathrm{Fe}(18 \mathrm{~h})_{\ldots} \mathrm{Fe}(18 \mathrm{~h})$ & 2.51 & 0.9 \\
\hline
\end{tabular}


Table 4-7. The magnetostrains of the bonds $(<4 \AA)$ in $\mathrm{R}_{2} \mathrm{Fe}_{17} \mathrm{C}_{2}$

samples.

\begin{tabular}{lccccc}
\hline \multicolumn{1}{c}{ Bond } & $\begin{array}{c}\text { Bondlength } \\
(\AA) \\
(300 \mathrm{~K})\end{array}$ & $\begin{array}{c}\mathrm{Y}_{2} \mathrm{Fe}_{17} \mathrm{C}_{2} \\
\lambda \times 10^{-3} \\
( \pm 0.7)\end{array}$ & $\begin{array}{c}\mathrm{Gd}_{2} \mathrm{Fe}_{17} \mathrm{C}_{2} \\
\lambda \times 10^{-3} \\
( \pm 0.7)\end{array}$ & $\begin{array}{c}\mathrm{Tb}_{2} \mathrm{Fe}_{17} \mathrm{C}_{2} \\
\lambda \times 10^{-3} \\
( \pm 0.7)\end{array}$ & $\begin{array}{c}\mathrm{Er}_{2} \mathrm{Fe}_{17} \mathrm{C}_{2} \\
\lambda \times 10^{-3} \\
( \pm 0.7)\end{array}$ \\
\hline $\mathrm{R}(6 \mathrm{c}) \_\mathrm{Fe}(6 \mathrm{c})$ & $3.07 \sim 3.10$ & 5.8 & 1.0 & 8.0 & 2.4 \\
$\mathrm{R}(6 \mathrm{c}) \_\mathrm{Fe}(9 \mathrm{~d})$ & $3.25 \sim 3.32$ & 3.4 & 6.0 & 5.7 & 6.2 \\
$\mathrm{R}(6 \mathrm{c}) \_\mathrm{Fe}(18 \mathrm{f})$ & $2.95 \sim 3.11$ & 4.0 & 5.2 & 3.5 & 3.6 \\
$\mathrm{R}(6 \mathrm{c}) \_\mathrm{Fe}(18 \mathrm{~h}) 1$ & $3.17 \sim 3.22$ & 2.1 & 4.9 & 5.0 & 3.0 \\
$\mathrm{R}(6 \mathrm{c}) \_\mathrm{Fe}(18 \mathrm{~h}) 2$ & $3.28 \sim 3.35$ & 10.8 & 10.6 & 11.1 & 10.4 \\
$\mathrm{R}(6 \mathrm{c}) \_\mathrm{Fe}(18 \mathrm{~h}) 3$ & $3.14 \sim 3.20$ & 12.0 & 14.2 & 14.0 & 13.1 \\
$\mathrm{Fe}(6 \mathrm{c}) \_\mathrm{Fe}(6 \mathrm{c})$ & $2.30 \sim 2.35$ & 17 & 16.4 & 15.8 & 16.7 \\
$\mathrm{Fe}(6 \mathrm{c}) \_\mathrm{Fe}(9 \mathrm{~d})$ & $2.66 \sim 2.88$ & 7.5 & 6.5 & 9.2 & 7.6 \\
$\mathrm{Fe}(6 \mathrm{c}) \_\mathrm{Fe}(18 \mathrm{f})$ & $2.75 \sim 2.79$ & 8.0 & 14.3 & 13.5 & 6.5 \\
$\mathrm{Fe}(6 \mathrm{c}) \_\mathrm{Fe}(18 \mathrm{~h})$ & $2.68 \sim 2.80$ & 4.4 & 1.8 & 5.4 & 6.0 \\
$\mathrm{Fe}(9 \mathrm{~d}) \_\mathrm{Fe}(18 \mathrm{f})$ & $2.45 \sim 2.49$ & 7.5 & 8.9 & 9.6 & 8.3 \\
$\mathrm{Fe}(9 \mathrm{~d}) \_\mathrm{Fe}(18 \mathrm{~h})$ & $2.48 \sim 2.50$ & 4.2 & 5.8 & 6.0 & 3.0 \\
$\mathrm{Fe}(18 \mathrm{f}) \_\mathrm{Fe}(18 \mathrm{f})$ & $2.50 \sim-2.70$ & 9.6 & 13.4 & 16.7 & 12.3 \\
$\mathrm{Fe}(18 \mathrm{f}) \_\mathrm{Fe}(18 \mathrm{~h}) 1$ & $2.54 \sim 2.60$ & 6.1 & 5.8 & 6.7 & 6.2 \\
$\mathrm{Fe}(18 \mathrm{f}) \_\mathrm{Fe}(18 \mathrm{~h}) 1$ & $2.57 \sim 2.67$ & 5.3 & 7.2 & 4.7 & 4.2 \\
$\mathrm{Fe}(18 \mathrm{~h}) \_\mathrm{Fe}(18 \mathrm{~h})$ & $2.48 \sim 2.56$ & 9.2 & 11.3 & 10.4 & 13.0 \\
\hline
\end{tabular}


Table 4-8. The average magnetostrain of the bonds around different sites in the sample studied.

\begin{tabular}{|c|c|c|c|c|c|}
\hline Site & & $\begin{array}{l}\mathrm{Y}_{2} \mathrm{Fe}_{17} \\
\times 10^{-3} \\
( \pm 0.7) \\
\end{array}$ & $\begin{array}{c}\mathrm{Gd}_{2} \mathrm{Fe}_{17} \\
\lambda \times 10^{-3} \\
( \pm 0.7)\end{array}$ & $\begin{array}{l}\mathrm{Tb}_{2} \mathrm{Fe}_{17} \\
\lambda \times 10^{-3} \\
( \pm 0.7)\end{array}$ & $\begin{array}{l}\mathrm{Er}_{2} \mathrm{Fe}_{17} \\
\lambda \times 10^{-3} \\
( \pm 0.7)\end{array}$ \\
\hline$R(2 d)$ & - & 3.8 & 6.2 & 3.8 & 3.6 \\
\hline$R(2 b)$ & - & 6.0 & 7.2 & 5.7 & 6.1 \\
\hline $\mathrm{Fe}(4 \mathrm{f})$ & - & 12.7 & 13.2 & 13.5 & 11.4 \\
\hline $\mathrm{Fe}(6 \mathrm{~g})$ & - & 9.6 & 9.4 & 10.8 & 7.9 \\
\hline $\mathrm{Fe}(12 j)$ & - & 10.3 & 10.8 & 10.7 & 10.4 \\
\hline $\mathrm{Fe}(12 \mathrm{k})$ & - & 6.9 & 7.9 & 7.6 & 5.0 \\
\hline Site & $\begin{array}{c}\mathrm{Nd}_{2} \mathrm{Fe}_{17} \\
\lambda \times 10^{-3} \\
( \pm 0.7)\end{array}$ & $\begin{array}{c}\mathrm{Y}_{2} \mathrm{Fe}_{17} \mathrm{C}_{2} \\
\lambda \times 10^{-3} \\
( \pm 0.7)\end{array}$ & $\begin{array}{c}\mathrm{Gd}_{2} \mathrm{Fe}_{17} \mathrm{C}_{2} \\
\lambda \times 10^{-3} \\
( \pm 0.7)\end{array}$ & $\begin{array}{c}\mathrm{Tb}_{2} \mathrm{Fe}_{17} \mathrm{C}_{2} \\
\lambda \times 10^{-3} \\
( \pm 0.7)\end{array}$ & $\begin{array}{c}\mathrm{Er}_{2} \mathrm{Fe}_{17} \mathrm{C}_{2} \\
\lambda \times 10^{-3} \\
( \pm 0.7)\end{array}$ \\
\hline$R(6 c)$ & 4.9 & 6.0 & 7.3 & 7.2 & 6.4 \\
\hline $\mathrm{Fe}(6 \mathrm{c})$ & 9.2 & 7.7 & 10.4 & 10.8 & 7.4 \\
\hline $\mathrm{Fe}(9 \mathrm{~d})$ & 6.8 & 6.0 & 7.3 & 8.0 & 5.9 \\
\hline $\mathrm{Fe}(18 f)$ & 8.7 & 7.3 & 9.9 & 10.2 & 7.5 \\
\hline $\mathrm{Fe}(18 \mathrm{~h})$ & 2.1 & 6.0 & 6.9 & 6.8 & 6.5 \\
\hline
\end{tabular}




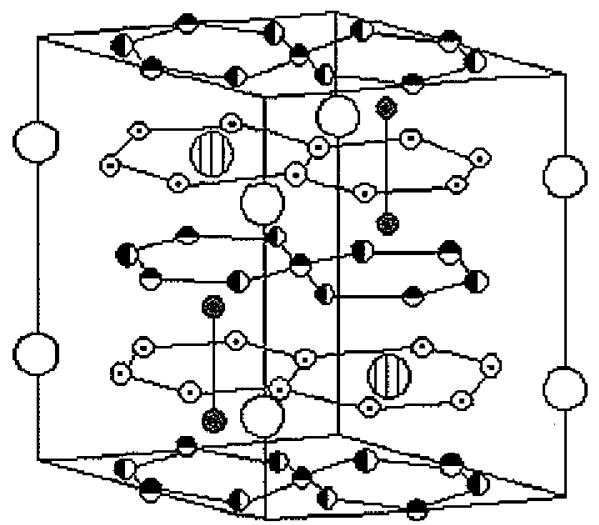

(ID) $2 \mathrm{~d} \mathrm{2h}^{\mathbf{h}}$

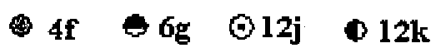

a

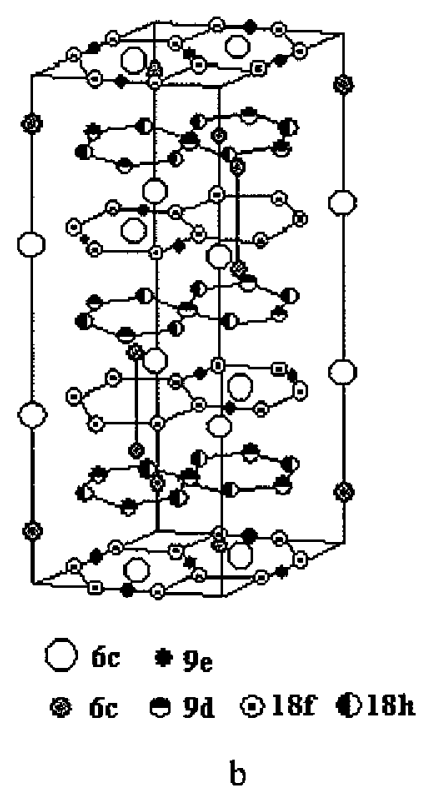

Figure 4-1. Crystal structure of $\mathrm{R}_{2} \mathrm{Fe}_{17}$, a. Hexagonal modification, $\mathrm{Th}_{2} \mathrm{Ni}_{17}$ type b. Rhombohedral modification, $\mathrm{Th}_{2} \mathrm{Zn}_{17}$ type. 


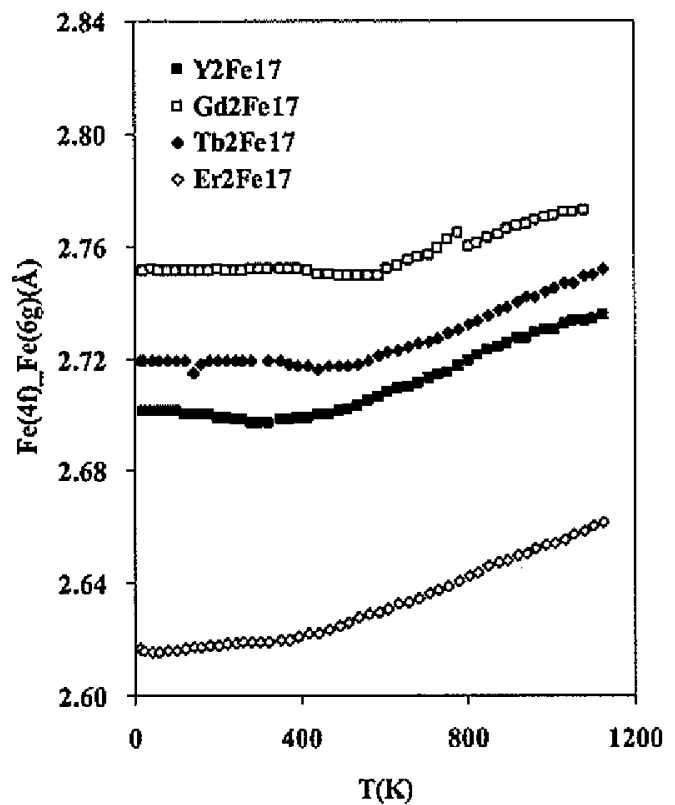

Figure 4-2. The temperature dependences of $\mathrm{Fe}(4 \mathrm{f}) \mathrm{Fe}(6 \mathrm{~g})$ bond lengths in $\mathrm{R}_{2} \mathrm{Fe}_{17}$ samples with hexagonal structure. 


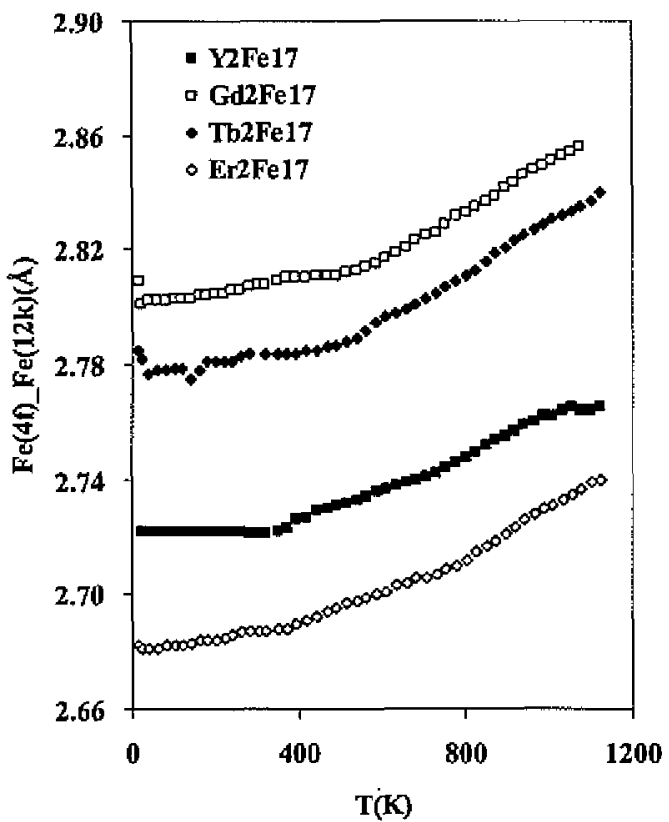

Figure 4-3. The temperature dependences of $\mathrm{Fe}(4 \mathrm{f}) \mathrm{Fe}(12 \mathrm{k})$

bond lengths in $\mathrm{R}_{2} \mathrm{Fe}_{17}$ samples with hexagonal structure. 


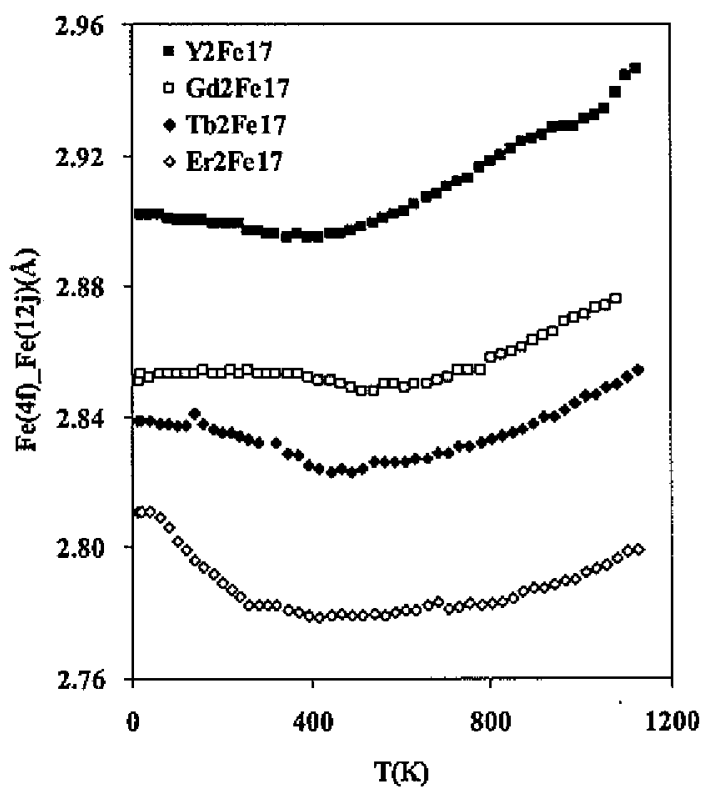

Figure 4-4. The temperature dependences of $F e(4 f) \_F e(12 j)$

bond lengths in $\mathrm{R}_{2} \mathrm{Fe}_{17}$ samples with hexagonal structure. 


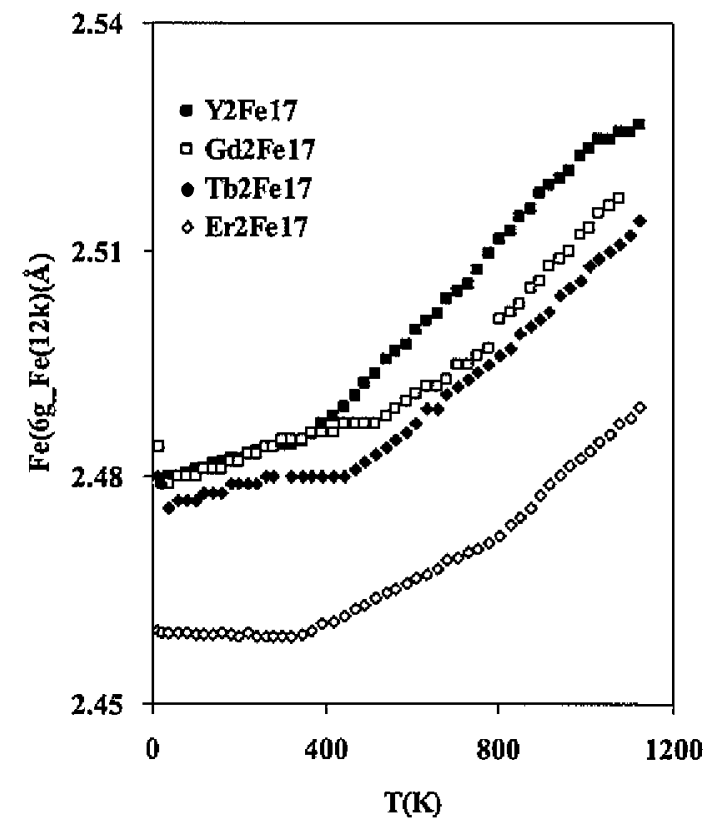

Figure 4-5. The temperature dependences of $\mathrm{Fe}(6 \mathrm{~g}) \mathrm{Fe}(12 \mathrm{k})$

bond lengths in $\mathrm{R}_{2} \mathrm{Fe}_{17}$ samples with hexagonal structure. 


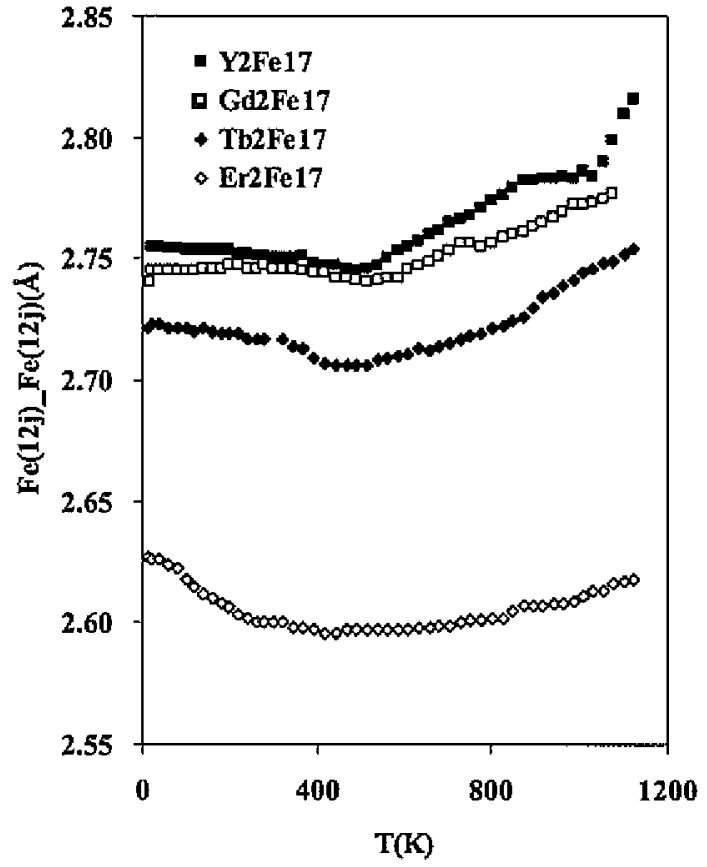

Figure 4-6. The temperature dependences of $\mathrm{Fe}(12 \mathrm{j}) \_\mathrm{Fe}(12 \mathrm{j})$

bond lengths in $\mathrm{R}_{2} \mathrm{Fe}_{17}$ samples with hexagonal structure. 


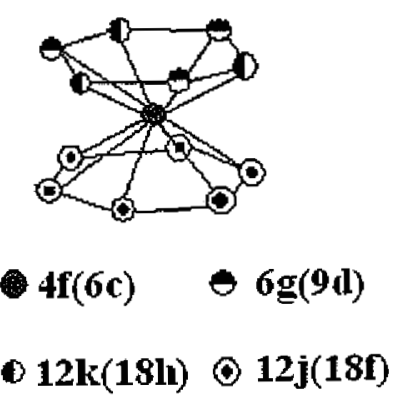

Figure 4-7. The Fe sublattice in $\mathrm{R}_{2} \mathrm{Fe}_{17} \mathrm{C}_{\mathrm{x}}(\mathrm{x}=0,2)$ structure. 


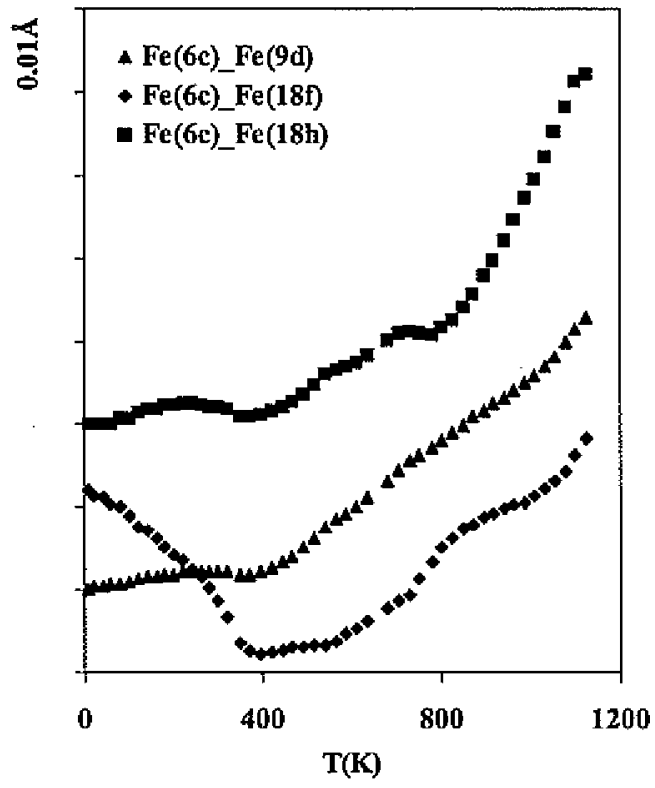

Figure 4-8. The temperature dependences of $\mathrm{Fe}(6 \mathrm{c}) \mathrm{Fe}(9 \mathrm{~d})$, $\mathrm{Fe}(6 \mathrm{c}) \mathrm{Fe}(18 \mathrm{f})$ and $\mathrm{Fe}(6 \mathrm{c}) \_\mathrm{Fe}(18 \mathrm{~h})$ bond lengths in $\mathrm{Nd}_{2} \mathrm{Fe}_{17}$ sample. 


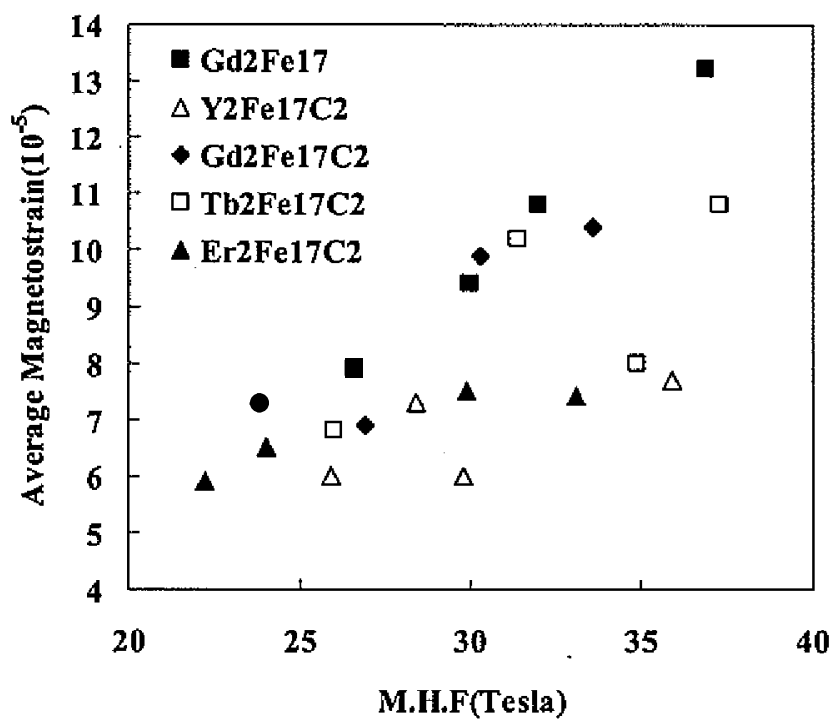

Figure 4-9. The average magnetostrains of sites vs. the

Mössbauer hyperfine field intensity in some samples studied. 


\subsection{REFERENCES}

${ }^{1}$ A. V. Andreev, Hand Book of the Magnetic Materials, Volume 8 (1995).

${ }^{2}$ D. Givord, R. Lemaire, IEEE Trans. Magn., MAG-110 (1974) 109.

${ }^{3}$ D. Gignoux, D. Givord, F. Givord and R. Lemaire, J. Magn. Magn. Mater., 10 (1979) 288293.

${ }^{4}$ A. V. Andreev, F.R. de Boer, T.H. Jacobs and K.H.J. Buschow, J. Magn. Magn. Mater., 104-107 (1992) 1305-1307.

${ }^{5}$ A.V. Andreev and M.L. Bartashevich, J. of Less-Common Met., 162 (1990) 33-37.

${ }^{6}$ T. H. Jacobs, K.H.J. Buschow, H. Muller, R. Grossinger. J. Magn. Magn. Mater., 115 (1992) 260.

${ }^{7}$ P. C. Ezekwenna, M. Shumsky, W.J. James, Ph. 1' Heritier. J. Magn. Magn. Mater., 168 (1997) 149-153.

${ }^{8}$ S. A. Nikitin, E.A. Ovtchenkov, I. S. Tereshina, A.A. Salamova, V.N. Verbetsky, J. Magn. Magn. Mater., 195 (1999) 464.

${ }^{9}$ T. Kamimoti, K. Kinoshita, J. Mochimaru, K.Konishi and H. Tange, J. Magn. Magn. Mater., 226-230 (2001) 993.

${ }^{10}$ K. H. L Buschow, Ferromagnetic Materials, E.P. Wohlfarth, Vol. 1 (1980) P.297.

${ }^{11}$ D. B. de Mooij and K,H.J. Buschow, J. Less-Common Met., 142 (1998) 349.

12 J. M. D Coey and H.Sun, J. Magn. Magn. Mater., 87 (1990) L251.

${ }^{13}$ Ning Yang, K. W. Dennis, R.W. McCallum, M. J. Kramer, Yuegang Zhang and Peter L. Lee, Physical Review B, to be submitted.

${ }^{14}$ A. C. Larson and R.B. Von Dreele, "General Structure Analysis System (GSAS)", Los Alamos National Laboratory Report LAUR, 86 (2000) 748.

${ }^{15}$ B. H. Toby, EXPGUI, a graphical user interface for GSAS, J. Appl. Cryst., 34 (2001) 210213.

${ }^{16}$ L. B. McCusker, R.B. Von Dreele, D.E. Cox, D. Louër and P. Scardi, J. Appl. Cryst., 32 (1999) 36-50.

${ }^{17}$ O. Isnard, S. Miraglia, J.L. Soubeyroux and D. Fruchart, J. Alloys Comp., 190 (1992) 129 135 .

${ }^{18}$ W. B. Yelon, Z.Hu, E.W. Singleton and G.C. Hadjipanayis, J. Appl. Phys., 78 (1995) 7196.

${ }^{19}$ J. P. Liu, F.R.de Boer and P.F. de Chatel, Physical Review B, 50-5 (1994) 3005.

${ }^{20}$ J.F. Herbst, Rev. Mod. Phys., 63 (1991) 819.

${ }^{21}$ Olivier Isnard, Daniel Fruchart, J. of Alloy and Compounds, 205 (1994) 1-15.

${ }^{22}$ L. S. Kong, B.G. Shen, L. Cao, J.G. Zhao, H.Y.Gong and Y.L. Chen, J. A.lloys Comp. 196 (1993) 183.

${ }^{23}$ X. Chen, D.H. Ryan, Z. Altounian and L.X. Liao, J. Appl. Phys., 73 (1993) 6038.

${ }^{24}$ L. S. Kong, B.G. Shen, L. Cao, H.Y.Gong and Y.L. Chen, J. Phys. Condens. Matter., 5 (1993) 2415.

${ }^{25}$ H. Fujii and H. Sun, Handbook of magnetic materials. Elsevier Science. Vol. 9 (1995).

${ }^{26}$ Ning Yang, K. W. Dennis, R.W. McCallum, M. J. Kramer, Yuegang Zhang and Peter L. Lee, J. Magn. Magn. Mater., to be submitted. 


\title{
CHAPTER 5
}

\section{AN EVALUATION OF THEORETICAL MODELS ON SPONTANEOUS MAGNETOSTRICTION}

\author{
Ning Yang ${ }^{1}{ }^{2}$, K. W. Dennis ${ }^{1}$, R.W. McCallum ${ }^{1}$, and M. J. Kramer ${ }^{1}$ \\ Yuegang Zhang ${ }^{2}$ and Peter L. Lee ${ }^{2}$ \\ A paper prepared for Physical Review B
}

\subsection{ABSTRACT}

The theoretical and modeling works on the spontaneous magnetostriction of rare earth transition metal compounds are reviewed and discussed. Two different models, based on localized moment and itinerant moment theories, are evaluated in light of new experimental results. The model by C.P. Bean, which is based on a collection of interacting magnetic dipoles and their interaction is approximated by the molecular field model, is discussed. A more phenomenological approach is to use the Landau - Devonshire function of the free energy density to model the volumetric spontaneous magnetostriction. Experimental results on a two classes of rare earth transition metal compounds show that Landau model have better accounts for the temperature dependence of the magnetostriction.

\footnotetext{
${ }^{1}$ Ames Laboratory and the Department of Materials Science and Engineering, Iowa State University, Ames, Iowa 50010.

${ }^{2}$ Advanced Photon Source, Argonne National Laboratory, Argonne, IL 60439.
} 


\subsection{INTRODUCTION}

Two different approaches for understanding spontaneous magnetostriction of transition metals (Invar alloys) have been proposed. One is based on the localized electrons, which is also called the Heisenberg model, where it is assumed that each atom carries its own permanent and temperature independent moment. The second approach is based on the itinerant magnetism which assumes composition dependence of the average moment. More than 20 different models have been published for the understanding of invar effect $[1,2,3,4,5,6,7]$. The most developed models is the " $2 \gamma$-state model" of Weiss [5]. The model was proposed initially within the group of local models. But in the late 1970's, the band structure calculations using the local spin density approximation predicted the existence of the two ferromagnetic states of Fe. In Weiss's model, it assumes two different magnetic states, a high-spin state with larger moment and large volume and a low-spin state with lower moment and volume. The invar anomalies occur when the population of high-spin states and low-spin states changes relative to each other, which is a temperature dependent process.

Modeling of the invar behavior for the rare earth transition metal compounds has been carried out with considering magnetic moments of various origins. In this paper, we will discuss a localized moment model proposed by E. C. Callen and H. B. Callen [8], a band structure model proposed by M. Shiga [9] and a coupled phase transition with magnetic disorder model proposed by C. P. Bean which considers the Gibbs free energy density in the compound [10]. A model based on the Landau- Devonshire formalization will be proposed and discussed. 


\subsection{THE LOCAL AND ITINERANT MOMENT MODELS}

There has been a considerable amount of theoretical modeling on the spontaneous magnetostriction of R-T compounds $[8,9,11]$. For most of the compounds the reduced volumetric spontaneous magnetostriction $\omega_{\mathrm{s}}(\mathrm{T}) / \omega_{\mathrm{s}}(5 \mathrm{~K})$ coincides with the temperature dependence of the square of magnetic moment,

$$
\omega_{s}(T) / \omega_{s}(5 K)=\mu_{m}^{2}
$$

In the studies of A.V. Andreev et al $[12,13]$ for $\mathrm{Y}_{2} \mathrm{Fe}_{14} \mathrm{~B}, \mathrm{Y}_{2} \mathrm{Fe}_{17}$ and its carbides, it is shown that this relation is perfectly satisfied. This supports the conclusion that the iron sublattice dominates the spontaneous magnetostriction. But in compounds where the $\mathrm{R}$ ion has a magnetic moment, experimental results are not fully modeled by this relationship, which may attribute to the R-T exchange interaction.

A model dealing with the volumetric magnetostriction in systems of localized moments was developed by E. C. Callen and H. B. Callen [8]. The model assumes that the magnetostriction arise from the modulation by the strain of single-ion energies, such as those involving crystal-field splitting. In this model, the spontaneous volume magnetostriction is given by the two-spin correlation function,

$$
\omega_{s}=\kappa C_{l o c} \sum_{i, j}\left\langle m_{i} \cdot m_{j}\right\rangle
$$

where $\kappa$ is the compressibility, $C_{l o \varepsilon}$ is the magnetovolume coupling constant summed over all lattice sites $\mathrm{i}, \mathrm{j}$. The magnetovolume effect is basically due to the volume dependence of the magnetic coupling constant and is associated with the exchange interaction $H_{e x}=-2 A m_{i} \cdot m_{j}$ between the localized moments. 
Magnetovolume effects in terms of the contribution of the band structure were considered by M. Shiga [6]. Using standard band theory, the spontaneous volume magnetostriction can be explained as follows: the band polarization causes an increase in the kinetic energy but the total kinetic energy can be reduced by a volume expansion because the $3 d$ band width is highly dependent on the atomic separation. In the first approximation, the increase of the kinetic energy is proportional to the square of the magnetization.

M. Shiga [9] extended the Stoner band model with volume dependent terms and proposed the following phenomenological relation,

$$
\omega_{s}=\kappa C_{b a n d} \sum_{i} m_{l}^{2}
$$

where $C_{b a n d}$ is the magnetovolume coupling constant due to band effects and the summation extends over all the temperature-dependent local moments $m_{l}$ residing on the lattice sites $i$. The magnetovolume effects in this model is the result of $3 \mathrm{~d}$ band splitting and the increase in kinetic energy associated with the transfers of electrons from the minority band to the majority band. The system tries to reduce the increase in kinetic energy by expanding the bond lengths.

For the R-T class of materials, it is necessary to consider contributions of the local moments and band splitting by combining the equations (5-2) and (5-3),

$$
\omega_{s}=\kappa\left(C_{l o c}^{R R} \sum_{R, R^{\prime}}\left\langle m_{R} \cdot m_{R^{\prime}}\right\rangle+C_{\text {loc }}^{R T} \sum_{R, T}\left\langle m_{R} \cdot m_{T}\right\rangle+C_{\text {band }}^{T T} \sum_{T} m_{T}^{2}+C_{l o c}^{T T} \sum_{T, T^{\prime}}\left\langle m_{T} \cdot m_{T^{\prime}}\right\rangle\right) \text { eq. } 5-4
$$

where the superscripts $R R, R T$ and $T T$ refer to the various types of exchange couplings between rare earth moments and transition metal moments. 
The first two contributions in Equation (5-4) are due to the $4 \mathrm{f}$ moments. The quantity $\omega_{s . f}$, the magnetostrain due to local $4 \mathrm{f}$ moments, can then be approximated to by the equation,

$$
\omega_{\mathrm{s}, \mathrm{f}}=\kappa\left[C_{R R}(g-1)^{2} J(J+1) \frac{d A_{R R}}{d \omega}+C_{R T}|(g-1) J| m_{T} \frac{d A_{R T}}{d \omega}\right] \quad \text { eq. 5-5 }
$$

where $\kappa$ is the compressibility, $C_{R R}$ and $C_{R T}$ are constants, and $A_{R R}$ and $A_{R T}$ are the exchange coupling constants between the $\mathrm{R}$ moments and between the $\mathrm{R}$ and $\mathrm{T}$ moments, respectively, which are independent of the R component in equation(5-5).

If the magnetostriction exclusively due to the transition metal's $d$ states, the expression may be simplified as,

$$
\omega_{s, d}(T)=\kappa\left(C_{l o c}^{T T}+C_{\text {band }}^{T T}\right) M_{T}^{2}(T)=\kappa C M_{T}^{2}(T)
$$

which is identical to eq. 5-1.

The experiments on the spontaneous magnetostriction of $\mathrm{R}_{2} \mathrm{Fe}_{14} \mathrm{~B}$ and $\mathrm{R}_{2} \mathrm{Fe}_{17} \mathrm{Cx}(\mathrm{x}=0,2)$ $(\mathrm{R}=\mathrm{Y}, \mathrm{Nd}, \mathrm{Gd}, \mathrm{Tb}, \mathrm{Er})$ using high-energy synchrotron $\mathrm{x}$-ray powder diffraction have shown that in the compounds, the Fe sublattice dominates the effects $[14,15,16]$. The reduced volumetric magnetostrains follow the squared magnetization of Fe sublattice well, which confirmed the theories of both local and itinerant moment models. The study of $\mathrm{R}_{2} \mathrm{Fe}_{14} \mathrm{~B}$ samples shows that the contribution of the rare earth sublattice is roughly proportional to the spin magnetic moment of the rare earth, which is in good agreement with the prediction of eq. $5-5$, which consists of two parts that are proportional to the spin moment of the rare earth. 


\subsection{A MODEL BY C. P. BEAN [10]}

C.P. Bean has proposed a model for the magnetic order and disorder transition, which is based on the assumption that the exchange interaction that gives rise to the ordered magnetic state depends on the interatomic spacing. The impetus for his model was the study of magnetic disorder as a first-order phase transformation, but it turned out to be suitable for both first order and second order transition. Since the spontaneous magnetostriction is the second order magnetic transition, it should be possible to describe the experimental results of $\mathrm{R}-\mathrm{T}$ intermetallic compounds with this model.

The Bean model considered is of a collection of interacting magnetic dipoles and assumed that their interaction is approximated by the molecular field model. The central assumption of the model is given as,

$$
T_{C}=T_{0}\left[1+\beta\left(v-v_{0}\right) / v_{0}\right]
$$

where $T_{C}$ is the Curie temperature, while $T_{0}$ would be the Curie temperature if the lattice were not compressible. $v$ is the measured lattice volume, and $v_{0}$ is the volume in the absence of the exchange interaction. $\beta$ is the slope of the dependence of $T_{C}$ on volume.

In the case of particles with spin equal to $1 / 2$, the Gibbs free energy per unit volume is, within the molecular field approximation,

$$
\begin{gathered}
G_{v}=-H M_{S} \sigma-N k T_{c} \sigma^{2} / 2+(1 / 2 K)\left[\left(v-v_{0}\right) / v_{0}\right]^{2}+P\left(v-v_{0}\right) / \nu_{0} \\
-T N k\left[\ln 2-\frac{1}{2} \ln \left(1-\sigma^{2}\right)-\sigma \tanh ^{-1} \sigma\right]
\end{gathered}
$$

where the first term on the right is the field term, the second one is the exchange term, the third one is distortion, the fourth one is pressure and the last one is the entropy term. $\mathrm{H}$ is the applied magnetic field, $M_{S}$ is the saturation magnetization, $\sigma$ is the relative magnetization, 
$\mathrm{N}$ is the number of particles per unit volume for volume $v_{0}$ while $k$ is the Boltzmann constant, and $K$ is the compressibility. $P$ and $T$ are the pressure and temperature respectively.

We can minimize the free energy with respect to the volume by combining eq. $5-7$ and eq. $5-8$, taking the partial derivative with respect to $v$ and equating the result to zero. The volume that minimizes the free energy satisfies the condition that,

$$
\left(v-v_{0}\right) / \nu_{0}=N K k T_{0} \beta \sigma^{2} / 2-P K
$$

This result shows that the volume change is due to a simple sum of the effects of magnetization and pressure. If the pressure is set to zero, the expression will give the volume that minimize the system free energy, from which it is can be seen that the volume change is proportional to the squared relative magnetization.

By substitution of eq.5-9 into eq. 5-8 and minimize the resulting expression with respect to $\sigma$ and set the applied field $\mathrm{H}$ to zero, determine the relation between the temperature and the normalized spontaneous magnetization can be determined,

$$
T / T_{0}=\left(\sigma / \tanh ^{-1} \sigma\right)\left(1+\eta \sigma^{2} / 3-P K \beta\right)
$$

where $\eta=\frac{3}{2} N k K T_{0} \beta^{2}$. For the second order transition, $\eta<1$.

With the applied pressure set equal to zero, the $\sigma$ as a function of $T / T_{0}$ can be determined numerically and inserted into eq. 5-9, which results in the volumetric magnetostrain as a function of reduced temperature. This relation is the prediction of magnetostriction of Bean model and is plotted in the Figure 5-1, Figure 5-2 and Figure 5-3 respectively to compare to the experimental curve of $\mathrm{R}_{2} \mathrm{Fe}_{14} \mathrm{~B}, \mathrm{R}_{2} \mathrm{Fe}_{17}$ and $\mathrm{R}_{2} \mathrm{Fe}_{17}$ carbides. 
The comparison shows that the Bean model doesn't fit the experimental curves very well. The reason can be attributed to the over estimation of the magnetization as a function of temperatures by eq. $5-10$.

\subsection{A LANDAU MODEL OF SPONTANEOUS MAGNETOSTRICTION}

Another approach is to use the Landau - Devonshire function of the free energy density to model the volumetric spontaneous magnetostriction. The function can be expressed as,

$$
F_{\widetilde{\varphi}}(e, T)=F(e, T)-\widetilde{\varphi} e
$$

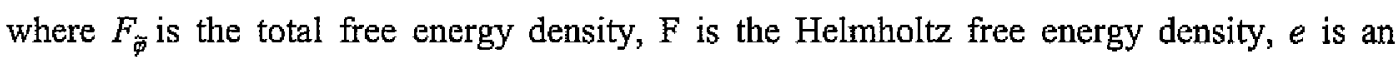
appropriate order parameter. $\widetilde{\varphi}$ is an external field conjugate to the order parameters. In the Landau theory of phase transformation, it is assumed that $F_{\ddot{p}}(e, T)$ can be expanded in a power series,

$$
F(e, T)=\sum_{i=0}^{\infty} F_{i}(T) e^{\prime}
$$

where $F_{i}(T)$ are analytic function of $\mathrm{T}$. The order parameter $e$ is chosen so that in the absence of external field, the high temperature phase corresponds to a vanishing $e$. For example, it can be a long range order parameter, such as the magnetization of a ferromagnetic materials or the sublattice magnetization of an antiferromagnetic materials. A useful approximation is obtained by truncating the series at $i=6$. So the temperature dependence of the coefficients is as follows,

$$
F(e, T)=F_{a}(T)+\frac{a}{2}\left(T-T_{C}\right) e^{2}+\frac{b}{4} e^{4}+\frac{c}{6} e^{6}
$$


where $a, b$ and $c$ are temperature independent constants to be determined experimentally [17].

In the case of spontaneous magnetostriction, the appropriate order parameter can be the magnetization $M$. The contraction effect of the magnetization will be accounted for by assuming that "T $\mathrm{T}_{c}$ is a function of volumetric strain $\varepsilon$ " by means of a magnetic Gruneisun approximation,

$$
T_{C}=T_{C}^{0}+T_{C}^{0} \gamma_{M} \varepsilon
$$

where $\gamma_{M}=\frac{1}{T_{C}^{0}} \frac{d T_{C}}{d \varepsilon}$

In addition, we must add to the free energy a term to decide the strain energy density,

$$
F(T)=F_{o}\left(T^{\prime}\right)+\frac{a}{2}\left(T-T_{C}^{0}-T_{C}^{0} \gamma_{M} \varepsilon\right) M^{2}+\frac{b}{4} M^{4}+\frac{c}{6} M^{6}+\frac{1}{2} K \varepsilon^{2}
$$

where $K$ is the bulk modulus in the paramagnetic state. The volumetric spontaneous magnetostriction is obtained by minimizing the energy density with respect to the strain,

$$
\begin{array}{r}
\partial F / \partial \varepsilon=0 \text { at } \varepsilon_{M} \text { where } \\
\varepsilon_{M}=\frac{a T_{C}^{0} \gamma_{M}}{2 K} M^{2}
\end{array}
$$

Thus in a stress-free (unclamped) sample,

$$
F(T)=F_{o}(T)+\frac{a}{2}\left(T-T_{C}^{0}\right) M^{2}+\left[\frac{b}{4}-\frac{a^{2}\left(T_{C}^{0}\right)^{2} \gamma_{M}{ }^{2}}{8 K}\right] M^{4}+\frac{c}{6} M^{6}
$$

By contrast, in a clamped (constant volume) sample,

$$
F(T)=F_{o}(T)+\frac{a}{2}\left(T-T_{c}^{0}\right) M^{2}+\frac{b}{4} M^{4}+\frac{c}{6} M^{6}
$$


The equilibrium magnetization in a clamped sample is yield by derivative equation with respect to $\mathrm{M}$. Thus,

$$
M\left[a\left(T-T_{C}^{0}\right)+b M^{2}+c M^{4}\right]=0
$$

and

$$
a\left(T-T_{C}^{0}\right)+3 b M^{2}+5 c M^{4} \geq 0
$$

If $T \geq T_{C}^{0}$ then $M=0$.

If $T \leq T_{C}^{0}$ then

$$
M^{2}=\frac{\sqrt{b^{2}+4 a\left(T_{c}^{0}-T\right) c}-b}{2 c}=\frac{b}{2 c}\left[\sqrt{1+\frac{4 a c T_{\mathcal{C}}^{0}(1-\tau)}{b^{2}}}-1\right]
$$

where $\tau=T / T_{C}^{0}$.

The values of the constants in the equations, in particular the volumetric magnetostriction can be determined experimentally. The results for an unclamped sample can be obtained from the eq.5-17 by replacing the content $\frac{b}{4}$ by $\frac{\hat{b}}{4}=\frac{b}{4}-\frac{a^{2}\left(T_{C}^{0}\right)^{2} \gamma_{M}{ }^{2}}{8 K}$. In this case, the ferromagnetic to paramagnetic transition can become first order. In the case of materials whose ferromagnetic to paramagnetic transition remains second-order, we can write the scaled magnetostriction using equation (5-16) and (5-21),

$$
\frac{\varepsilon_{M}(T)}{\varepsilon_{M}(0)}=\frac{M^{2}(T)}{M^{0}(0)}=\frac{\sqrt{1+\alpha(1-\tau)}-1}{\sqrt{1+\alpha}-1}
$$

where

$$
\alpha=\frac{4 a c T_{C}^{0}}{\hat{b}^{2}}=\frac{4 a c T_{C}^{0}}{\left[b-\frac{a^{2}\left(T_{C}^{0}\right)^{2} \gamma_{m}^{2}}{2 K}\right]^{2}}
$$


Using eq. 5-21, the ratio of $\frac{\varepsilon_{M}(T)}{\varepsilon_{M}(0)}$ as a function of $\tau$ is plotted for various values of parameter $\alpha$ (Figure 5-4). From Figure 5-4, it can been seen that the larger the value of $\alpha$, the more parabolic-like the shape the curve will be. From the magnetostriction data on $\mathrm{R}_{2} \mathrm{Fe}_{14} \mathrm{~B}$ and $\mathrm{R}_{2} \mathrm{Fe}_{17}$, a single parameter $\alpha$ can be used to scale the constants in eq. 5-15 to obtain a general trend of the data.

Comparison the theoretical curves from Landau model discussed above with the experimental curves of volumetric spontaneous magnetostrain of the $\mathrm{R}_{2} \mathrm{Fe}_{14} \mathrm{~B}, \mathrm{R}_{2} \mathrm{Fe}_{17}$ and $\mathbf{R}_{2} \mathrm{Fe}_{17}$ carbides are also plotted in Figure 5-1, Figure 5-2 and Figure 5-3 respectively. It can be seen that the theoretical curves closely follow the experimental curves. The higher temperature data fit the model better than the lower temperature data.

There are some shortcomings of this model. In the first place, the long range ordering based on the molecular field theory is not in agreement with the experiments. This demonstrates the extreme long range character of the exchange interactions that give rise to the ordered state. One consequence of this discrepancy in the model is that it does not account for ordering above the Curie temperature, persistence in the magnetostrain above the magnetically measured Curie temperature observed in all the experiments. Another shortcoming of the model is that it assumes that exchange interactions, as well as the Curie temperature, are only a function of the strain in the lattice. The model presented also assumes isotropic linear-elastic properties of the rare earth transition metal compounds, which is absolutely not true. In addition, the rare earth and iron sublattice do not impart the same exchange interaction strength, which in turn, affects the thermal expansion behaviors of the lattice. 
Because the Landau model of the spontaneous magnetostriction is very general, it can be used in either first order or second order magnetic transitions, like the Bean model. But compared to Bean model, the Landau model provides the prediction with better simulation to the experimental curves.

\subsection{CONCLUSION}

The general models considering the spontaneous magnetostriction in rare earth transition metal compounds were discussed. Both of the molecular field theory and band theory have very similar predication of the invar effect, as well as the reduced mathematic expressions. The experimental results confirm predictions of theories that the reduced magnetostrain is proportional to the squared magnetization of $\mathrm{Fe}$ sublattice and the rare earth contribution is proportional to the spin moment of rare earth. Using the Landau theory for phase transitions, we proposed a phenomenological model for the spontaneous magnetostriction of the R-T ferromagnets. The key assumption is the volumetric dependence of the Curie temperature. Compared to the model by C.P. Bean, the Landau model provides more reasonable prediction of the magnetostrictive behavior while using a simpler mathematical formulation.

\subsection{ACKNOWLEDGEMENTS}

The author would like to thanks David Welch for his insightful comments. The work at Ames Laboratory was supported by the United States Department of Energy (USDOE),

Office of Science (OS), Office of Basic Energy Sciences (BES), through Iowa State University under Contract W-7405-ENG-82. The Midwest Universities Collaborative Access Team (MUCAT) sector at the APS is supported by the U.S. Department of Energy, 
Basic Energy Sciences, Office of Science, through the Ames Laboratory under Contract No. W-7405-Eng-82. Use of the Advanced Photon Source was supported by the U.S. Department of Energy, Basic Energy Sciences, Office of Science, under Contract No. W-31-109-Eng-38. 


\subsection{CAPTIONS}

Figure 5-1. The comparison of Bean model and Landau model with the volumetric spontaneous magnetostriction of $\mathrm{R}_{2} \mathrm{Fe}_{14} \mathrm{~B}$.

Figure 5-2. The comparison of Bean Model and Landau model with the volumetric spontaneous magnetostriction of $\mathrm{R}_{2} \mathrm{Fe}_{17}$.

Figure 5-3. The comparison of Bean Model and Landau model with the volumetric spontaneous magnetostriction of $\mathrm{R}_{2} \mathrm{Fe}_{17} \mathrm{C}_{2}$.

Figure 5-4. The plots of Landau model with different $\alpha$ value. 


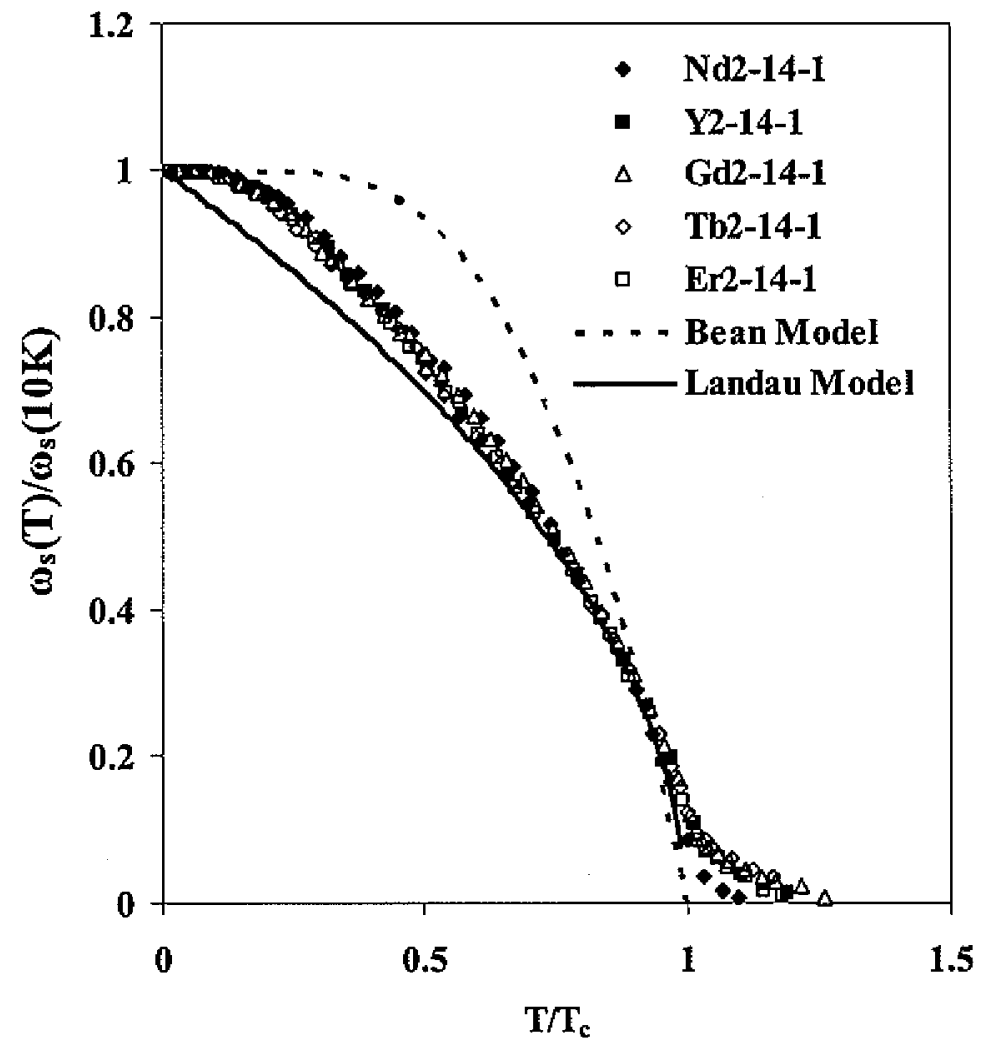

Figure 5-1. The comparison of Bean model and Landau model with the volumetric spontaneous magnetostriction of $\mathrm{R}_{2} \mathrm{Fe}_{14} \mathrm{~B}$. 


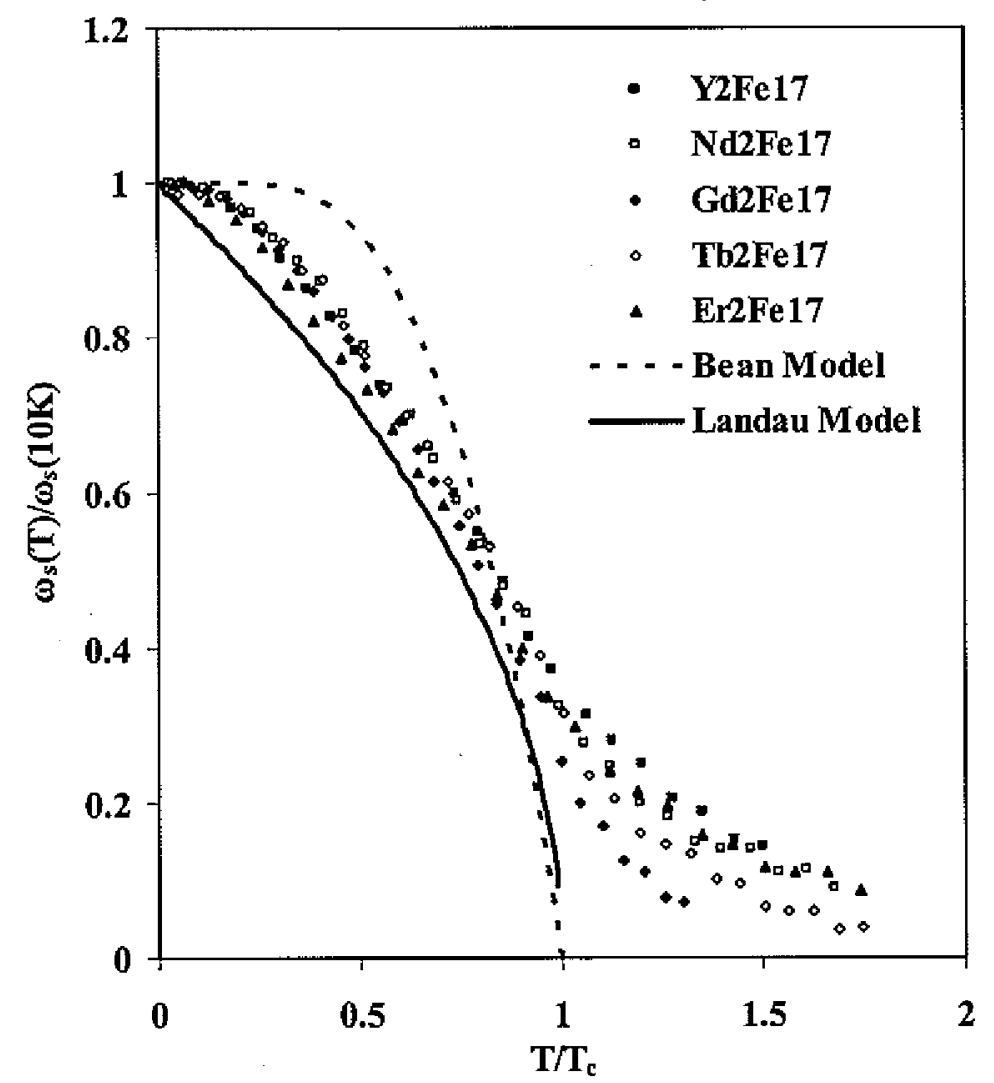

Figure 5-2. The comparison of Bean Model and Landau model with the volumetric spontaneous magnetostriction of $\mathrm{R}_{2} \mathrm{Fe}_{17}$. 


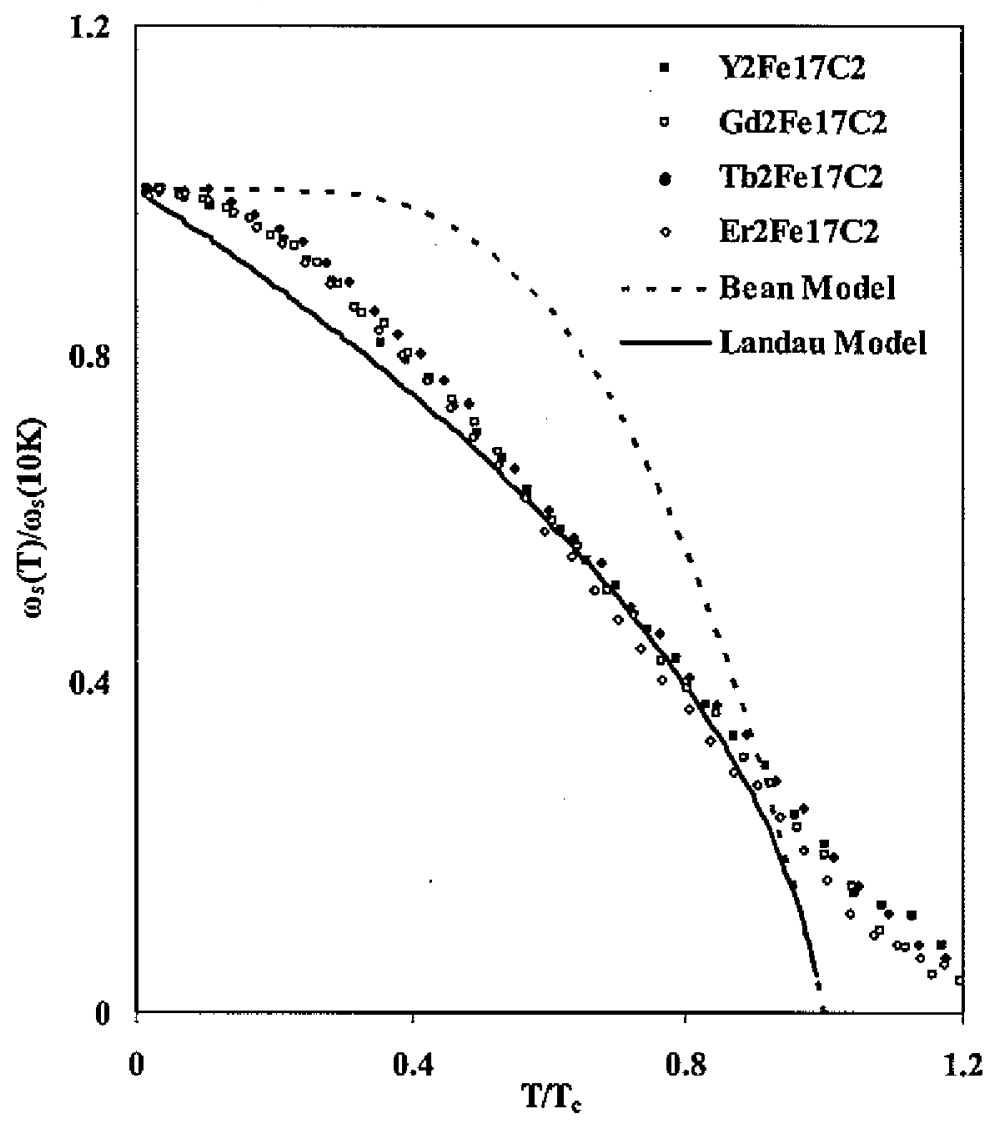

Figure 5-3. The comparison of Bean Model and Landau model with the volumetric spontaneous magnetostriction of $\mathrm{R}_{2} \mathrm{Fe}_{17} \mathrm{C}_{2}$. 


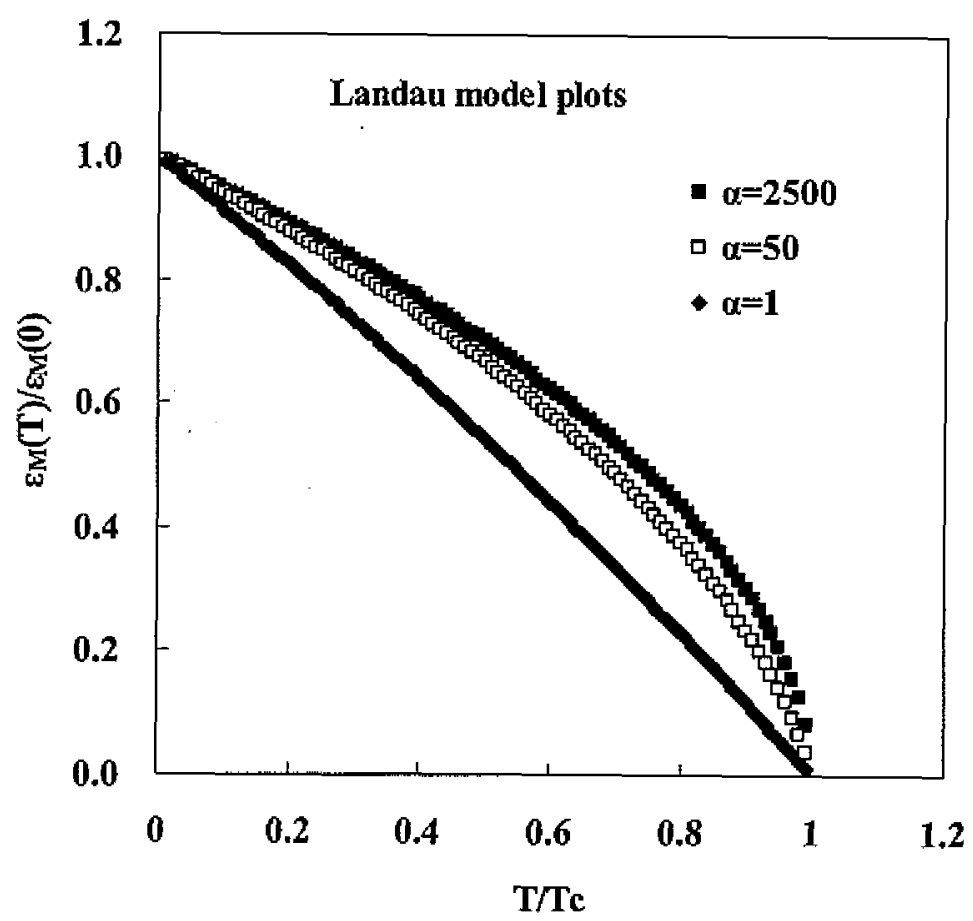

Figure 5-4. The plots of Landau model with different $\alpha$ value. 


\subsection{REFERENCES}

${ }^{1}$ E. F. Wasserman, Ferromagnetic Materials, 5 (1990) 237.

${ }^{2}$ E. I. Kondorsky and V.L. Sedov, J. Appl. Phys., 31 (1960) 331.

${ }^{3}$ A. Z. Menshikov, J. Magn. Magn. Mater., 10 (1979) 205.

${ }^{4}$ W. F. Schlosser, J. Phys. \& Chem. Solids., 32 (1971) 939.

${ }^{5}$ R. J. Weiss, Proc. Phys. Soc. London, 82 (1963) 281.

${ }^{6}$ M. Shiga and Y. Nakamura, J. Phys. Soc. Jpn., 26 (1969) 24.

${ }^{7}$ J. F. Janack and A.R. Williams, 1976, Phys. Rev. B, 14 (1976) 4199.

${ }^{8}$ E. C. Callen and H.B. Callen, Phys. Rev., 139 (1965) 455.

${ }^{9}$ M. Shiga, J. Phys. Soc. Jpn., 50 (1981) 2573.

${ }^{10}$ C. P. Bean and D.S. Rodbell, Phy. Rev. 126 (1962) 104.

${ }^{11}$ K. H. L Buschow, R. Grössinger, J. Less-common Metals, 135 (1987) 39.

${ }^{12}$ A. V. Andreev, F.R. de Boer, T.H. Jacobs and K.H.L Buschow, Physica B, 175 (1991) 361 .

${ }^{13}$ A. V. Andreev, A.V. Deryagin, S.M. Zadvorkin, and S.V. Terent'ev, Sov. Phys. Solid State, 27(6) (1985) 987.

${ }^{14}$ Ning Yang, K. W. Dennis, R.W. McCallum, M. J. Kramer, Yuegang Zhang and Peter L. Lee, J. Magn. Magn. Mater., to be submitted.

${ }^{15}$ Ning Yang, K. W. Dennis, R.W. McCallum, M. J. Kramer, Yuegang Zhang and Peter L. Lee, Physical Review B, to be submitted.

${ }^{16}$ Ning Yang, K. W. Dennis, R.W. McCallum, M. J. Kramer, Yuegang Zhang and Peter L. Lee, Physical Review B, to be submitted.

${ }^{17}$ M. Brakate and J. Sprekels, Hysterisis and Phase Transitions, Applied mathematical Vol. 121 Springe 1996 


\section{CHAPTER 6}

\section{GENERAL CONCLUSION}

\subsection{GENERAL DISCUSSION}

The spontaneous magnetostriction with large negative volumetric strain $(\sim-2 \%)$ is observed in both $\mathrm{R}_{2} \mathrm{Fe}_{14} \mathrm{~B}$ and $\mathrm{R}_{2} \mathrm{Fe}_{17} \mathrm{C}_{\mathrm{x}}(\mathrm{x}=0,2)$. The common feature of rare earth transition metal compounds is related to the short bond lengths in the structure. Both classes of compounds show large anisotropic spontaneous magnetostrains, which is determined by the magnetocrystalline anisotropies of their structures. This study confirms that the spontaneous magnetostriction extends to temperatures substantially above $T_{c}$ in this class of compounds and supports the view that the local iron moments in iron base metallic materials do not disappear above $T_{c}$. In addition, the short range magnetic ordering is highly temperature dependent. The lower the Curie temperature, the stronger the short range ordering is above the Curie temperature.

The a-axes of $\mathrm{R}_{2} \mathrm{Fe}_{14} \mathrm{~B}$ compounds have a larger spontaneous magnetostrain than the $c$ axes, which is determined by the axial magnetocrystalline anisotropy. The Fe sublattice is proved to dominate the spontaneous magnetostriction of the structure, which has a contribution proportional to the squared Fe sublattice magnetization. Compared to the Fe sublattice, the rare earth sublattice provides a minor contribution, which is roughly proportional to the spin magnetic moment of the rare earth. The hexagonal Fe sublattice

provides a larger contribution due to the relatively larger magnetostrain between Fe(j2) site 
and its neighboring sites. Different bonds show different amounts of magnetostrain, which appears to be determined by the local environment rather than the actual bond length.

The c-axes of $\mathrm{R} 2 \mathrm{Fe} 17 \mathrm{Cx}(\mathrm{x}=0,2)$ display larger magnetostrain than a-axes due to their planar magnetocrystalline anisotropy, while the effect of the interstitial carbon is to attenuate the anisotropy of spontaneous magnetostriction. The spontaneous magnetostriction of R2Fe17 and their carbides are also dominated by the Fe sublattice. The contribution of the rare earth sublattice to the spontaneous magnetostriction in R2Fe17 also appears to be determined by their local environment.The interstitial carbon expands the distances between rare earth and the neighboring $\mathrm{Fe}$ sites but squeezes the Fe hexagons The increased Curie temperature with interstitial atoms is due to the larger separation of the two parallel hexagonal sublayers.

The bonds around $\mathrm{Fe}(4 \mathrm{f})$ in the hexagonal polymorph and $\mathrm{Fe}(6 \mathrm{c})$ in rhombohedra polymorph have the largest average magnetostrains, which appears to be related to their larger magnetic moment. In $\mathrm{R}_{2} \mathrm{Fe}_{17} \mathrm{C}_{2}$ phases, the Fe-Fe bonds are shorter and magnetostrain of these bonds is smaller compared to their analogue $\mathrm{Fe}-\mathrm{Fe}$ bonds in the $\mathrm{R}_{2} \mathrm{Fe}_{17}$ phases. On the other hand, the magnetostrains of R-Fe bonds increase. The magnetostrain for both $\mathrm{Fe}-\mathrm{Fe}$ bonds and R-Fe bonds are proportional to their bond lengths, which is contrary to the prediction based on the negative interaction theory.

The $\mathrm{Fe}(\mathrm{j} 2)$ sites in $\mathrm{R}_{2} \mathrm{Fe}_{14} \mathrm{~B}$ and $\mathrm{Fe}(4 \mathrm{f})$ and $\mathrm{Fe}(6 \mathrm{c})$ sites in $\mathrm{R}_{2} \mathrm{Fe}_{17} \mathrm{C}_{\mathrm{x}}(\mathrm{x}=0,2)$ with hexagonal and rhombohedral polymorphs are analogues both structurally and magnetically. This study shows that the bonds around those sites have relatively larger bond lengths resulting in larger average magnetostrains. The magnitude of the magnetostrains are proportional to the magnetic moment of the ions and the corresponding Wigner-Seitz cell 
volume. For the Fe sites in $\mathrm{R}_{2} \mathrm{Fe}_{17} \mathrm{C}_{\mathrm{x}}(\mathrm{x}=0,2)$, the average magnetostrain of the bonds is proportional to their hyperfine field intensity of the atomic sites. These data show that careful structural analysis is an accurate means to measure the site dependence moments in ferromagnetic alloys.

\subsection{RECOMMENDATIONS FOR FUTURE RESEARCH}

With the detailed information about the bond length changeS as a function of temperature, verification of detailed modeling of the interactions between R-T or T-T sites is possible. This work should combine the theoretical aspects of the compounds which include their electronic and magnetic structures as a function of temperature. This type of detailed structural information provides deeper understanding of physical properties of rare-earth transition metal compounds and can guide researchers into more rational selection criteria for potentially new magnetic compounds. 


\section{APPENDIX EXPERMENTAL DETAILS}

\section{THE RIETVELD REFINEMENT OF X-RAY PATTERNS}

Figures 1-3 illustrate the experimental and calculated patterns of $R_{2} \mathrm{Fe}_{14} \mathrm{~B}, \mathrm{R}_{2} \mathrm{Fe}_{17}$ and $\mathrm{R}_{2} \mathrm{Fe}_{17} \mathrm{C}_{2}$ samples. The experimental pattern show very good signal noise ratio and the calculated patterns fit the experimental patterns very well. During the refinement, the background were refined with a function as following[1],

$$
I_{b}=a \sum_{j=1}^{N} B_{j} \frac{Q^{2(j-1)}}{(j-1) !}+b \sum_{j=1}^{N} B_{j} \frac{(j-1) !}{Q^{2(j-1)}}
$$

The first part of the function is designed to account for background contributions that increase with $\mathrm{Q}$, which principally origins from the thermal-diffuse scattering. The second part accounts for the background contribution that tends to rise at sma1l $\mathrm{Q}$, which is from the air scattering. The combination of these two parts can account for the background contribution at both low and high $\mathrm{Q}$.

The peak profiles were refined with a function employing a multi-term Simpson's rule and integration of the Pseudo-Viogt function[1]. The theta independent terms in Gaussian and Lorentzian function were refined, as well as the peak asymmetry. The thermal parameters were refined showing a linear relation with the temperature (Figure 4), as expected.

Small amount of pure iron were detected in some of the samples and was accounted for in the fitting by refining both the volume fraction and the lattice parameters of the second phase. 
The thermal expansion behaviors of pure iron has been well determined and the result from our refinement of Fe phase show a very good agreement with the existing data [], confirming the reliability of these experiments.

\section{THE TEMPERATURE CONTROL}

Because of the range of temperatures spanned in these measurements, two different apparatuses were used The temperature of the higher temperature furnace is controlled by a Eurotherm controller with the silicon relay. The temperature stability of the furnace is very good and the oscillation of the temperature around setpoint is $\pm 1 \mathrm{~K}$. The temperature at samples position was measured using two thermal couples, one was used for controlling the furnace while the second, closer to the sample was used both as a backup thermocouple and a direct measure of the sample temperature. The relation between the readings of these two thermal couples were recorded and tabulated and the sample temperature at any control value could then be determined.

The major difficulty of the low temperature measurements was reliable temperature measurement. It is difficult to cool down a powder sample due to the poor contact between the powder particles. In order to improve the thermal contact between cooling source and the samples, $2 \mathrm{~mm}$ diameter copper rods were used to seal the ends of the capillary tubes containing the samples. The copper rods were fully contact with cooling source and the powder directly contacted with the copper rode. To improve the heat exchange between the powder particles, Helium gas was sealed inside the capillaries. $\mathrm{A} \mathrm{Mn}_{3} \mathrm{GaC}$ powder sample, which has very well defined magnetic phase transition at $160 \mathrm{~K}$ and a corresponding volumetric change, was use to verify the temperature calibration $\left[^{2}\right.$. Figure 5 shows the 
temperature dependence of unit cell volume of $\mathrm{Mn}_{3} \mathrm{GaC}$ and the comparison with the $\mathrm{DC}$ SQUID measurements. It clearly shows that our measured transition of $160 \mathrm{~K}$ is very similar to the DC SQUID. A second temperature calibration point is the Spin reorientation temperature of $\mathrm{Nd}_{2} \mathrm{Fe}_{14} \mathrm{~B}$ sample. As shown in Chapter 2, Figure 2-8, the spin reorientation along with a volume change occurs around $135 \mathrm{~K}$, which is also in good agreement with the temperature determined by DC SQUID measurement.

\section{EXPERIMENTAL ERROR ANALYSIS}

The errors of the x-ray diffraction experiments come from two parts, the systematic error and the statistical error. The systematic error includes the following parts,

1. The wavelength change of the $x$-ray beams. Due to the instability of the monochrometer, the energy of the $\mathrm{x}$-ray beam may shift and therefore the wavelength of the beam changes. Because the calculation of the lattice parameters highly deperids on the wavelength of the beams, the small shift of the wavelength gives rise to a systematic error. During measurements of a single sample $(\sim 8$ Hours), the energy shift is around $10 \mathrm{eV}$, the corresponding wavelength change is then about $2 \times 10-5 \AA$. This is well within the uncertainty of the Rietveld analysis.

2. A second source of systematic error is a shift in the distance between the sample and detector. The wavelength was determined independently using a solid state energy dispersive detector, while sample to detector distance was calculated using the NIST silicon standard $(640 \mathrm{c})$. The design of the low temperature cryogenic allows for the direct alignment of the samples and the actual sample position can be very close to the position of silicon standard. But for the high temperature 
furnace, the sample was blocked by the furnace body and therefore there are always possibilities for displacement of the samples. These two uncertainties contributed to the mismatch between the low temperature data and high temperature data sets.

3. The uncertainty of the temperature measurement will reduce the accuracy of these results but the precision should be unaffected provided there are no obvious discrepancies in temperature control. The PID controlling of the furnace are different from low temperature range $\left(<400^{\circ} \mathrm{C}\right)$ to high temperature range $\left(>400^{\circ} \mathrm{C}\right)$, which required additional scrutiny of the data.

The statistical error comes from the read out of the Mar345 image plate. Although the error is quite small, it is still the major contribution of the uncertainity for some of the data. The intensity of the pattern generated from averaging the mar image is not the actual count of photon but several times larger than the actual photon counts. As a result, the actual error of the refinement should be several times bigger than the value obtained in GSAS as well. 


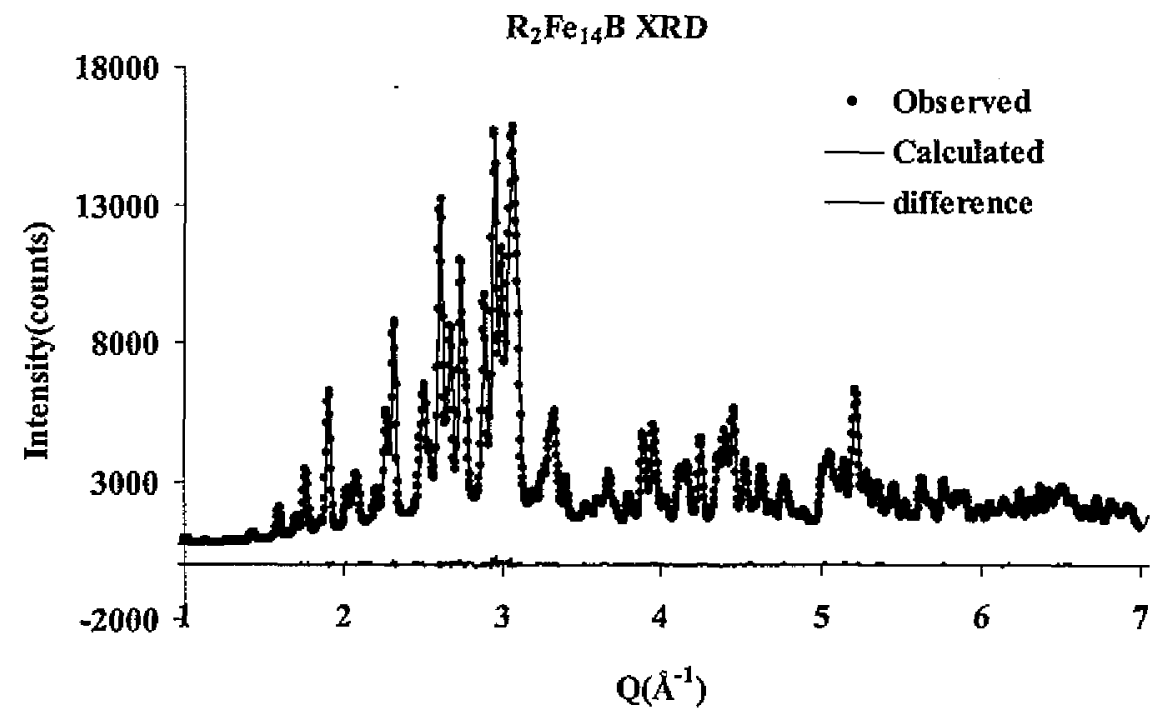

Figure 1. The typical experimental $\mathrm{x}$-ray diffraction pattern, the calculated pattern and difference of the patterns of $\mathrm{R}_{2} \mathrm{Fe}_{14} \mathrm{~B}$ phases. 


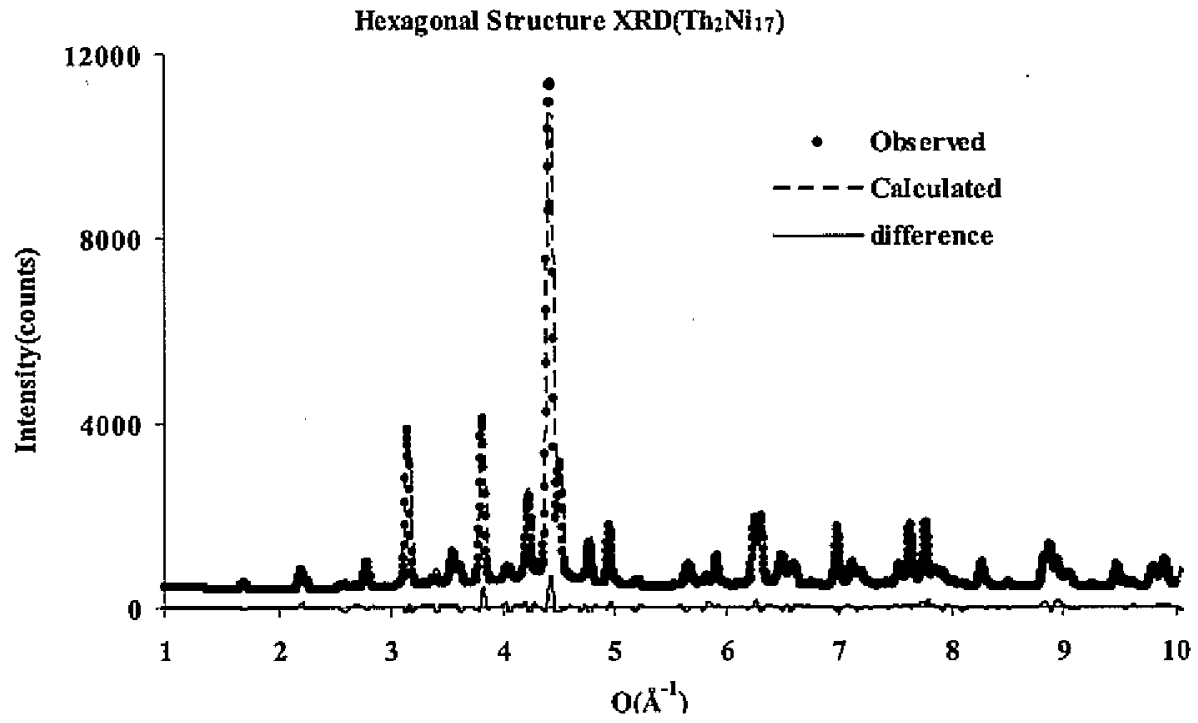

Figure 2. The experimental and calculated patterns of $\mathrm{R}_{2} \mathrm{Fe}_{17}$ phases with Hexagonal structure modification. 


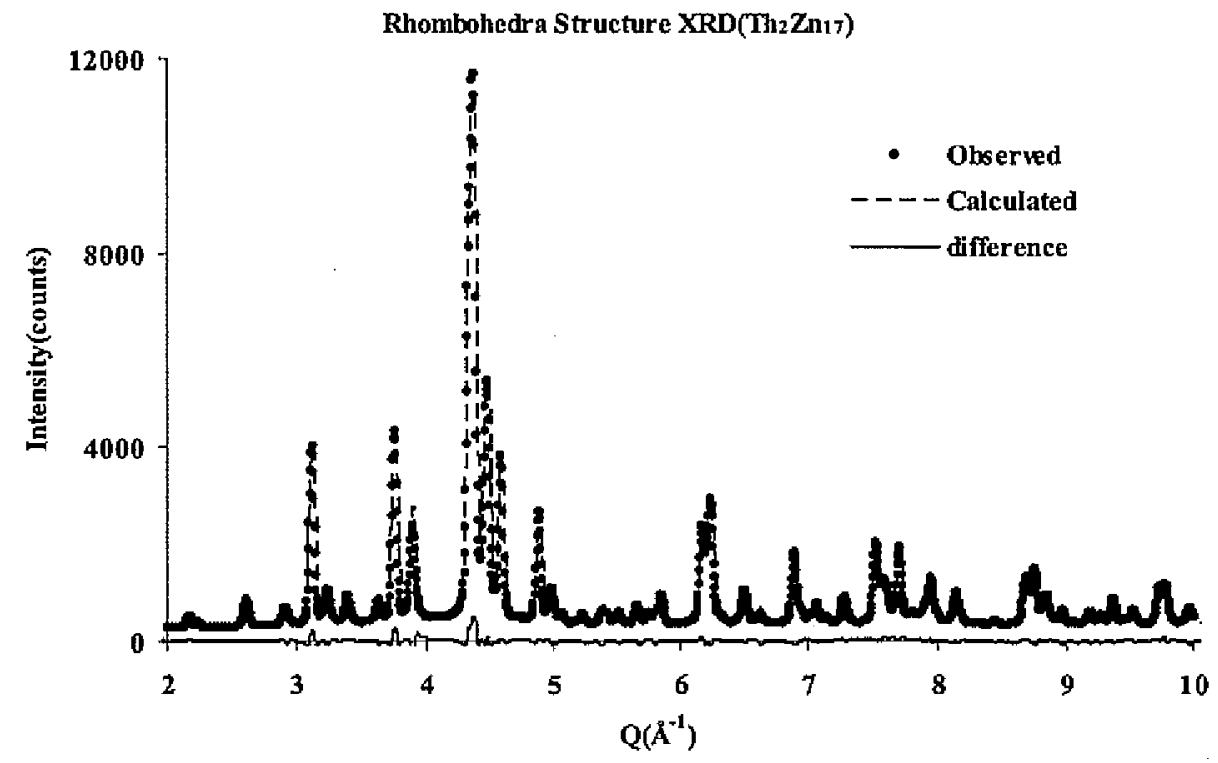

Figure 3. The experimental and calculated patterns of $\mathrm{R}_{2} \mathrm{Fe}_{17}$

phases with rhombohedral structure. 


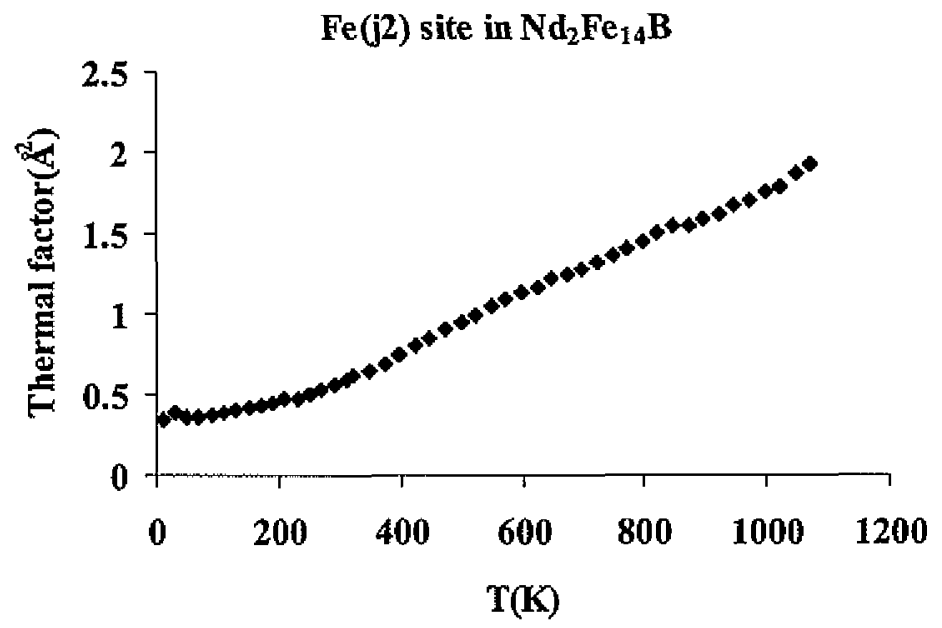

Figure 4. The linear temperature dependence of the thermal factor of $\mathrm{Fe}(\mathrm{j} 2)$ sites in $\mathrm{Nd}_{2} \mathrm{Fe}_{14} \mathrm{~B}$ 

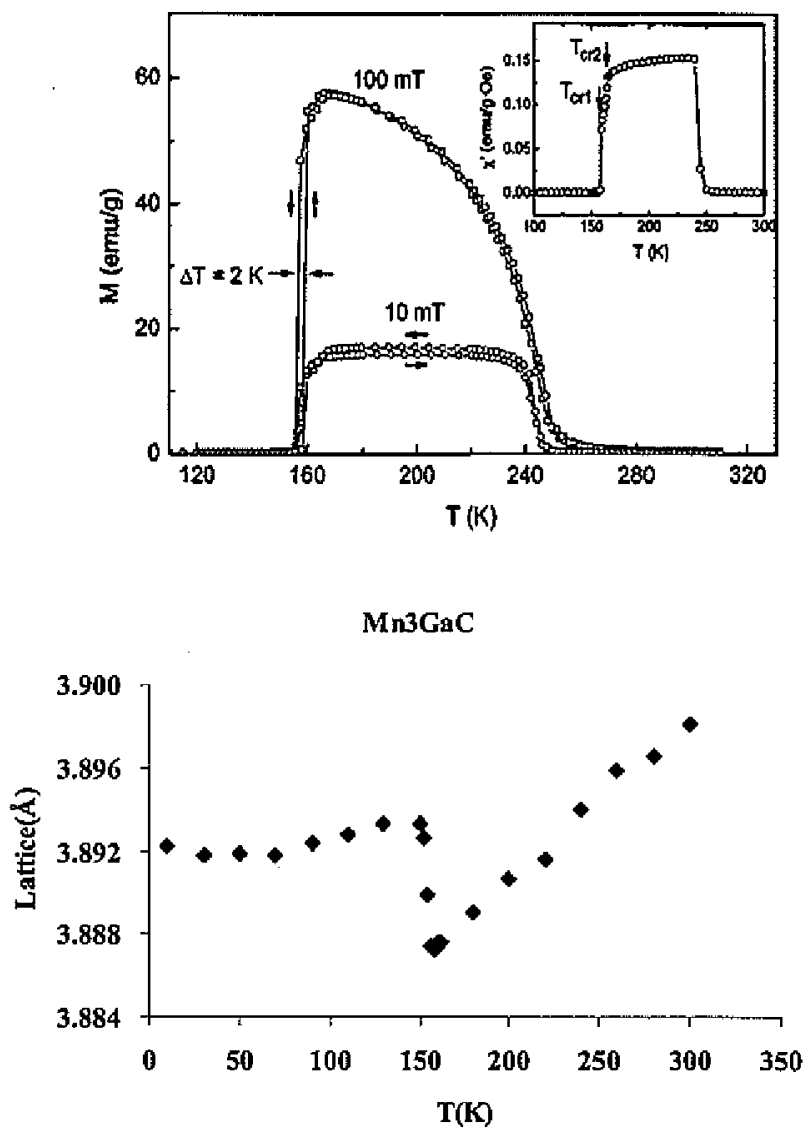

Figure 5. The temperature comparison of the lattice change in our experiment with the magnetic transition measured with SQUID 


\section{REFERENCES}

'A.C. Larson and R.B. Von Dreele, "General Structure Analysis System (GSAS)", Los Alamos National Laboratory Report LAUR 86-748 (2000).

${ }^{2}$ Yu MH, Lewis L H, Moodenbaugh AR J. OF APPLIED PHYSICS, 93 (2003) 1012810130. 


\section{ACKNOWLEDGEMENTS}

I would like to thank Professor Matthew J. Kramer and Dr. Peter Lee for their academic guidance and financial support through my graduate study. With their direction and help, I have had the opportunity to work on this challenging project.

I would like to thank Professor R. William McCallum, Mr. Kevin Dennis in Ames Laboratory for their help with the samples preparation and characterization and Yuegang Zhang, Douglas Robinson, Didier Wermeille (APS Sector 6), Mark Beno and Jennifer Linton (sector 11) for their help at the beamlines.

I would like to dedicate this work to my beloved parents, Bayue Yang and Guorong Cai for their love and encouragement throughout all the years of my education and my life.

This work was reformed at Ames Laboratory under Contract No. W-7405-Eng-82 with the U.S. Department of Energy. The work performed at Advanced Photon Source was supported by the U.S. Department of Energy, Office of Science, Basic Energy Sciences, under Contract No. W-31-109-Eng-38. The Midwest Universities Collaborative Access Team (MUCAT) sector at the APS is supported by the U.S. Department of Energy, Office of

Science, Basic Energy Sciences, through the Ames Laboratory. The United States government has assigned the DOE Report number IS-T 1993 to this thesis. 